E

N42Z

NMAIREF

$V .13$

CONTRIBUTIONS FROM THE

MUSEUM OF THE AMERICAN INDIAN

HEYE FOUNDATION

Vol. XIII

INLAID STONE AND BONE

ARTIFACTS FROM

SOUTHERN CALIFORNIA

BY

E. K. BURNETT

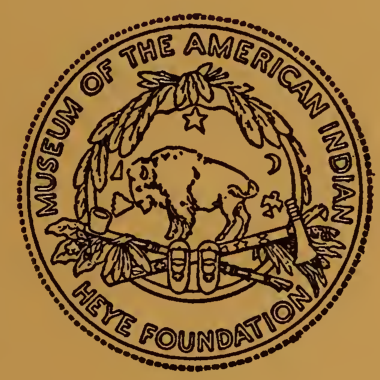

NEW YORK

MUSEUM OF THE AMERICAN INDIAN

HEYE FOUNDATION

1944

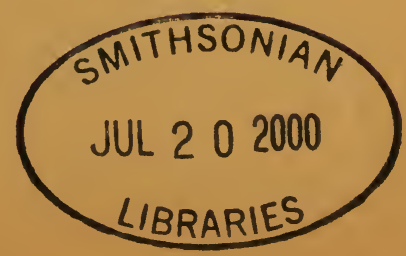




$\frac{u}{u}$
$\frac{w}{2}$
$\frac{0}{5}$
$\frac{2}{2}$
$\frac{\alpha}{4}$
$\frac{\alpha}{4}$

章 


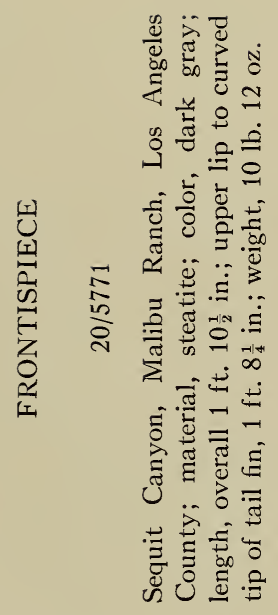





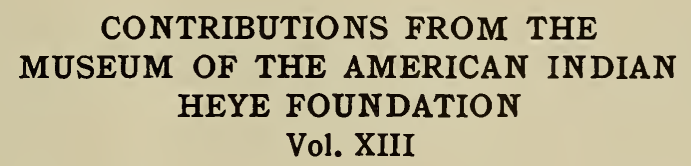

\section{INLAID STONE AND BONE ARTIFACTS FROM SOUTHERN CALIFORNIA}

BY

E. K. BURNETT

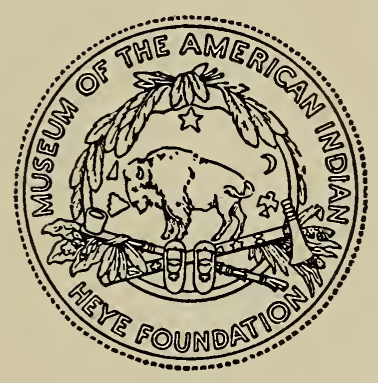

NEW YORK

MUSEUM OF THE AMERICAN INDIAN

HEYE FOUNDATION

1944 



\section{CONTENTS}

PAGE

Bibliography. . . . . . . . . . . . . . . . . 60

Introduction . . . . . . . . . . . . . . . . . . . 13

Marine and animal forms.................. 35

Miscellaneous bone........................ 53

Miscellaneous stone. . . . . . . . . . . . . . . . . 40

Ornaments......................... 45

Pipes and cloud blowers .................. 21

Point Dume............................. 18

Ramera Canyon........................... 18

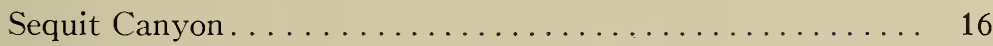

Sites and burials. ...................... 14

Solstice Canyon . . . . . . . . . . . . . . . . . . . . 20

Vessels.................................. 54

Wands................................. 54 

LIST OF ILLUSTRATIONS

PLATE NO

Beads........................... XLV, XLVI

Blades............................. XLIV

Bowls . . . . . . . . . . . . . . . . . . . . LII-LXIS

Burials ............................. IV, V

Canoes........................................ LI

Cog stones.......................... XLI

Drum stick. . . . . . . . . . . . . . . . . . . . LIX

Flutes............................. XXXIX, LIX

Hair ornaments . . . . . . . . . . . . . . . . . LIV-LVIII

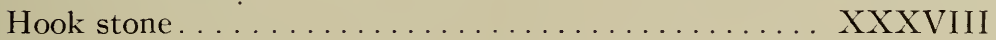

Jars................. LXI, LXV, LXVII, LXVIII

Ladles.............................. LXI

Marine and animal forms.............. XXVI-XXXVI

Miscellaneous stone................ XXXVII-XLIV

Necklaces and breast ornaments............... LI-LIII

Pendants. . . . . . . . . . . . . . . . . . . . . .

Pestles. . . . . . . . . . . . . . . . . . . . . . . .

Pipes and cloud blowers........... Frontispiece, VI-XXI

Rattle.................................. LIX

Sites........................ II, III

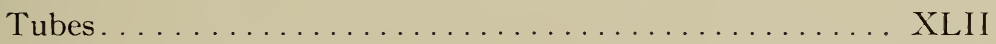

Vessels . . . . . . . . . . . . . . . . . . . LXI-LXXI

Wands .................................. L 

The artifacts described in this monograph have been accumulated over a period of sixteen years, some coming from excavation, some through the acquisition of individual collections, and still others by purchase from dealers. The thought was to bring together a number of specimens showing shell inlay and presenting forms that have not as yet been illustrated. Therefore, it has not been deemed necessary to go into a detailed description of the excavations which, of course, yielded many of the commoner artifacts usually found in burial and village sites on the coast and islands of Southern California. The author, Mr. E. K. Burnett, has given much study to the respective pieces illustrated in this catalogue so that they might be fully and clearly described. This institution acknowledges with sincere appreciation the generous grant from The Viking Fund, Incorporated that has made this publication possible.

George G. Heye DIRECTOR 



\section{INTRODUCTION}

$\mathrm{B}$

$\mathrm{Y}$ far the larger number of specimens here illustrated were excavated during the years 1939-1941 from sites under imminent destruction by grading crews along the route of the Roosevelt Highway and by building and landscaping activities on the newly opened Rancho Malibu Lands properties westward of Santa Monica. Some are from Catalina and San Nicholas Islands and a few pieces are from a cave on Boney Mountain situated only some 8 miles from the ocean and near a reputed Indian trail through Sequit Canyon to a sulphur spring southeast of the ridge. Other specimens not from the coastal areas of Ventura, Los Angeles, Orange and San Diego Counties or from the Islands are here included either because they appear to be of coastal provenience, because it is felt they possess similarities of form, or that they present interesting comparisons.

Permission to excavate the Malibu sites was graciously granted by Mr. Howard Bonsall, president of the Marblehead Land Company, owners and developers of the property. Mr. J. L. Gibson, who has been a surveyor among the Santa Monica hills for thirty years and who is connected with the Louis T. Bush Company, sales agents for the tract, was not alone most helpful in locating the sites but gave enthusiastic support to the work throughout.

The actual field work was largely done by Mr. O. T. Littleton of Los Angeles, helped, from time to time, by Mr. A. R. Sanger of Los Angeles. Some pieces were acquired from Mr. Herman Strandt of Anaheim. The data for a brief description of the Malibu sites were obtained from the field notes and photographs made by Mr. Littleton and from the personal observations of the Director.

The great need for haste, to keep ahead of road machinery and building operations, is unfortunate. The data obtained could have been greatly augmented had there been time for more leisurely excavation.

It is expected that other sites in the immediate area, now located but uninvestigated, can be excavated without the pressures under which the work at Sequit, Solstice and Lower Ramera canyons was done. 
For the purposes of this catalogue no attempt has been made at full laboratory analysis of the various types of stone represented in the illustrated specimens. Dr. Frederick H. Pough, Chairman and Curator of the Department of Geology and Mineralogy at the American Museum of Natural History, observed the collection and was kind enough to suggest identifications of many of the pieces then on exhibit.

Nor was it considered necessary in all instances to injure a specimen by removing shell or bone units in attempted identification as to origin. The shells represented in decoration at least include abalone, keyhole limpet, oliva, olivella, pismo clam and sea snail. In description, the unit is noted as being a base if the section of shell is of sufficient size to show its natural contour; and as a disc if it is perfectly or crudely formed and shows not any, or only a small, central perforation. If the shell has been ground to a point where only a thin wall remains, the unit is distinguished from the disc by being described as a ring.

Some of the latter category are remarkably small and are so perfect in outline as to give rise to the question of their manufacture, although it is generally believed that they were fashioned from olivella shell. Putnam ${ }^{1}$ mentions small discs, $1 \frac{1}{2}$ to $2 \mathrm{~mm}$. in diameter, as being considered too regular for handwork and suggests that they probably are branches of a recent crinoid or other radiate. Rogers ${ }^{2}$ discusses possible methods of manufacture in some detail.

The regularity in size and the thinness of walls are quite astonishing; and the suggestion has been made that, possibly, they are really thin cross sections of dentalia shells.

\section{SITES AND BURIALS}

The principal sites herein briefly described are located in Los Angeles County on the stretch of coast westward of Santa Monica known as Malibu Ranch, a property which now includes the Rindge Ranch, shown on older maps of the territory.

The coast along this stretch has a narrow beach from which a bluff rises abruptly to heights in some places of 100 feet. This escarpment is broken by numerous mouths of arroyos which carry down from the coastal hills, there being twenty-three of these esteros

${ }^{1}$ Putnam, 1879, pp. 267-8, pl. XII, figs. 1, 2.

${ }^{2}$ Rogers, 1929, p. 413. 
throughout the length of the Malibu Ranch property, some 26 miles.

A narrow plateau or shelf crowns the coastal cliff bordered on its inland side by hills which rise from 100 to 2000 feet above sea level. A coastal highway has recently been completed along this plateau skirting the shoreline except where it circles behind the peninsula tipped by Point Dume, the crest of which rises to a height of 215 feet.

The coastal sites are all near the cliff edge and, except for those on Point Dume, are located at one side of an arroyo mouth.

In general, the burials conformed to similar patterns reported by all investigators from many sites along the Southern California littoral and on the Islands. Skeletons, for the most part, were positioned reclining on the right side with legs well flexed, although this was not constant, even within one cemetery. Heavy stone, metates and broken pieces of mortars, manos, pestles and bowls were common among the refuse in addition to whole or fractured vessels and implements quite evidently placed as burial accompaniments.

Burials containing Spanish contact material were for the most part undisturbed and the bones of these were generally in a far better state of preservation than those lacking trade accompaniments, which might be considered to be of earlier date. Judging from the relatively small areas set aside as cemeteries and the confusion of graves at all levels, it would seem that no taboo existed against careless digging through interments already made. Many more recent burials accompanied by trade implements were found to have been made to a deeper level directly through earlier graves containing no intrusive material. The irregularity of interment may represent the practice of re-burial, reported by $\mathrm{Orr}^{1}$ from Cemeteries D and E at Mescalitan and discussed by Rogers. ${ }^{2}$

Graves containing deposits of ocher were quite frequent, masses of the pigment, sometimes pure, sometimes mixed with asphaltum, being found independently in flattened globular masses as well as in vessels or shells of a number of varieties. A considerable incidence of it in powdered form was noted. In many instances it was obvious that the powdered material had been spread over the body and that moisture, through the years, had caused it to color the bones and everything below them. In one burial sufficient powdered pigment to fill a gallon pail was found underlying the skeleton. For

${ }^{1}$ Orr, 1943, pp. 21, 25

${ }^{2}$ Rogers, 1929, p. 377. 
the most part, paint burials had the more elaborate accompaniments, and the majority of these graves was found undisturbed.

No arched or partition arrangement of whale ribs, as reported by Yarrow ${ }^{1}$ from the Islands and the Santa Barbara mainland area, was encountered. Where whale bones were found, they varied from four feet in length to small fragments and occurred mixed in the general debris about one foot above the skeleton. Apparently; these were placed over the graves indiscriminately.

A number of the burials presented layers of a completely disintegrated brownish mass which may have been the remains of a body wrapping or a fiber matting upon which the deceased had been placed.

No great quantity of animal bones was found in graves or through the midden refuse at any of the Malibu Ranch sites. Probably one burial in ten yielded one or two heavy flipper bones of the seal, and deer tibiae were found in about the same percentage. These latter bones, however, invariably had been pointed and are either to be classed as utensils or hair ornaments. A few sea-otter teeth were found at the Solstice Canyon site. The flesh of game animals, apparently, did not enter importantly into the diet of these people.

Few isolated graves were found, the burials being centered in a small area either within the camp site or at its immediate periphery. This feature together with the indiscriminate positioning of the bodies and the irregular levels at which they were found, shows an expected downcoast extension of the burial customs reported from the Santa Barbara area and the Islands.

SEQUIT CANYON. Surface manifestations of village refuse extended over an area approximating 175 yards along the embankment top and 100 yards in width. Work on the coastal highway prevented excavation beyond the fence shown at the left of the view of the site (pl. II). This illustration shows the burial ground area, approximately $60 \times 40$ feet, which unlike that at Solstice Canyon was near one end of the site, not at its center.

One hundred and forty burials were located at depths from 2 to 5 feet within this small area, most of the skeletal material being badly decayed or crushed.

A number of burials at this site showed evidence of having been disturbed, the remains of five being mixed in a general confusion.

${ }^{1}$ Yarrow, 1879, p. 36. 
Contact material existed in some of the graves, bits of bottle glass, trade beads and badly rusted iron blades being found with interments even at the deeper levels. Burials with no contact material but containing elaborate native accompaniments were from all levels, sometimes overlying graves with trade artifacts that evidently had been entered and despoiled. The disorderly arrangement of burials as to depth and orientation makes any attempt at establishing a chronological sequence most difficult.

In fifteen of the graves from the deeper levels layers of chia seeds underlay the skeletons to a depth of from 1 to 4 inches and some of the bodies had probably been covered with a blanket of them at the time of interment. In these seed burials only rarely were any but the most commonplace accompaniments found.

Seventeen of the graves at Sequit Canyon contained fragments of wooden planking drilled at regular intervals along their edges and smeared with asphaltum. Some plugs of asphaltum still remain in the perforations in the wood, and a number recovered from areas where the wood had entirely disintegrated bear the markings of twisted vegetal fiber cordage which had originally existed as lashings between the planks and which the asphaltum had overlain.

No arrangement of these wooden fragments, which are found, usually, under the skeleton, suggests that they were from a canoe, as reported in burials encountered by Schumacher ${ }^{1}$ and Yarrow. ${ }^{2}$ These planks are some $\frac{1}{2}$ to $\frac{3}{4}$ inches in thickness and probably had an original width of about 5 inches. No idea as to original length can be had, as in every instance they are broken and with jagged ends. These are to be considered, perhaps, as remnants of a plank grave lining, rather than suggesting a custom of canoe burial.

Perforated fragments of asphaltum smeared wood occur occasionally throughout all the Malibu Ranch sites but in no such proportion nor in the fair state of preservation at other sites as those found at Sequit.

In at least two of the burials here, it could be positively ascertained that objects had been deposited in the mouth of the deceased. One in which the curved pipes (CAT. 20/4650-51) and a seal effigy pipe (CAT. 20/4649), none of which is here illustrated, were found, seven gypsum crystals had been so placed; and in the burial (pl. Iv)

${ }^{1}$ Schumacher, 1875 , pp. 335-50.

Schumacher, 1877, pp. 37-56.

2 Yarrow, 1879, p. 38. 
with which the elaborate fish pipes (pl. XvII) were associated, a large quantity of small shell and glass trade beads had been so deposited.

At one end of the burial area and 20 inches below the present surface a 14 to 18 inch layer of ash and burned shell was uncovered. The area was 12 feet long and had an average width of 5 feet. A few calcined human bones were found mixed in the ash, no artifacts of any description being present.

Despite the extent of this site, the largest yet excavated, only twelve mortars, whole or fragmentary, were found. Eight were of hard sandstone, three of steatite, and one of a gray granite.

POINT DUME. Several sites exist at Point Dume or its immediate vicinity. The principal one as yet located covers about 3 acres at the base of the hilly eminence and eastward along the bluff edge (pl. II). Refuse was found here to a depth of 4 feet and many whole and fragmented abalone shells were encountered throughout. The soil is quite sandy and at the northwest corner of the site, at the rear of the Point Dume hill, evidences still remain of what must have been at one time a spring of considerable size. Perhaps here was located the best and most accessible fresh water supply for the native villages of the Point Dume area.

Another site in this vicinity occupies an area not over 100 by 200 feet. There were some shell debris and a few seal bones encountered but no extensive deposits of refuse were found. This site lies a mile westward of the Point between the bank of Zuma Canyon and the new coastal highway, and the creek embankment shows interesting stratification. The disturbed surface area, of about 3 feet, rests upon another 3 feet of silt and gravel under which lies about a 2 foot stratum of very old debris. No excavations have as yet been made at this level.

The other area where test diggings were made showed no such concentration of midden refuse as at the two just described, but at the very crest of Point Dume, almost at surface level some interesting specimens were found, among them the ladle or asphaltum melting cup shown on pl. Lxx. The main burial area on Point Dume has not as yet been located.

LOWER RAMERA CANYON. Midden debris containing a large quantity and variety of sea shells and large fish bones covered about an acre of ground on an almost level shelf or terrace in the escarpment which, at this point, slopes gently to the beach. A more or less uniform depth of 8 feet of deposit was encountered except in 
the comparatively small burial area shown as the cleared space in the central foreground of the illustration, pl. III. This photograph was made in 1939 upon completing excavations. The property has since been sold, built upon and landscaped. The graves were all found in an oily, sticky black soil-typical of many reported village sites along this coast-devoid of shells. Some burials were as shallow as 12 inches some as deep as 6 feet.

Most of the interments had been covered with flat sandstone slabs from 2 to 4 inches thick, some weighing as much as a hundred pounds, probably brought there from a distance of some 2 miles where an outcropping of similar stone now exists. No pavement or platform arrangement, as has been reported by Rogers, ${ }^{1}$ existed in these burials. In all cases the slabs and other larger boulders were apparently thrown upon the graves indiscriminately as interments were made. Approximately two hundred burials were encountered, the exact number being doubtful because of the crushed condition of the skeletal material.

Here, there was less regularity as to body positioning than at any other site, some skeletons being found in full prone extension, some flexed and laid sidewise, and some in a sitting posture. Several multiple burials were noted. In one instance, it appeared that five bodies had been dumped into a grave just large enough to hold them, the hole having been dug through earlier burials, the fragmentary bones of which were found mixed with those of the five and throughout the soil immediately surrounding the multiple grave. The finer artifacts were found in the later burials.

Many different kinds of burial accompaniments were encountered here, as at other sites, but the large number of broken mortars and bowls was most unusual. Some were so badly shattered as to make an actual count impossible but there must be parts of nearly one hundred vessels of varying sizes and weights including eight metates of soft sandstone. Of some fifty mortars, thirty-seven are of scoria, the largest having a rim diameter of 26 inches, ten are of varying grades of sandstone, and three are of steatite. The bowls and ollas are of steatite and serpentine. The unbroken pestles found were not scattered throughout the soil and rock debris, but were concentrated in a circular area of about an 8 foot diameter.

There seemed to exist, in fact, a somewhat segregated disposition of accompaniments in the burials at this site. Graves in one

1 Rogers, 1929, p. 67, pl. 57. 
area contained nothing but blades, while those in another, only effigies. No contact material appeared in any burial at this site.

A site farther up Ramera Canyon was located but war restrictions have prevented any but the excavation of one burial. This site is of interest, however, in that there is no incidence of asphaltum in any artifact so far found and not one of them is of steatite.

The most unusual piece from this site, and not here illustrated, is an open mouth fish pipe fashioned from diatomaceous earth (CAT. 20/5497). It is crudely formed, perhaps due to the softness of the material, but it follows the general lines of those shown on pl. xvirI. The truncated dorsal fin is grooved for the reception of a malachite pebble which apparently was bound in place by cordage, the grooved markings of which are present around the body.

SOLSTICE CANYON. The location of the burial ground at this site is shown on pl. III, roughly within the area enclosed by the fence. At the time of excavation the ground level was 5 feet higher at the center of the area than now shown, and burials extended toward the bluff edge to a point about where the automobiles are parked.

The midden was of the expected coast type of this area, and a marked density of interments existed in a radius of 25 feet from the center occurring at depths of between 3 to 5 . feet. Here the bodies were regularly placed most generally flexed on either right or left side.

Many of the burials had no accompaniments save stone and shell beads, some in great quantity. In several instances beads had been placed in the mouth, and a few graves showed clusters of smaller beads lying as in strung position although the stringing had disintegrated. One skeleton had an arrowpoint in its mouth, and one, some small shell ornaments. Chia seeds were found in the smaller bowls in some burials where breakage had not occurred from the disposition of large stones over the graves.

Two burials at this site, and within close proximity of each other, were of quite unusual interest. In each instance the bones of the right hand were found in the mouth with those of the left in a semiflexed position under the chin. Yarrow ${ }^{1}$ reports finding a similar incidence at La Patera, in the Santa Barbara area. One of these had a disc of abalone shell in each eye socket. These discs are not illustrated. Each has two complete perforations, as if for suspen-

1 Yarrow, 1879, p. 36. 
sion, a series of superficial drillings arranged in regular order, and chevron incisings around approximately half of its circumference.

It was possible to photograph some of the burials. Four of these with some of their accompaniments in situ are shown on pls. IV, v.

Plate IV shows the position of the three elaborate fish pipes already mentioned under the general description of the Sequit Canyon site and illustrated on pls. XVII, XIX, Xx. The largest dorsal fin of 20/4647 had been broken from the body and lay between it and the skull. Otherwise the specimens were intact. This skeleton was reached at a depth of 4 feet.

The other illustration on pl. IV shows a partly excavated skeleton in a site of as yet undetermined size just off the Decker Road in Lachuza Canyon. The small steatite seal (20/5492), with trade beads representing eyes, is not illustrated. The cloud blower (pl. $\mathrm{XXI}$ ) is to be seen resting next to the left tibia. Its companion piece (pl. XXII) was found directly under the right scapula. The bone mouthpiece had been broken, but was found near by.

Plate $\mathrm{v}$, left, shows three specimens in situ, the sandstone inlaid disc with a center well ( $\mathrm{pl}$. XLI), the unusual cloud blower (pl. XXv) and a tubular fish form pipe of badly decomposed steatite (20/4892), not here illustrated. The long bone stem of the cloud-blower was loose and was removed for protective purposes before the photograph was made.

The other illustration on this plate shows another Sequit Canyon burial with some accompaniments in the positions in which they were found. The inlaid bead (20/5231) is illustrated on pl. XLV. The serpentine and the cruder steatite pipes are illustrated on $\mathrm{pl}$. XII.

\section{PIPES AND CLOUD BLOWERS}

Tubular smoking pipes of stone, with or without separate mouthpieces, have been previously reported from the coastal areas of the southern counties of California and the off shore islands, more particularly Santa Catalina and San Nicholas. However, most of those previously illustrated from the Museum's collections are of moderate size, simple in form, many being merely cigar or cone shaped tubes, and are without decoration. ${ }^{1}$ One from San Miguel Island, illustrated in $1921,{ }^{2}$ has three circumferential ridges, one

${ }^{1}$ West, 1934 , pls. 13 , fig. 9 ; 16 , figs. $8-11 ; 17 ; 18$, figs. $1-4 ; 19$.

${ }^{2}$ Heye, 1921, pl. XXVII. 
just anterior to the stem, one at the tube's center, and the third forming the rim of the bowl.

For the most part, the large number of straight or curved tubular stone and pottery pipes are of these simpler unornamented forms, a few having a perforated pointed projection at about the tube's center. In two specimens from San Nicholas Island the projection is cylindrical and is drilled to connect with the bowl receptacle. These are not here illustrated.

Whether, in the light of the more recent finding of pipes which portray fish form, these projecting flanges may now be considered to indicate conventionalized dorsal fins, poses an in teresting question.

It is realized that differentiating between pipes and smoke cloud blowers constitutes a somewhat arbitrary expedient. Some of the tubular pipes, indeed, may not have been employed for smoking in the general sense of the term but, rather, to expel smoke clouds as a ceremonial activity.

Fages ${ }^{1}$ mentions the blowing of smoke upon the body of the deceased as a burial custom among the coastal peoples.

Where no bowl receptacle is present and yet where drillings connect the mouthpiece with some other outlet, specimens are here distinguished as cloud blowers.

In the tubular pipes, if the drilling of the bowl is enlarged, the depth of such area is noted. Where measurement is not recorded, the drilling is gradual with no abrupt demarcation between the bore of the bowl receptacle and the smaller lumen connecting the stem orifice.

Some of the fish forms seem to defy identification. It has been suggested that the black sea bass, the rubber lipped perch, the marbled sculpin and the trigger fish may be represented. Walford ${ }^{2}$ illustrates the trumpet fish and Schultz ${ }^{3}$ the pipe fish, either of which might be the prototype of some of the pipe forms.

\section{PLATE VI}

CAT. 20/981. The tube has a single annular band of perforated shell discs inlaid in asphaltum at about its center and three reddish perforated stone discs set slightly tilted in unevenly spaced counter-

1 Priestley, 1937 , p. 34.

2 Walford, 1937, pl. 68.

${ }^{3}$ Schultz, 1938, pl. XIII. 
sinkings in a line along the tube's long axis, between the shell inlay and the stem. This specimen has a perforated steatite disc, not shown in the illustration, which exactly fits the bowl opening at the rim.

CAT. 20/982. In addition to somewhat crude incisings, there is a four course band of perforated shell discs laid in asphaltum just back of the bowl rim, and a single inlay of similar discs, but set on edge, circles the tube toward the stem. An evenly spaced meander of exceedingly small inlaid rings is found between this band and the mouthpiece.

\section{PLATE VII}

Two of the pipes illustrated on this plate demonstrate an interesting feature. Instead of the worked areas to receive the inlay being in the tube surface proper, they are found as grooves in the annular ornamental flanges developed in the original shaping of the tube.

CAT. 20/3828: The specimen shows a grooved annular flange toward the mouthpiece in which inlaid shell rings are still present. A parallel flange dividing the remaining length of the tube in half has been rounded and smoothed. It presents no evidence of any attempt to groove it to receive an inlay similar to that in the posterior ring.

CAT. 20/1030. This pipe is without the circular ridges found on the other two specimens but has an annular countersunk area toward the bowl of sufficient width to hold an inlay of ten rows of more or less uniformly matched larger size shell discs. A single ring of discs is inlaid toward the mouthpiece end.

CAT. 19/1614. This specimen is well fashioned and is the longest tube in the collections, $1 \mathrm{ft} .9 \frac{3}{4}$ in. No evidences of original inlays exist except that the groove at the bowl rim retains a thin coating of asphaltum. Quite probably the wider groove between the central parallel ridges was never intended to receive an inlay. The crest of each of these ridges, incidentally, has a shallow incised line running around the full circumference. A thin irregular smear of asphaltum exists over a small area of the tube's inner surface. This specimen is not of as recent recovery as most of the others here discussed. It was found in 1895 during excavations for the Metropole Hotel at Avalon. 


\section{PLATE VIII}

CAT. 19/57. This tube presents a departure in carving from that of the other pipes yet discussed. The grooved flange or ridge toward the mouthpiece opening is similar to those already described (pl. vII) and carries an annular inlay of shell rings. Just behind the slightly belled rim of the bowl, however, four tapered flutings are found extending backward along the tube. On the crest of each of these areas is found a single line of perforated shell inlays, for the most part rectangular in form, which joins an anterior circular band also of a single row of similar shell units. The terminal unit of each line is a thick walled shell ring.

CAT. 18/6074. Although the sculpture is somewhat cruder and the flutings not so regularly formed, this tube is quite similar to the specimen just above. It has the same general arrangement of shell rectangles at the bowl end of the tube and of rings in the annular flange toward the stem opening. Three larger shell discs are overlaid in asphaltum across the body of the tube at about its center. These are somewhat thicker than those generally found.

\section{PLATE IX}

CAT. 20/1136. The shell disc and ring decoration on this specimen is not inlaid, but presents a more definite design than any on the previously described tubes. Bands of asphaltum have been overlaid around the pipe and the shell discs pressed lightly into this substance. What appear at first glance to be breaks in the wide band are found to be definitely formed points arranged at quite regularly spaced intervals. There are eight of these in total. The arrangement of the discs in the narrow band of asphaltum toward the mouthpiece is interesting in that two courses of smaller rings, interspaced with considerable accuracy, complement the single main band of larger shell discs. A collar of asphaltum circles the stem orifice, reinforcing the juncture of the mouthpiece. Discs and rings have been overlaid here with some precision of arrangement. The mouthpiece is of bone and its under surface carries a few cross hatched lines.

CAT. 20/1581. This pipe combines both usual sculpture and shell decoration. Each element of the elaborate inlaid design is set in a countersunk area of precise outline. The ornamental ridge, while presenting a sharply cut side toward the mouthpiece, tapers 
gradually toward the expanded bowl. There are five tanged arrow, and the same number of smaller triangle, inlays spaced symmetrically around the tube. A crude incised meander circles the area between the bases of the small triangles and the inlaid band of discs posterior to them. Behind its incurving rim the bowl is enlarged laterally to conform to the bulge of the tube. The remnant of a broken bone mouthpiece is adhered in the stem orifice by asphaltum.

\section{PLATE X}

CAT. 20/1029. This elaborate tube presents three spiralled rattlesnakes carved in relief in addition to three annular grooved ridges in which thick shell discs are set on edge in asphaltum. The snakes' bodies carry diamond incising and the rattles are depicted by deeper transverse grooves. Eyes are shown in only one head and are not inlaid. Shell rings carefully selected as to size are set in an overall pattern in an overlay of asphaltum between the carved reptiles.

CAT. 20/3300. Three lizards carved spirally in relief occupy the main central length of the tube. The sculpture is somewhat crude, particularly as compared with that of the accompanying specimen on this plate, and the surfaces of the areas cut away to produce the lizards are most uneven. No evidence is present that any inlay ever existed on these areas, not even a trace of asphaltum being observed. The shell units comprising the annular bands are irregularly set and are not carefully matched as to size. Diagonal incisings occur on the annular flanges directed outward from the inlaid bands. The eyes of the lizards are represented by inlaid perforated shell discs, the pupils being formed by the asphaltum that oozed through as they were pressed into place. Scales are depicted on the reptilian bodies by $\mathrm{v}$ shaped incisings, their apices being directed, for the most part, tailward. The light weight of this specimen, as compared with others of like size, is due to the fact that the stone is badly decomposed from weathering.

\section{PLATE XI}

The pipes shown on this plate illustrate a type ranging between the straight tubular and the simulated trumpet forms.

CAT. 20/3720. This specimen has a double row of small shell rings, quite carefully selected as to size, inlaid in a prepared groove 
around the central ridge. The mouthpiece is of dark serpentine veined with asbestos and it appears that, in inserting this stem, the pipe wall was cracked. This fracture is present and the smear of asphaltum over the junction shows marks of an earlier cord wrapping placed there to reinforce the weakened tube.

CAT. 20/3719. This tube shows slightly more curve than the preceding and has the added sculptural feature of a large expansion approximately two-thirds of the distance backward from the bowl rim. This area contains four evenly spaced shell ring inlaid medallions, each similar to the lateral one shown in the illustration except that on the under surface, where the inlay is but a single transverse line of eight units. There are four triangular inlays similarly spaced just posterior to the bowl rim, their apices directed rearward, that on the superior surface being elongated by the addition of three shell units. The bone mouthpiece is intact and its insertion is reinforced by the usual asphaltum.

\section{PLATE XII}

CAT. 20/5233. Still more curve is shown in the forms of this and the following specimen. Four inlays of shell discs occur on flattened areas of the bowl just behind the rim. Those placed laterally are roughly oval; that on the bottom is pear shaped; the one on the top surface has an extension of a single line of perforated discs extending posteriorly to the annular ridge toward the mouthpiece. These inlays are shallow and the shell units are raised, therefore, slightly above the surface of the tube. A larger piece of abalone shell, now somewhat broken and irregular, is overlaid on the bottom just in front of the annular ridge. This feature is just discernable in the illustration. The tubular mouthpiece is of bone.

CAT. 20/5234. This specimen has three annular bands of inlaid rings, two being of three rows each and one a single row. Four evenly spaced triangular inlays are based on this latter band with their acute apices directed toward the bowl. Just at the stem orifice the diameter of the tube diminishes sharply and the inserted bone mouthpiece is held in place with a thick smear of asphaltum. 


\section{PLATE XIII}

CAT. 20/2587. This is a most elaborate and well-fashioned pipe carved from two pieces of stone joined together at the medial ridge. Drilling from bowl to mouthpiece on this arc through one stone probably presented insurmountable difficulties. The discs occurring as annular rings cresting the two main stone ridges are set on vertical axes. The staggered double row of perforated discs forming the ring located centrally between the medial ridge and the stem orifice are a shallow overlay, the asphaltum base holding them being slightly raised above the surface of the tube. The perforated flange on the bowl, shown in profile in the illustration, has a circular surface from the front aspect in which are inlaid a larger central, and twelve smaller shell discs. The bone mouthpiece is intact.

\section{PLATE XIV}

CAT. 20/1044. Represents a most unusual form of sculpture. More than half the length of the tube forward from the stem opening has a screw-thread grooving which completes a well executed spiral design. A shallow rounded groove above the anterior terminal of this spiral and a similar one just behind the rim of the bowl enclose an area in which occur eight elongated triangular inlays of shell discs set between two single annular rows of shell rings arranged on edge. These triangles are spaced symmetrically, those on the top surface being shorter and lengthening as they progress to the under surface of the bowl. This pipe has a distinctly bluish cast, somewhat milky in spots, probably caused by contact with fire. The mouthpiece, a cylinder of light brown steatite, is intact.

CAT. 20/977.* A fairly regular arrangement of incised cross hatching appears on the body of the pipe between the well defined carved annular ridges. The groove in the bowl ridge to receive the rectangular inlays is quite shallow and several of the shell units, therefore, rise above the stone surfaces. The mouthpiece is of similar stone to the pipe proper, although of a lighter color, and its insertion in the main tube is reinforced by a ring of asphaltum.

* Of the three elbow pipes illustrated here and on the following plate, two have inlays of rectangular shell units. A fragmentary stone pipe bowk with a similar inlay from San Nicholas Island, illustrated by West (West, 1934, pl. 20, fig. 7), has been in the collections for some time and gave earlier hint of the occurrence of this type of specimen. 


\section{PLATE XV}

CAT. 20/5222. This specimen has two annular bands of inlaid perforated shell discs, that toward the stem opening consisting of six rows set between parallel ridges circling the tube. The units comprising the double row around the tapered bowl rim expansion are somewhat broken.

CAT. 20/3830. Is another example of highly skilled sculpture. Five rows of rectangular shell inlay units band the stem portion of the tube between parallel annular ridges, and four circle the almost vertical bowl section. The diameter of the tube diminishes abruptly at the stem orifice which shows no evidence of ever having held a mouthpiece.

\section{PLATE XVI}

CAT. 20/3715. A simple form of fish pipe. The high pointed dorsal fin suggests the effigy being that of a killer-whale, although the appendage is not as centrally located as is found in most representations of that species. The lower prominence on the dorsal surface nearer the mouthpiece may represent the adipose dorsal, but it is of sufficient height to suggest a caudal fin. The rounded protuberance below this and on the under surface is a possible indication of the anal fin. There are three large inlays of perforated light tinted abalone shell, two circular pieces so placed as to represent eyes and one oval unit on the ventral surface in line with the lateral pieces. The circumference of one of the eye discs is serrated, a feature often met in shell discs from the Islands. The single band of shell decoration around the wide ridge just behind the bowl rim is, too, unusual in that it is the only incidence in the group of the use of entire olivella shells. The tips of these have been ground off, as is found in those used for stringing. Tool marks are plentiful on all surfaces. The stone mouthpiece has been fashioned cylindrically to simulate the shape of one of bone.

CAT. 20/3716. This pipe shows an approach to more realistic sculpture, the conventionalized lines of the tube giving way to the flowing curves of an actual fish and the body of the tube being oval on a vertical axis throughout. The high dorsal fin is more accurately positioned and the carefully spaced incisings occurring on the less prominent dorsal fin are angled rearward in representation of the natural arrangement of its jointed rays. An anal fin is indicated. The three incised lines which occur bilaterally in the raised 
triangular area under the pointed fin may indicate pectoral fins or, possibly, gill covers. Eyes are represented by two elevated truncated buttons, each containing an inlay of small shell rings. The asphaltum in which they are set shows traces of red paint, as do all of the incisings. The mouthpiece is a drilled cylinder of steatite.

\section{PLATE XVII}

The forms of the two pipes here illustrated show a bizarre phase in marine effigy.

CAT. 20/3718. The high dorsal fin is curved with the point directed tailward, the adipose dorsal being prominently indicated as are the abdominal fins placed bilaterally under the latter eminence. No anal fin is present. A single perforated shell disc is imbedded on the vertebral crest just anterior to the mouthpiece in a overlaid mass of asphaltum. Two flattened ovoid areas which occur bilaterally on the head area contain similarly shaped inlays of small shell rings and may indicate gill covers. The body of the tube is generally flattened in its horizontal axis and the under surface is almost flat and has no decoration. The eye arrangement in this and the following specimens is of particular interest. Two elongated cones, their apices merging with the general body of the tube, have been carefully fashioned in the sculpture, their protruding bases being inlaid with a single perforated shell ring. A squeeze of asphaltum through the central perforation of the shell simulates the pupil. The mouthpiece is of serpentine with asbestos veins and appears to be joined to the main tube merely by a ring of asphaltum, and not inserted into it.

CAT. 20/4646. An excellent example of both sculpture and decoration. Two dorsal fins are depicted, the pointed one being the posterior and angled acutely toward the mouthpiece of the tube. The protruding eye cones are set closely together and the squeezes of asphaltum through the inset perforated shell bases, which indicate eyes, give considerable expression to the face. Three grooves form ridges in the snout which realistically portray retraction. The rims of both upper and lower lips have rounded serrations with grooves from them extending into the mouth. The under jaw protrudes. A piece of antler is inserted in a socket made for its reception on the under surface. This constitutes a handle or stand by which the pipe might have been held in a smoking position or 
set upright in the ground and, at the same time, represents a ventral fin. At its insertion into the pipe, and inlaid in the asphaltum holding it in place, there is a single circle of shell discs. Besides the wide overlaid band of discs and rings near the mouthpiece and the $\mathrm{v}$ shaped shell ring overlay on either side of the head, which, again, may be representations of gill covers, there is a heart shaped shell ring overlay extending from a point near the apices of the eye cones to the rise of the front dorsal fin, its auricular lobes directed toward this eminence. There is also a double row of shell rings set at the insertion point of the cylindrical steatite mouthpiece.

\section{PLATE XVIII}

CAT. 20/5221. A pipe of competent workmanship and the only specimen in the series having a curved mouthpiece of steatite. The whole body is oval in its vertical axis. The eye cones are almost perfectly formed and the shell inlays representing the eyes are bases of olivella retaining their natural round. Grooves have been made in the mouth rim to simulate soft tissue. A feature of this pipe is that the bilateral representations of pectoral fins are flattened on the bottom to form a stand for the tube. A small dorsal fin is present. The material of the mouthpiece is so similar in color to that of the pipe proper that it may well have come from the same stone blank.

CAT. 20/3717. Another specimen of expert workmanship. The dorsal fin and adipose are present, although no ventral or anal appendages are suggested. The whole body is oval in its vertical axis and a section of the abdominal surface projects from the general body line. This area is traversed by five arched parallel grooves which form six raised sections that simulate sucker pads. The eyes are represented by sculptured cones containing inlays of perforated shell bases. The asphaltum holding them in place is painted red, and a squeeze through each perforation forms the pupil. The upper lip protrudes. The manner in which the soft wrinkled quality of the mouth borders is expressed is present in other specimens here illustrated but none of the others reaches the degree of realism shown in this pipe. A shallow annular ring on the tube may represent the division between tube and mouthpiece, although it is believed that a separate stem was inserted at one time. Areas on the tube surfaces are discolored by asphaltum smears. 


\section{PLATE XIX}

CAT. 20/4648. This is another specimen of realistic carving, the slight upward curve of the caudal extremity giving a definite suggestion of movement. The pectoral area of the body is expanded. The conoidal eye sockets are well formed and are inlaid with large perforated shell bases set in asphaltum. Two lightly incised parallel lines follow the vertebral crest from the apex of the head to a point $1 \frac{1}{4}$ in. anterior to the mouthpiece. From these a series of diamond incisings, indicating scales, extend downward to single longitudinal lines running bilaterally from the mouth to about the center of the tapered tail area. The ventral fin of whale bone, $3 \frac{1}{2}$ in. in length, is set in a socket in the under surface of the body. The bowl expands laterally to conform to the body contour. The mouth surfaces show a liberal coating of red paint as do all the deeper incisings. Traces of it also exist over the shell eyes, on the whale bone handle or stand and over the asphaltum joining it to the fish body. The mouthpiece is of bone.

\section{PLATE XX}

CAT. 20/4647. This pipe combines a fantastic concept of form with a marked excellence of execution. The main body is expanded laterally just above the ventral fin to form a bulge $3 \frac{1}{4}$ in. in diameter, and tapers to a narrow caudal peduncle. The tail is deeply forked; its two symmetrical pointed segments being on a horizontal plane. The stand or handle, simulating a ventral fin, is of whale bone. On the under surface of the body just at the narrowest portion of the caudal peduncle a large, thick perforated shell disc is inlaid, undoubtedly to represent the anal orifice. The eyes are represented by perforated shell bases set in asphaltum, which is painted red. The upper snout is retracted and the rim of the lower segment, which is undershot, is shown somewhat drooped and thickened. The superimposed auxiliary body, if such it be, emerges gradually from a point between the eyes and terminates in a tapered extremity in which the bone mouthpiece is set at a slight angle in asphaltum. Three separate rows of small shell rings occur as inlays on the dorsal ridge of the secondary body. One extends rearward from the peak of the fin arising at about the middle of the eye cones, which fin has a single shell ring at its tip, to the base of the anterior prominent dorsal fin and terminates in a large, thick perforated disc overlaid 
at that point in asphaltum. The second starts at a similar larger overlay at the rear base of the second high fin and extends to the curved base of the small posterior prominence. The third lies along a portion of the crest of the terminal mouthpiece area, but is of small shell rings only. The bowl area is enlarged laterally to conform to the body contour. A drilling continues from its posterior wall angled upward and rearward to form the stem orifice. Considerable traces of red paint are found on the stand or handle and over the entire body, being particularly thick in the deeper incisings.

\section{FRONTISPIECE}

CAT. 20/5771. The largest specimen among the present collection, being $1 \mathrm{ft} .8 \frac{1}{4}$ in. long. The eyes are set close together, each in the stylized cone socket, on the dorsal surface and are represented by the bases of either large olivella or sea snail shell with pupils of asphaltum. Projecting from the shallow grooving separating the cone sockets is a small fin and behind this area a large dorsal fin rises to a height of $11 \frac{1}{2} \mathrm{in}$. from the under surface of the body. A vertical caudal fin occurs just above the junction of the bone mouthpiece. The snout is retracted, ridges in the upper segment emphasizing the position. Grooves along the inner surfaces of the mouth realistically portray the softer tissues of that area. The gill covers are represented by inlays of somewhat crude shell discs and the gill openings by the crenulated outer lips of cypraeiform shells unidentified as to species but, although these are now white, probably spadicea. The belly of the fish shows no attempt to represent an anal fin and is not decorated in any manner.

\section{PLATE XXI}

CAT. 20/5495. The mouth, dorsal fin arrangement and general body form classifies this carving as representing a killer-whale. A blow-hole is found in the top of the head under a single perforated shell disc. The course of the drilling connecting this opening with the mouthpiece is shown on pl. xxıv. Eyes are shown as inlaid perfforated discs and more or less symmetrical inlays exist bilaterally on the body and somewhat raised above its surface. The large segments forming the central ring of these are sections of limpet calluses. The mouthpiece is of pismo clam shell, an unusual feature. It is adhered in place with asphaltum, there being four shell rings 
overlaid dorsally in this mass. Crude incised lines run backward along the under jaw from the lower lip edge. There is a ventral drilling in the body on a line with the lateral inlays, probably a socket for a stand or handle no longer present.

\section{PLATES XXII, XXIII}

CAT. 20/5496. A specimen of excellent workmanship but recovered with the tail flanges so broken that no exact determination can be reached as to their original extent. One lateral fin was unimpaired and this permitted complete restoration of its mate, considerable of which was also missing. This sculpture is shown in two views so that the mouth arrangement and the general body symmetry might be illustrated. A band of perforated shell discs circles the high dorsal fin joining at its rear base and running down the dorsal crest of the body to divide again just anterior to the insertion of the mouthpiece, which it then circles. Similar discs are grouped in roughly triangular inlays at the body junction of the lateral fins. The tip of the dorsal fin also shows old breakage, but it probably was never of much greater height. A drilled channel runs from the orifice in this appendage downward through the body to the belly surface where it is sealed by the broken butt of a whale bone stand or handle still adhered by asphaltum in the socket drilled to receive it. Connecting with this, a longitudinal drilling runs posteriorly at a slight angle to connect with the mouthpiece. The exact course of this channel is shown on pl. xxIv. The mouthpiece is of bone set in asphaltum, a heavy smear of which substance extends a short way up the stem.

\section{PLATE XXIV}

It was deemed necessary to show, if possible, the exact courses of the drilled channels through the two killer-whale effigy cloud blowers.

After considerable experimentation, exographs of these specimens were finally obtained. Because so much of the outline was lost in the long x-ray exposure necessary to penetrate the thicker portions of the specimens, reproduction of the actual negatives proved impracticable. Carbon-pencil tracings were, therefore, made for illustration here. Although accentuated in the drawings, the exact outlines of the drilled channels were followed with all possible accuracy. 
CAT. 20/5495. The uniform diameter of the bore of the longitudinal channel; from mouthpiece orifice to well into the snout, suggests the use of a reed drill. The drilling from the blow-hole, slanted down to enter the long channel, appears to have been commenced with a stone drill and completed with a reed.

CAT. 20/5496. Here again the longitudinal channel seems to have been formed with the use of a reed drill after one of stone had been used for the initial opening at the mouthpiece orifice. The vertical channeling appears to have been accomplished with the use of drills of four sizes, the uppermost section, in the dorsal fin, by use of a reed. The starting point on the ventral body is now plugged with the butt of the original stand or handle set in asphaltum. The connecting drilling from the tip of the dorsal fin probably shows the use of a reed. As the distal part of this appendage was missing when the specimen was found, the type of implement used initially in the drilling operation is conjectural. If a stone drill, however, the diameter of the fin precludes any but one of small gauge.

\section{PLATE XXV}

CAT. 20/4891. Although the mouth of this specimen is enlarged to some depth before it tapers to a narrow drilling, which might class it as a smoking pipe rather than a cloud blower, it is felt that it should be described with the latter group. Regardless of its exact category it is, perhaps, the most outstanding specimen of both series. From the dorsal view, identification of the effigy would seem to center in the ray species which are found along this area of the California coast. The head and mouth arrangement, however, present characteristics of the tortoise or turtle groups, as will be noted in the upper detailed view, photographed on a larger scale. The specimen shows two sets of eyes, one represented by the shell bases with oval perforations set in the eye cones, and one by large, thick perforated discs overlaid in asphaltum at the junction of the apices of these cones with the neck line of the main body. Nostrils are present and a pointed tongue is definitely formed on the under surface of the mouth. Lightly curved, roughly parallel single lines of shell disc inlays extend bilaterally from the vertebral crest outward almost to the body edge. The circle of shell discs at the junction of the mouthpiece with the body is overlaid on the asphaltum mass which seals this orifice. The under side of the ex- 
panded tail is fluted. The bowl area is enlarged dorsally and laterally to conform to the body contour. Many striated tool marks. are found as are traces of red paint. The mouthpiece is of bone and measures $6 \frac{5}{8}$ in. in length from its point of insertion. It is set at an angle of almost $40^{\circ}$. Neither this feature nor its full length are shown in the view selected best to illustrate the more important features and to present the specimen at the largest possible scale.

\section{MARINE AND ANIMAL FORMS}

From the collection of stone carvings in marine and animal effigy only a limited number of the more unusual specimens are illustrated.

Marine and animal forms have come from, particularly, San Nicholas Island. These are generally larger than any from mainland sites and, as far as the collections of this institution are concerned, are all carved in the full round with the exception of a few fish effigies, one of which is of bone.

The forms represented are killer whale, ranging in length from $4 \frac{1}{4}$ to $12 \frac{3}{4}$ in. and in weight from $2 \mathrm{oz}$. to $8 \mathrm{lb}$., sail fish, seal, walrus, bear, deer, dog, tortoise, flying bird and frog. The animal forms range from $2 \frac{1}{2}$ to $5 \frac{1}{2}$ in. in length.

From the mainland, except for three seals and one bear, the latter chipped from black flint, the effigies are all of fish form. The sail fish, dolphin, marlin, whale and ray are recognizable among these. They range in length from $1 \frac{1}{4} \mathrm{in}$. and are for the most part flat. From Point Dume there also exist a series of what appear to be sea snail effigies, the foot disc being carefully fashioned. These are in full round and the tapered end is grooved, as is found in the so called plummet forms. The largest is 3 in. in length and weighs $2 \mathrm{oz}$. They are not here illustrated.

On these commoner forms, shell inlays, even in representation of eyes, are rare. Several have superficially drilled sockets which may have once held rings or discs and in a few of the smaller fish forms the perforations marking the eye may have been for suspension.

The larger ventral sockets occurring in some of the specimens here illustrated may bespeak their having been on staffs or pedestals of some kind. 


\section{PLATE XXYI}

CAT. 20/1123. A representation probably of a hammer-headed shark. Nostrils are shown in the snout and eyes are indicated by small shell rings set in asphaltum at the apices of bulbous projections from the head. The mouth is well formed. There is a drilled hole on the ventral surface of the body which probably constituted a socket for a handle or stand similar to those found in some of the fish pipes. A thin smear of asphaltum is found over the surfaces of this drilling.

C.AT. 20/1855. Another representation of a shark, but with a conventionalized body and no tail. The mouth and nostrils are well indicated and shell inlays set laterally in the snout area represent eyes. The upper surface of the head area is somewhat concave giving prominence to the snout. There is a large drilling on the ventral surface probably a socket for a handle of some sort but containing no traces of asphaltum. This specimen has been photographed at an angle of approximately $45^{\circ}$, leaning toward the camera, hence it appears much foreshortened.

\section{PLATE XXVII}

CAT. 20/3727. A small killer-whale effigy. Transverse grooves occur across the upper snout of this specimen and the rentral surface of the under jaw is scored with a series of deep grooves spaced along the lip line and converging to a central point on the under surface of the body just anterior to the drilled socket in which a handle of some sort was probably originally located. The eye sockets are deep set on either side of the snout, shell rings set in asphaltum representing these organs. Larger perforated discs are set laterally on either side of the body. The tail forks to form two symmetrical lateral flanges and also has a dorsal projection.

CAT. 20/1856. A most relastic piece of sculpture which, from its breadth at mid body and the long pointed tail, leaves little doubt of its representing a sting-ray. The shell rings inlaid as eyes may have been purposely broken to give the impression of the upward direction of the pupils. The mouth is well depicted and the tool marks on the body and tail tend generally along a uniform longitudinal axis. A hole has been drilled into the under surface of the fish but no traces of asphaltum are found in it. 


\section{PLATE XXVIII}

CAT. 20/1122. An unusual fish form, being the only specimen in the series depicting a pouched under jaw. A rather definite crest extends from the tip of the snout dorsally to the beginning of the tail area. The shell inlays representing eyes are set in deep sockets, the grooves along the snout, leading to them, being well formed. It is not clear whether the circular dillings in which the mouth line ends bilaterally were originally made to hold inlays. A pointed tongue with a longitudinal central groove is well defined in the floor of the mouth. The under surface of the flattened tail, which is leaf shaped in contour, is scored with deep groovings generally fanning out from a central point under the body. The ventral surface just behind the jaw pouch carries a drilled socket containing no traces of asphaltum.

\section{PLATE XXIX}

CAT. 20/1124. From the body curve, probably a representation of a leaping dolphin. Deep grooves extend downward from the eye sockets to the mouth line forming the pouched gill areas. No shell inlays are found as eyes, nor is there any trace of asphaltum in the sockets. Crude incisings denote the rays of the tail fin, which area is considerably flattened dorsoventrally as compared with the rest of the body.

CAT. 20/998. A symmetrically carved fish effigy having a well defined mouth back under the blunt, rounded snout. The deep groove which appears as a gill slit in the illustration runs completely under the body and, from the ventral view, marks the head area as distinctly separate from the body. The eyes are simulated by two projections from the head, the area between which is somewhat flattened. Nostrils are represented. Shallow notchings occurring transversly along the dorsal crest of the body possibly depict the rays of a fin.

\section{PLATE XXX}

CAT. 20/988. A larger example of flattened fish effigy, possibly representing a marlin. The dorsal fincrest is serrated and crudely incised to indicate rays. The eyes are formed by perforated shell rings inlaid in asphaltum. Crudely incised lines occuring bilaterally just below and behind the eyes may indicate gill covers or slits. 
CAT. 20/990. A well worked specimen in the full round possibly representing a marlin or sword fish. Shell discs are inlaid to indicate eyes.

\section{PLATE XXXI}

CAT. 20/1854. A sail fish in which the large dorsal fin is portrayed with particular realism. One segment of the tail fin is broken and this may have originally curved forward upon the body or extended upward, either position lending an added sense of motion to the fish. The eyes are inlaid shell rings. Tool marks are plentiful, the striae being, generally, in a horizontal direction.

\section{PLATE XXXII}

CAT. 20/3726. One of the most interesting carvings of the series. The open mouth with the retracted upper lip is found in several of the smoking pipe forms illustrated and described elsewhere in these pages, as are the protruding eyes represented by inlaid shell bases, and the high, pointed dorsal fin. The lobster or prawn body and tail are unique to this specimen. Four deep, arced grooves traverse the ventral thorax area and form five ridges which may indicate sucker pads or multiple forelegs. The bilateral projections just anterior to the retracted tail, each with two grooves on its under surface, may indicate fins or rudimentary rear legs. One interesting feature of the shell eyes is that both inlays have purposely or accidentally, been set at an angle which directs the plane of the pupils downward and inward. Flutings occur in the expanded tail on both upper and under surfaces. There are traces of red paint in some of the deeper incisings. Tool marks are plentiful.

\section{PLATES XXXIII, XXXIV}

CAT. 20/3740. Although this unusual specimen is a bowl, the piece is included in this, rather than the vessel, series because of its greater morphological interest. Both fore and hind legs are partly flexed at their mid joints which positioning lends the impression that the form represented falls within the spider family group. A well formed pointed tail, slightly curved at an upward angle, however, might argue against this classification. Of the two central legs, one has been broken and the stump resmoothed. The mouth is open with both upper and lower lips slightly retracted. Because 
of the foreshortening occasioned by positioning the piece for the view angled from above, an almost exact lateral view is also shown to give an idea of the depth of the body proper and the paired symmetry of both front and hind legs. The eye sockets are carefully made raised buttons the centers of which have been countersunk to receive sections of shell bases inlaid in asphaltum. The rim of the bowl opening is raised slightly above the body surface proper and the collar thus formed is decorated with radiating evenly spaced incisings. The receptacle has almost vertical walls and is not hollowed to conform with the globular body contour. Tool marks are numerous on all surfaces. This piece shows signs of once having been well covered with red paint. Considerable smear remains upon the body and in the receptacle, and is particularly thick over the asphaltum of the eye inlays. It may have been a paint mortar.

\section{PLATE XXXV}

CAT. 20/3776. A seal in recumbent pose in which, were the specimen balanced evenly on its rather ridged under body, both anterior flippers would be off the ground. The mouth is indicated by a horizontal groove and the eyes by small superficial drillings too small to receive the typical shell inlays. No nostrils occur. The posterior body is somewhat pointed.

CAT. 20/999. At least two examples in the collections represent swimming seals. Others may, but motion is not definitely portrayed in their sculpture. This specimen is well fashioned with eyes and mouth indicated, and a series of roughly parallel groovings on the dorsal surface of the pointed secondary tail may possibly represent skin wrinkles. The anterior flippers each carry two dorsal and one ventral groovings which lend realism to those appendages. The bilateral rear flippers, although carefully formed, are not so fluted. Considerable red paint exists in the dorsal tail incisings.

CAT. 20/3731. A pose somewhat in duplication of 20/3776 but with the head lifted and the mouth partly open as if the seal were barking. Rounded flutings in the breast and throat areas simulate folds in the tissues. Two small drillings in the snout indicate either nostrils or eyes. A deep vertical groove forks the main tail terminal. Tool marks are present in considerable number. 


\section{PLATE XXXVI}

CAT. 14/8851. Walrus forms are found on the Islands, not one being found in the collections from the mainland. This is an interesting specimen judged from the position in which the animal is carved. Eyes are indicated by shallow drillings which show no evidences of having held inlays. The tusks are clearly indicated and both fore and rear flippers are well formed.

CAT. 20/3728. A well finished example of an ambulatory barking seal. The neck and head curves realistically to the left and the right fore-flipper is advanced. The mouth is open and the eyes are small shell rings. The extended rear flippers are carefully formed and are widely spread. The broken stump of a stand or handle of whale bone remains adhered by asphaltum in the socket prepared for it on the under surface. Its location is visible in the illustration.

\section{MISCELLANEOUS OBJECTS OF STONE}

As with the marine and animal effigy series, it is possible here only to illustrate the more unusual specimens of miscellaneous stone objects.

Hook-stones, for instance, exist in considerable number in the collections, the Islands being more prominently represented as sites of provenience than the mainland. The objects range in size from $1 \frac{3}{8} \mathrm{in}$, to $8 \frac{5}{8} \mathrm{in}$. in length and from slightly more than $\frac{1}{4} \mathrm{oz}$. to $6 \mathrm{lb}$. $8 \mathrm{oz}$. in weight.

These have been called bird effigies by some writers, and one specimen from Clifton-by-the-Sea, Los Angeles County, has a creasted breast area and considerable point to the hook which gives it a marked bird resemblance.

While but one inlaid specimen in the category is illustrated, and it has no comparable associate in the series, several from San Nicholas Island are also so decorated while others carry incised designs.

The stone flute (pl. xxxrx) is an outstanding piece in a series of five, all from San Nicholas Island. Three of these closely follow the form of the illustrated specimen. Two have a similar arrangement of eight finger holes and the other, six stops more widely spaced along the tube. The fifth piece is a longer cylinder of stone. 
and of much less diameter, having four finger holes spaced evenly at its center. None of these other specimens is inlaid.

No stone flutes exist in the collections from mainland sites although several of these instruments, as well as whistles, of bone do so occur.

Perforated stones, cogged and smooth of varying sizes are well represented, practically from all mainland and island sites. Many of them are crude and are of a coarse grained sandstone. Not a few carry shell inlays of one type or another. Of the five here illustrated, four are selected for the excellence of their carving and one for the unusual arrangement of its cogs and the amount of inlaid shell it carries.

The dividing line between larger and heavier tubular stone beads and smaller and lighter tubes must be drawn with some flexibility. Even some of the larger bone tubes, although light enough for practical suspension, and, therefore, classified as beads, may not have been ornaments.

In addition to the cache of twenty-one tubes reported and described by Heye,$^{1}$ specimens of varying sizes are represented from both mainland and island sites. Some are slightly barrel shape but most are straight cylinders bored equally throughout. Except for one other of considerably less diameter, the three tubes illustrated (pl. XLII) are the only inlaid specimens.

Pestles from the Southern California littoral and the Islands occur in varying lengths and a variety of stones. For the most part they are undecorated save for occasional annular flanges or collars near the top of the implement, although one or two not here illustrated have inlays of shell.

Two miniature pestles, one $3 \frac{1}{2}$ in. and the other $3 \frac{3}{4}$ in. in length, were found with small mortars at two mainland sites. The pointed handle of one is decorated with a ring of cross-hatching and of inlaid shell discs. Both implements are well formed.

Except for these two, the size range of the pestles runs about that of the specimens illustrated. A somewhat slender example from Santa Catalina Island, with the handle tip broken and missing, still measures $3 \mathrm{ft} .2$ in. in length.

While perhaps chipped stone has no place here, a few of the finer shell decorated blades are illustrated. One of the best examples of

${ }^{1}$ Heye, 1927, pp. 315-323. 
workmanship is a bear effigy chipped from black flint. This piece is from Point Dume and is not here illustrated.

\section{PLATE XXXVII}

CAT. 20/3797. Three discs of unusual form and competent workmanship. While the outline of the central aperture varies somewhat in each, there can be no doubt that they were meant to be similar. These might be ceremonial hand-axes. The arrangement of the incised lines at the hand grip is thought to depict a butterfly or a crab, but as they merely follow the contours of the carving quite probably this form is purely incidental to the general attempt at decoration. The incisings as shown in the illustration occur on both sides. Both the inner aperture and the peripheral edges are thinner than the body of the ring, which is spindle shape in cross section, but are not sharpened to anything contemplating a cutting edge. There remain traces of red paint in most of the incisings.

\section{PLATE XXXVIII}

CAT. 20/2940. An unusual example of the problematical hookstone sometimes considered a bird effigy. A line inlay of eight shell discs occupies the center crest of the hook and the broad end of the base has a raised center portion in which two large shell rings are inlaid in asphaltum.

\section{PLATE XXXIX}

CAT. 20/3836. A stone flute with eight evenly spaced finger holes and five single unit shell disc inlays staggered between the two rows. A single course of shell discs and rings encircles either end of the main tube at points just before the areas of reduced circumference are reached.

CAT. 20/3723. A well executed spike shaped implement carved to represent a conventionalized marine or animal form. The circular head is perforated at its center and its upper rim has been worked to represent a broad, blunt nose with a crudely formed mouth. Extensive tool marks exist on the main body of the piece and its two symmetrical central projections.

C.AT. 20/1594. A well worked top shaped drill with a point of milky quartz set in asphaltum. A hole has been drilled at the shaft end but no remnants of the shaft exist in this socket. 


\section{PLATE XL}

This plate illustrates four circular perforated stones, all from San Nicholas Island.

CAT. 19/81. A specimen with a smooth periphery and a flower petal design, possibly representing the sun, carved in bas relief on its upper surface. The under surface is plain.

CAT. 19/80. The circumference has shallow serrations or cogs and the upper surface is decorated with volutes emanating from an annular incising circling the central perforation. The under surface is plain.

CAT. 20/3838. In this specimen the cogs have been somewhat flattened or rounded. The upper surface is decorated with a collar around the central perforation formed by a deep circular groove in the body of the stone. The under surface is plain.

CAT. 19/82. A carefully worked specimen in which the flutings and serrations are carved with accuracy. The plain central portion of the upper surface circling the perforation is slightly convex. The under surface is.plain.

\section{PLATE XLI}

CAT. 20/5770. Circular perforated stone with four cogs around its body. The two projections shown in the illustration have single line shell disc inlays of five and four units respectively. The other two cogs have three unit inlays. A single course of well formed shell discs circles the central perforation on both flat surfaces. The perforation contains the remnants of a wooden hafting set in asphaltum, which shows traces of red paint.

CAT. 20/4893. A large disc with a central well, possibly a ceremonial paint mortar. The upper surface of the specimen is slightly convex with broad, shallow flutings between the inlays. The under surface is flat and without decoration. The perforated shell inlay units forming a broad collar around the central boring and the spokes radiating from it to the circumference are both rings and discs, some of the latter being roughly rectangular or oval in outline. There are traces of red paint over the shells and in the receptacle.

\section{PLATE XLII}

CAT. 20/5230. A slightly barrel shaped specimen, with a straight drilling accounting for the walls being thicker throughout its central 
portion. An eleven band inlay of small shell rings, the courses being somewhat uneven, is found circling the tube's surface toward one end.

C.AT. 20/3746. This specimen is a straight cylinder and the ten roughly aligned annular courses of shell discs are overlaid on a band of asphaltum.

CAT. 20/3745. A barrel shaped specimen with two inlaid rings of shell discs enclosing eight regularly spaced annular grooves which contain asphaltum.

\section{PLATE XLIII}

CAT. 20/1028. A pestle of sandstone. Near the tapered end several courses of shell discs are overlaid in a band of asphaltum.

CAT. 20/2585. A pestle of wood with a base of diorite. In an asphaltum ring, just above the junction of the base with the shaft, a single line of rectangular perforated shell units circles the specimen. The expanded handle tip has been cut away to receive an inlay of several courses of shell discs in somewhat irregular arrangement.

CAT. 18/9182. A pestle of sandstone, the top of which has an expanded ridge holding three parallel courses of shell discs overlaid on edge in bands of asphaltum. The central ring is of thick units, probably clam shell.

C.AT. 20/2584. A well sculptured pestle of decomposed steatite. There is no indication that the space between the two parallel ridges just below the pointed tip ever held an inlay.

\section{PLATE XLIV}

C.AT. 20/1065. A blade of cream white color with a portion of the wooden hafting still attached by the heavy smear of asphaltum into which shell rings have been pressed, both sides of the blade carrying this decoration.

CAT. 20/1063. A blade of bluish white color. The shell ring overlay at the site of original hafting occurs bilaterally but the central smear of asphaltum into which a rough piece of abalone shell has been pressed is on only one side.

CAT. 20/4666. A stone blade in wooden handle from the socket of which an overlay of shell rings extends in the form of an attenuated triangle on either side. 
CAT. 20/1583. A blade of black flint, the base of which is ornamented bilaterally with shell discs pressed into an asphaltum smear. Impress of a previous pronged hafting appears in the bitumen.

CAT. 20/1062. A blade of obsidian on which occurs an overlay of shell discs and rings on one side only.

\section{ORNAMENTS}

Tubular beads of stone and bone are well represented in the collection. Those of the latter material are tubes with an overlay of asphaltum into which shell discs have been set in over-all pattern, or in roughly longitudinal courses.

Stone beads are largely of steatite, although several are of serpentine with asbestos veining. Some are plain cylinders drilled more or less uniformly throughout; others, more particularly from Santa Cruz Island, are expanded at their centers and have collars at each end-not unlike those illustrated by Orr. ${ }^{1}$

One interesting group of nine beads comes from a burial in the vicinity of Point Dume. Eight are straight tubes ranging from $3 \frac{1}{2}$ to $6 \frac{1}{8} \mathrm{in}$. in length and one curved, $5 \frac{3}{4} \mathrm{in}$. long. These are of a light gray steatite and are decorated with closely spaced circular stripes of asphaltum.

A few beads are deeply grooved at regular intervals forming globular sections along the tube. Most of the stone beads are not inlaid or overlaid with shell units but several of the more interesting types that are so decorated are here illustrated.

In connection with the bone implements called here hair ornaments, it is indeed possible that the more spatulate forms may be sweat scrapers, as mentioned by Fages ${ }^{2}$ and Font. ${ }^{3}$ Some of the spatulate steatite specimens in the collection, and not here illustrated, seem too heavy for hair ornamentation.

\section{PLATE XLV}

CAT. 20/5231. A slightly tapered tubular bead showing considerable wear around the rim of both ends. It has a central annular inlay consisting of three rows of tiny, well matched shell rings with two parallel bands each of two rows of these rings on either side.

${ }^{1}$ Orr, 1943, pl. 7.

${ }^{2}$ Priestley, 1937, pp. 67-8.

${ }^{3}$ Bolton, 1930, vol. IV, p. 250. 
CAT. 20/2591, 20/2592. The specimens are similar, except that one has three inlaid annular rings of shell discs set on edge, and the other, four rows. The collections contain eight specimens of the three row type and four of the other.

CAT. 20/1054. This bead has nine annular grooves, more or less evenly spaced along its surface, in which single rows of somewhat thick walled shell rings have been inlaid in a resinous substance, not in asphaltum as are the other specimens shown on this plate.

CAT. 20/5491. Curved steatite bead, segment of the necklace shown on pl. LI. This detailed view of the member shows the hourglass inlay on its upper surface not discernible in the illustration of the entire necklace.

\section{PLATE XLVI}

CAT. 19/9453. Under this number five specimens of curved halfround stone beads are illustrated. While these were found together and may have once been units of the same ornament it will be noted that in size and decoration they group into two pairs and one odd bead. The larger square or rectangular inlays on the flat faces of the specimens are irregularly shaped and are of a pale abalone shell. The central circular inlays shown on the two lower specimens are the rounded bases of shells, possibly olivella, rather than flat discs. There is no incising nor inlay on the rounded obverse surfaces of the units. Traces of red paint exist in many of the incised lines, particularly in the cross hatching on the lower two units.

\section{PLATE XLVII}

CAT. 19/9460-19/9464. The five perforated ornaments illustrated on this plate all come from one location at Buena Vista Lake, Kern County. Except for $a$, where the shell discs are inlaid-and which specimen also shows incised decoration-the shell units are all embedded in thick smears of asphaltum overlaid on the stone surfaces. It is quite evident that the areas of decoration were originally larger, as much of the outer surfacing of asphaltum is lost. In $c$, the large central ring is probably a limpet callus. In $d$, the larger shell units in the irregular upper course are of a pale abalone. In $e$, the two large central discs are of high colored abalone, as are most of the smaller ones throughout the field. 


\section{PLATE XLVIII}

CAT. 19/9422. A flat slab with an inlaid figure which may represent a conventionalized animal. The shell units are all rectangular, are well matched and have been most carefully and evenly perforated. All of the five large perforations along the curve of the specimen's upper perimeter show some wear, three of them in quite a definite degree.

\section{PLATE XLIX}

CAT. 19/104. A circular suspension ornament of bone, probably from a whale scapula. Some of the overlay shell units are rectangular, a characteristic to be noted in many inlaid pieces from San Nicholas Island, but most of them are slightly wedge shaped, the better to fit the circular course of their arrangement.

CAT. 20/3709. A perforated pendant of considerable size, the shell decoration occurring on the face only. Channels made for the line inlays are in evidence where the shell units have been lost. Both perforations show marked grooving from wear, and the edge of the specimen at one of the suspension holes seems to have been purposely notched by drilling. Tool marks are in evidence on both front and rear surfaces but the transverse incisings on the face of the pendant have light herringbone pendant lines which show a definite decorative arrangement.

\section{PLATE L}

CAT. 20/1051. An oval pendant of red stone. A circumferential groove has been fashioned to receive the closely fitted shell segments which are set on edge in the usual asphaltum. The scorings evident on both flat surfaces of the pendant are without definite arrangement and appear to be tool marks.

CAT. 20/1049. This specimen is illustrated with the pendants because of its decoration, although it may possibly be a sinker. The shell disc inlays on the face of the piece are all present. The obverse has four aligned inlay counter-sinkings which show the central asphaltum node pressed through the original perforated shell units, which are now missing.

CAT. 20/1021. A well and delicately fashioned ring with a broad flattened projection containing three perforations. The specimen 
is illustrated with this flange downward in the supposition that the ring possibly hung over the ear, or that hair was drawn through it, and the perforations were used to attach pendant feathers. It is equally as possible, of course, that the perforations were for suspension and that the piece should properly be reversed for illustration.

\section{PLATE LI}

CAT. 20/5491. A necklace consisting of a large cylindrical curved member, fourteen cylindrical beads of graduated size, with a pendant of two barrel-shaped beads and a flat, roughly triangular unit. The arrangement in which this specimen is illustrated was not alone indicated by the more or less undisturbed position in which it was found, but is confirmed by the drilling of the large central curved and inlaid unit. This member is not drilled entirely through, but only from either end to a point marked by the surface rings of shell inlays. From there perforations angle to the under surface of the bead, opening at points indicated by the position of the barrel-shaped drops. The central portion of the curved bead is solid. This curved segment is shown in more detail on pl. XLv. The drilling of the flat pendant runs across the top of the piece. The face of this unit holds a double circle of small inlaid shell rings in the center of which an amethyst crystal is set in asphaltum.

\section{PLATE LII}

On this plate and the following two unusual breast ornaments are illustrated. Although one is not from the coast area it is included as being an interesting comparison with that from Santa Catalina.

CAT. 20/3301-20/3305. A breast ornament consisting of five units, the four pendant pieces of which are inlaid with rough, unshaped, bits of turquoise enclosed in a crude incised meander into the lines of which asphaltum has been rubbed. The arrangement in which the units have been photographed is suggested by the angle of worn area noted at each perforation. The uppermost pendant segment has two annular grooves at either side of the inlaid area, the outer one for the attachment of the large crescent pendant below it, the inner for that of the small semi-lunar piece located in the space between the two. The lowest unit, more nearly the true gorget form than any of its companions, was suspended from per- 
forations through the unit immediately above. The rounded ter-。 minals of the neck ring have been drilled laterally.

\section{PLATE LIIJ}

CAT. 20/2937. A large neck ring consisting of two units. The upper one in the illustration is cylindrical except for a flattened area at each pointed terminal where the perforations for the attachment of the breast segment are found. The ends of this lower unit are notched to permit a close fitting with the terminal points of the upper piece. Seven entire fresh water pearls are inlaid in this broader and flatter unit, and these are enclosed in an equal number of crude diamond incisings whose vertical apices meet parallel incised lines forming a frame for the inlaid area. Grooves from the perforations show the wear from lashings of thong or fiber which originally bound the pieces together. This specimen shows much more precise workmanship than the ornament illustrated on pl. LII.

\section{PLATE LIV}

CAT. 20/5768. A most elaborate hair ornament of bone. The head is decorated with a single transverse row of complete olivella shells and three rows of shell discs. The fields divided by these bands carry overlays of shell rings, the central one of which is arranged in a double course meander. Parallel rows of shell rings occur in graded lengths to conform to the contour of the head as it narrows to form the body of the pin. The head is convex and its under surface is undecorated. The pin is also curved slightly in its long axis following the contour of the bone, probably a whale rib, from which it was fashioned. Asphaltum apparently has been rubbed into the irregularities of the surfaces.

\section{PLATE LV}

CAT. 19/9425. A long curved bone pin, probably a hair ornament. The head is carved into a ring set on a projecting collar of bone and the encircling asphaltum smear extending downward from this annular projection and carrying the overlaid shell rings is sufficiently thick to be flush with the collar. Traces of red paint are present over the bitumen.

CAT. 20/3761. A spatulate bone hair ornament with an almost circular perforation in its head. Just below this four annular rows 
- of shell discs are overlaid. Traces of red paint exist over the asphaltum.

CAT. 20/1129. A spatulate bone hair ornament with an oval perforation in its head. The full circumferential contour of the original bone remains just below this point forming a wide ring around which three annular rows of shell discs are overlaid. This overlay expands symmetrically on the back of the specimen to extend upward and downward from the circular band. Traces of asphaltum in the surface irregularities probably show an original coating of the substance.

CAT. 20/4654. A spatulate bone hair ornament with an oval perforation toward the extremity of the tapered head. The expanded area of the pin has an overlay of shell rings and discs, the whole generally oval in outline. Five incised lines notch either side of the neck of the specimen and extend to both front and rear surfaces. Otherwise the obverse of the pin is not decorated. The ornament is slightly curved on its long axis and traces of red paint are found over the asphaltum and in the surface irregularities of the bone.

\section{PLATE LVI}

CAT. 20/3762. A semi-spatulate bone hair ornament, the head of which is formed by two fish vertebrae adhered together with asphaltum. This material has also been pressed into the reticulated areas around the perimeters of both segments. A shaped mass of asphaltum attaches the head and a thick cap of the substance holds an inset rock crystal. Shell discs occur in more or less regular annular arrangement above and below the vertebral units. Traces of red paint are found over all the head area.

CAT. 20/1848. A spatulate bone hair ornament with an elaborately decorated cylindrical head, probably formed by one or two larger marine or animal vertebrae, as in the preceding pin, but covered with a thick wall of asphaltum and, therefore, not visible. The flat upper surface has an incised eleven pointed sun figure, the tip of each point ending at the periphery. The cylinder walls carry a series of annular courses of shell discs set more or less regularly. A limpet callus has been pressed into the asphaltum at the junction of the head and the pin body. The under surface of the cylinder carries seventeen incised spokes radiating from the limpet ring to 
the periphery. There are traces of asphaltum in the surface irregularities of the long bone.

CAT. 20/1849. A spatulate bone hair ornament. The articular expansion of the bone remains and to this is adhered a thick section of pale abalone shell set in asphaltum to form the head. Behind this, and set against the side of the bony prominence, is a thin roughly triangular section of pale abalone shell having four perforations. The collar of asphaltum extending downward along the thicker portion of the pin contains overlaid shell disc units. Asphaltum fills the longitudinal inner cavity where the bone has been split. Traces of red paint occur on the bone surfaces.

\section{PLATE LVII}

CAT. 20/3763. A semi-spatulate bone hair ornament with a thick coating of asphaltum covering its entire head. In this substance has been set a number of translucent pebbles resembling moonstones.

CAT. 20/1036. A bone hair ornament of unusual construction. The head is a disc of steatite, a slot socket in which receives the insertion of the flattened bone pin. At the approximate center of this disc, on both face and reverse, a shell disc overlay covers a perforation. Just below this drilling and on a central line with the long axis of the pin, another circular perforation exists on both front and rear surfaces. This is now filled with asphaltum. Between these two holes remnants of fiber cordage are closely adhered to both surfaces of the stone. It has not been felt necessary to dismember the specimen to prove the point, but it would seem that the arrangement of the perforations and the remaining shreds of cordage probably represent the manner of lashing the head, through corresponding holes in the bone, to the body of the ornament. A circle of overlaid minute shell rings occurs on the face of the stone head and the area outside this carries light chevron incisings with dots in the solid triangular interspaces. The reverse carries a lightly incised triangle and dot design occupying about the same area as the chevron and dot markings on the face. Around the perimeter of the disc a single course of very small shell rings has been inlaid. About quarter way down the body of the pin a drilled circular section of abalone shell has been fitted tightly to the bone and adhered with asphaltum, resembling the arrangement of a 
spindle whorl. The face of the body of the pin between this and the stone head carries lightly incised chevron markings set between parallel transverse incisings.

CAT. 20/3760. A spatulate bone pin, possibly a hair ornament, with an asymmetrical triangular head resembling a projectile point in form. The head and body of this pin are not in one piece, the two segments being joined with asphaltum. One side of the head is decorated with an overlay, in a thick coating of asphaltum, of various sized and somewhat crude shell discs, many large enough to retain the curve of the shell from which they were formed.

\section{PLATE LVIII}

CAT. 20/3764. A spatulate bone hair ornament decorated with trade beads. The bone retains its full round at the head, one wall having been cut away and the remaining surface shaped to have a slightly expanded tip. The head is decorated with two large opalescent bluish green cylindrical beads set symmetrically at either side, and is capped with three courses of blue globular beads dividing which are two rows of small opaque red cylinder beads set end to end. The obverse of the pin's head carries an incised chevron design. Three lightly incised diagonal lines occur on the front surface at either side of the central groove.

CAT. 20/1130. A bone hair ornament with a long head having, centrally located, a wide band of asphaltum holding three courses of disc and ring shell inlays overlaid between transverse incised parallel lines. A fragment of abalone shell has been fashioned to fit into the concave inner surface of the bone wall to which it is adhered with asphaltum. This irridescent ornament extends beyond the head of the pin and is shaped to a smooth, asymmetrical point. The reverse side of the pin's body has two series of deeply incised transverse lines, one of two, the other of three groovings.

CAT. 11/8428. A triangular bone pin, possibly a hair ornament, with a smear of asphaltum over its head. No depressions are found in the bitumen which might establish the probability of an original shell inlay. One of the triangular surfaces carries an area of carefully spaced incised cross-hatchings extending from the neck almost half way to the point. Another surface has incised decoration consisting of a six pointed sun or star figure, three crosses and a small area of cross hatching near the neck. The third surface has only a smear of asphaltum. The point of the pin is unusually sharp. 
CAT. 19/9442. A round bone hair ornament with an overlay of turquois chips in asphaltum circling its head.

\section{MISCELLANEOUS BONE}

\section{PLATE LIX}

CAT. 20/4664. A right human humerus which may have been a drum stick. A well carved seal effigy of steatite, with small shell rings inlaid to represent eyes, is set in the shaft of the bone and an asphaltum smear which extends along the shaft holds an overlay of shell discs among which are a few rings. The head of the bone, although somewhat smoothed, remains almost intact, and a fairly thick smear of asphaltum paint is found circling the neck.

CAT. 20/4665. A most unusual rattle composed of a bipointed section of whale rib to the upper arced surface of which six whole limpet shells, graded in pairs as to size, are lashed by vegetal splints laced through two perforations in the bone and corresponding drillings in each shell. This attachment is reinforced with smears of asphaltum. Between these, limpet rings and circular segments of the upper shell are overlaid with shell discs along the bone, and the central hand grip is decorated with an overlay of shell discs on its upper surface. The under surface of the long bone carries incised decoration in the form of a series of parallel transverse lines between which are found single and double meanders, the latter forming a diamond design at the hand grip. In each instance the upper segment of the limpet shell has been adhered to its lashed base with asphaltum. All contain pebbles.

CAT. 20/3833. Many whistles and flutes of bone exist in the collections. Some are undecorated except for bitumen smears, others have bands of shell disc overlays. The whistle illustrated is the most unusual of the entire series. The bone head carries three inlays of a lightly tinted abalone shell, two of which are circular, the third, roughly oblong. The shaft is circled by twenty courses of rectangular, perforated shell units of almost uniform size and overlaid with precision. All surfaces of the bone without shell decoration have been generously coated with asphaltum, over which traces of red paint exist. 


\section{IVANDS}

\section{PLATE LX}

CAT. 19/9512-B. A wooden wand painted red with an inlaid panel of rectangular sections of abalone shell set between two flat spindle-shaped pieces of bone on either broad surface of the shaft just below its winged expansion. The chipped stone blade is cream white with greenish black mottlings and is inserted into a socket in the wood and held in place with resin.

CAT. 19/9512-A. A wooden wand painted red. The inlaid panel of abalone shell decoration is much deeper than that on the preceding specimen and is composed of six regularly set courses. Flat sections of bone frame the panel at its extremities. The chipped obsidian blade is set into the wand and there is a thick ring of resin at this juncture.

CAT. 19/9511-B. A wooden wand painted red. The countersunk area of the shaft just below the expanded portion is smeared with resin in which are rough fragments of abalone shell. From comparison with a similar specimen from Desert Mountain, San Diego County, which is not illustrated, it is believed that the ornamental shell units were merely broken bits and were not regularly formed. Thick smears of resin hold the chert blade in place.

CAT. 19/9511-A. A wooden wand of unusual decoration. The shaft has no bilateral winged expansion as in most of those in our collection or elsewhere reported. At the top of the shaft clumps of vegetal fibers have been adhered with resin and fringe the insertion area of the chipped blade. Two larger pieces of abalone shell are adhered to the front side, with two rows of larger shell discs. The upper abalone overlay has bilateral notches on its upper surface and one perforation; the lower, three perforations, one of which breaks into the rim. The rear of the wand carries the two rows of discs but no abalone units, although a central'smear between the disc lines may have at one time held such an overlay. The specimen is painted red.

\section{VESSELS}

Quite a wide variety of bowls and mortars are represented in the collections from mainland as well as island sites. Among them are found the expected shapes, in both shallow and deep forms. The material is predominantly steatite and sandstone, although a few 
are of serpentine. One interesting specimen, a double bowl, from Santa Catalina Island, is not illustrated. It represents the only example of this type of vessel in the collection. Most of the vessels are circular, some few are oval and two, both from the Islands, are rectangular.

The largest specimen having shell decoration is of sandstone, has a height of $10 \frac{1}{2}$ in., a rim diameter of $14 \frac{3}{4}$ in. and weighs $65 \mathrm{lb}$. Its walls are only slightly out-curved and taper to a flat base. The rim carries as an overlay a double row of perforated shell discs. It is from the Sequit Canyon site and is not here illustrated.

The only boat form from a mainland site represented in the collections is illustrated on pl. Lxvi. Besides the one illustrated on the same plate, nine other specimens, both crude and well fashioned, are from Santa Catalina and San Nicholas Islands.

\section{PLATE LXI}

CAT. 19/9439. A four-legged vessel of almost perfect symmetry. One section of the rim shows a broken area which had been partly resmoothed. Two deep parallel grooves enclose an annular band of evenly spaced diagonal incisings on the outer wall surface. A single vertical groove is found centered on each leg. No decoration in shell is present.

CAT. 19/1615. An excellent example of well proportioned and symmetrical sculpture. The flat-bottomed vessel has been hollowed out to some degree, but the walls are unusually thick. A raised band below the shoulder has been grooved to receive inlays of shell discs, and another incised annular line circles the vessel between this and the shoulder. The neck area is decorated with a carefully executed incised design of joined diamonds. This vessel came from the same site as the flanged tubular pipe (CAT. 19/1614) illustrated on pl. viI.

\section{PLATE LXII}

CAT. 20/1579. Slightly oval bowl with a meander of somewhat irregularly fashioned perforated shell discs inlaid at the shoulder curve. An incising occurs around the crest of the rim and from this to the body junction occur patches of lightly graven hatchings. Many tool marks exist on all surfaces.

CAT. 20/3770. A well proportioned almost hemispherical bowl, its surfaces showing many tool marks. The wide rim is decorated 
with deep evenly spaced diagonal groovings, in each of which exist heavy traces of red paint. The top of the rim has a single annular groove containing only asphaltum. It is doubtful if shell inlays ever were present here.

\section{PLATE LXIII}

CAT. 20/5493. A small bowl with unusually thin walls. Two parallel annular grooves decorate the slightly expanded rim collar. The lower one has an inlay of small shell rings from which six groupings of similar inlays project downward upon the vessel's body at equally spaced intervals. A carefully incised meander is found between the ring of inlays and the upper circular groove.

CAT. 20/4652. A more crudely made bowl with thicker walls than the preceding specimen. Diagonal incised hatchings form a narrow band around the vessel just below the shoulder. A single row of small shell rings is inlaid on the surface of the inslanting rim.

CAT. 20/3837. A small oval vessel having equiposed node projections centered at the base of either long wall. The ends are decorated with rounded keel ridges. A single annular row of larger, thick walled shell rings is inlaid in asphaltum around the rim. The receptacle has not been hollowed to conform to the outer contour of the vessel and the walls are, therefore, unusually thick.

\section{PLATE LXIV}

CAT. 20/3742. A small jar with an inlay of a single row of shell rings around the top of the rim. A band of lightly hatched incisings, occurring between two roughly parallel annular lines, decorates the wall of the vessel.

CAT. 20/3743. A miniature olla with a collar of shell discs set on edge in asphaltum circling the neck of the vessel in a grooved annular flange just below the rim.

CAT. 20/3741. A shallow bowl with thin walls. The outer surface of the rim collar is decorated with a well spaced, double incised meander and the rim edge with a single annular row of small shell rings inlaid in asphaltum.

CAT. 20/1578. An oval bowl, the decoration on which is confined to the rim collar. A single ring of perforated shell discs is enclosed on the outside by a band of lightly incised diagonal cross hatchings and on the inside by a narrower band of straight hatching. 


\section{PLATE LXV}

CAT. 20/1576. A globular jar with a ring of shell discs set on edge in asphaltum around the collar of the contracted opening. The shoulder area of the vessel is decorated with a somewhat irregular meander inlay of shell discs.

CAT. 20/1577. A tapered globular jar with cover. The rim just outside the flange upon which the cover rests has a single annular inlay of small shell rings. Just below this, and around the collar of the vessel, occurs a band of larger shell discs set on edge in asphaltum. Around the shoulder two parallel incised lines enclose a series of evenly spaced incised diagonal hatchings. These graven lines all contain asphaltum.

\section{PLATE LXVI}

CAT. 20/3753. An unusual carving representing a watercraft. The gunwales carry an inlay of shell discs set on edge and an incised diagonal hatching extends downward on the outside to a point opposite an approximated thwart line. Both bow and stern are partially decked and these areas have shell disc and ring inlays. Traces of red paint are found, particularly on the inner surfaces.

CAT. 19/9397. A carving representing a watercraft with high bow and stern. A series of incisings form boxes containing $x$ 's just under the gunwales.

\section{PLATE LXVII}

CAT. 20/1047. Small flattened jar with cover. A single annular incised line is found at the center of the vessel's wall and a ring of inlaid shell discs encircles the rim and is completely hidden by the cover flange when it is in place. The two notches in the cover's periphery fit over two drilled apertures in the flat rim of the container which are angled inward to perforate the wall just below the contracted opening. The cover has a central perforation now filled with asphaltum. When found, the vessel contained a quantity of finely wrought shell rings. The under side of the cover is shown in the illustration, its upper surface being slightly convex and undecorated.

CAT. 20/1138. A horn shaped container of well executed workmanship. Below the three perforations at the rim a single incised line encircles the container and constitutes a base for evenly spaced 
incised triangles. Eight diamond shaped inlays of shell discs and rings are spaced evenly around the wall surface and an incised meander below them completes the decoration. A large perforation occurs at the tip end of the horn.

\section{PLATE LXVIII}

CAT. 20/1046. A shaped cylindrical container with a truncated conical base. This area shows a thick smear of asphaltum as if it once may have been adhered in the socket of a staff or pedestal. Three perforations exist near the rim of the vessel and widely spaced single unit shell disc inlays occur on its walls.

CAT. 20/3755. A cone shaped container with two perforations just below its rim. The wall is decorated with single unit shell ring inlays spaced with semiregularity.

CAT. 20/1575. A small cylindrical jar with single unit shell disc inlays spaced with some regularity around the wall. Just below the rim an annular incised line occurs, and between it and the vessel's opening lighter and less well executed diagonal hatchings are found. There are three perforations just below the rim.

\section{PLATE LXIX}

CAT. 20/1580. A well proportioned ladle with two parallel deeply incised rings and single unit shell disc inlays in somewhat regular arrangement ornamenting the handle. Tool marks are in great evidence.

\section{PLATE LXX}

CAT. 20/1587. A ladle or dipper-like object which, from the appearance of the inner surface of the bowl, has at some time contained asphaltum. There is a perforation at the heel of the bowl extending inward to the container. This does not appear in the illustration. A broad ridge extends around the handle near its pointed tip and has a double course of inlaid shell disc bands above and below the large lateral perforation. On either side of the handle small inlaid shell areas extend forward toward the bowl. Tool marks are plentiful on all surfaces. 


\section{PLATE LXXI}

CAT. 20/4653. An unusual specimen, unique to this collection. From its form and the hollowed receptacle at the upper end, it might be classed as a torch. Directly under the rim collar two parallel annular incised lines confine a series of somewhat roughly and lightly executed diagonal hatchings. Pendant from a single circle of inlaid shell rings are a series of evenly spaced inlays in the form of a reversed $\sqrt{ }$ mark. The body tapers symmetrically toward the pointed tip and expands into two annular ridges just before this is reached. The upper, larger ridge shows a nick that appears to have been a smoothed break. The specimen has a number of small pitted areas on its outer surfaces, some of which have been filled in with asphaltum. 


\section{BIBLIOGRAPHY}

Bolton, Herbert E.

1930 Font's Complete Diary. Anza's California Expeditions, vol. IV.

FAGES

1937 See Priestley, Herbert I.

FONT

1930 See Bolton, Herbert E.

Heye, George G.

1921 Certain Artifacts from San Miguel Island, California. New York, Museum of the American Indian, Heye Foundation, Indian Notes and Monographs, VII, no. 4.

1927 Shaman's Cache from Southern California. New York, Museum of the American Indian, Heye Foundation, Indian Notes, IV, no. 4.

Orr, Phil. C.

1943 Archaeology of Mescalitan Island and Customs of the Canalinos. Santa Barbara, Santa Barbara Museum of Natural History, Occasional Papers no. 5.

Priestley, Herbert I.

1937 A Historical, Political and Natural Description of California by Pedro Fages. Berkeley, University of California Press.

Putnam, Frederick W.

1879 See Wheeler Report.

Rogers, David Banks

1929 Prehistoric Man of the Santa Barbara Coast. Santa Barbara, Santa Barbara Museum of Natural History.

Schultz, Leonard P.

1938 Treasures of the Pacific. In National Geographic Magazine LXXIV, no. 4.

\section{Schumacher, Paul}

1875 Ancient Graves and Shell Heaps of California. In Annual Report, Regents of the Smithsonian Institution for 1874. Washington.

1877 Researches in the Kjökkenmöddings and Graves of a Former Population of the Santa Barbara Islands and the Adjacent Mainland. In U. S. Geological and Geographical Survey of the Territories, Bulletin III. Washington.

WALFord, Lionel A.

1937 Marine and Game Fishes of the Pacific Coast-Alaska to the Equator. Santa Barbara, Santa Barbara Museum of Natural History.

West, George A.

1934 Tobacco, Pipes and Smoking Customs of the American Indians. Milwaukee, Public Museum of Milwaukee, Bulletin XVII, 2 vols.

WHEELER REPORT

1879 Report upon United States Geographical Surveys West of the 100th Meridian, vol. VII, Washington.

YARROW, H. C.

1879 See Wheeler Report. 


\section{P L A T ES}


PLATE II

\section{Sequit Canyon}

View of approximate burial area.

\section{Point Dume}

View looking east over area of principal site. 

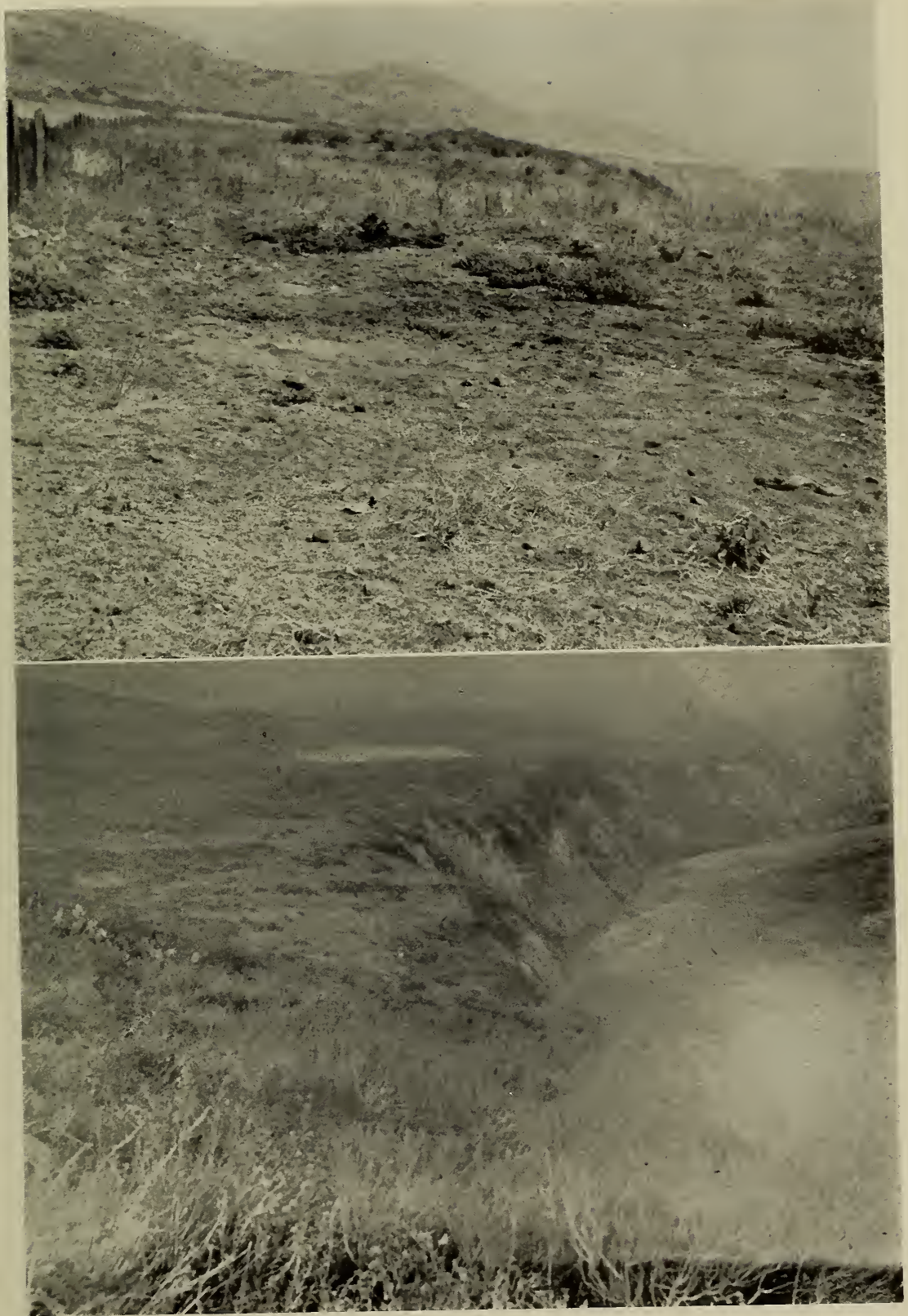

SEQUIT CANYON

POINT DUME 
PLATE III

\section{Lower Ramera Canyon}

The burial area is approximated by the cleared space.

\section{Solstice Canyon}

The fenced area approximates the burial ground. 

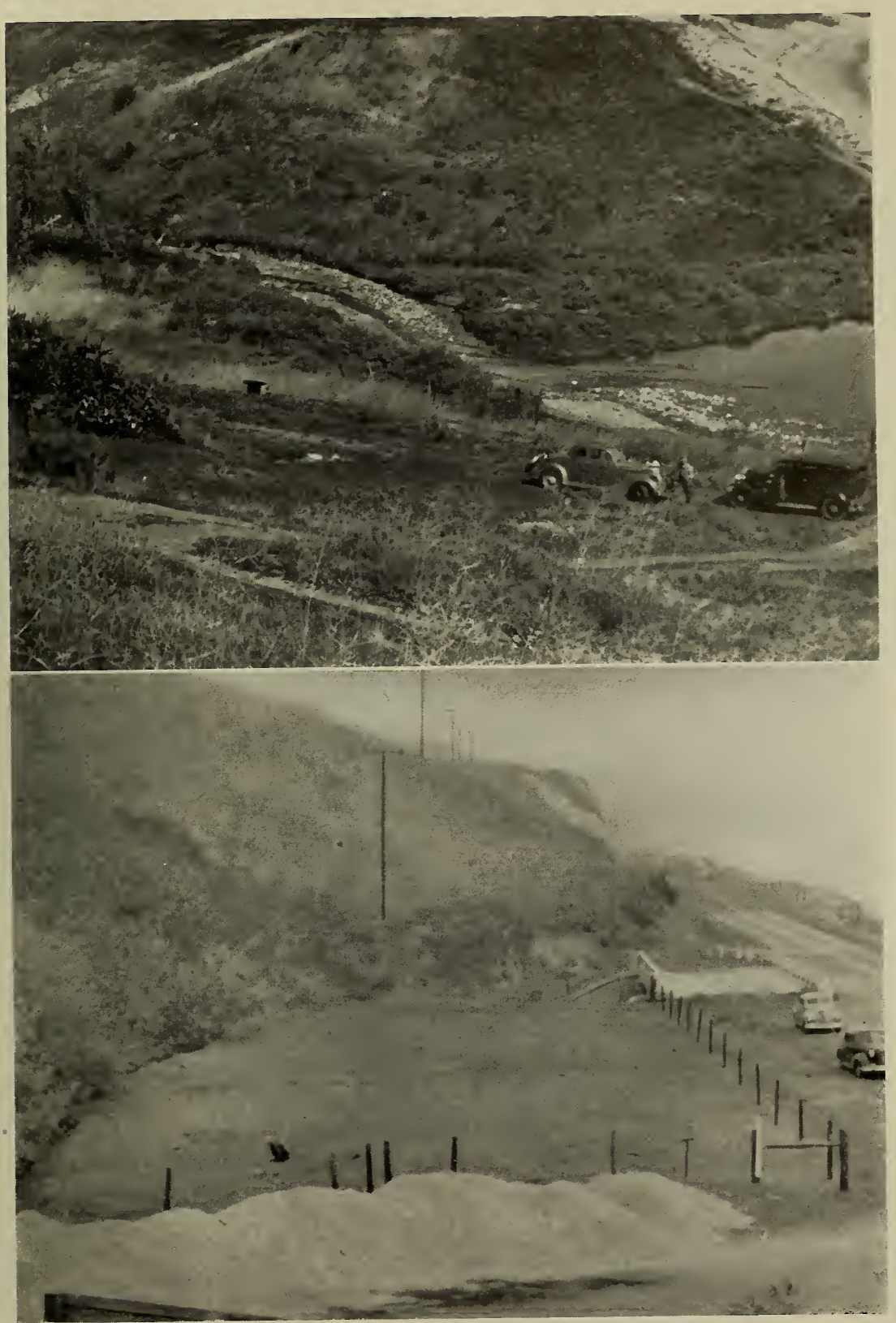

LOWER RAMERA CANYON SOLSTICE CANYON 


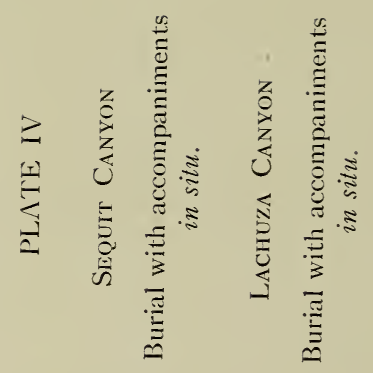




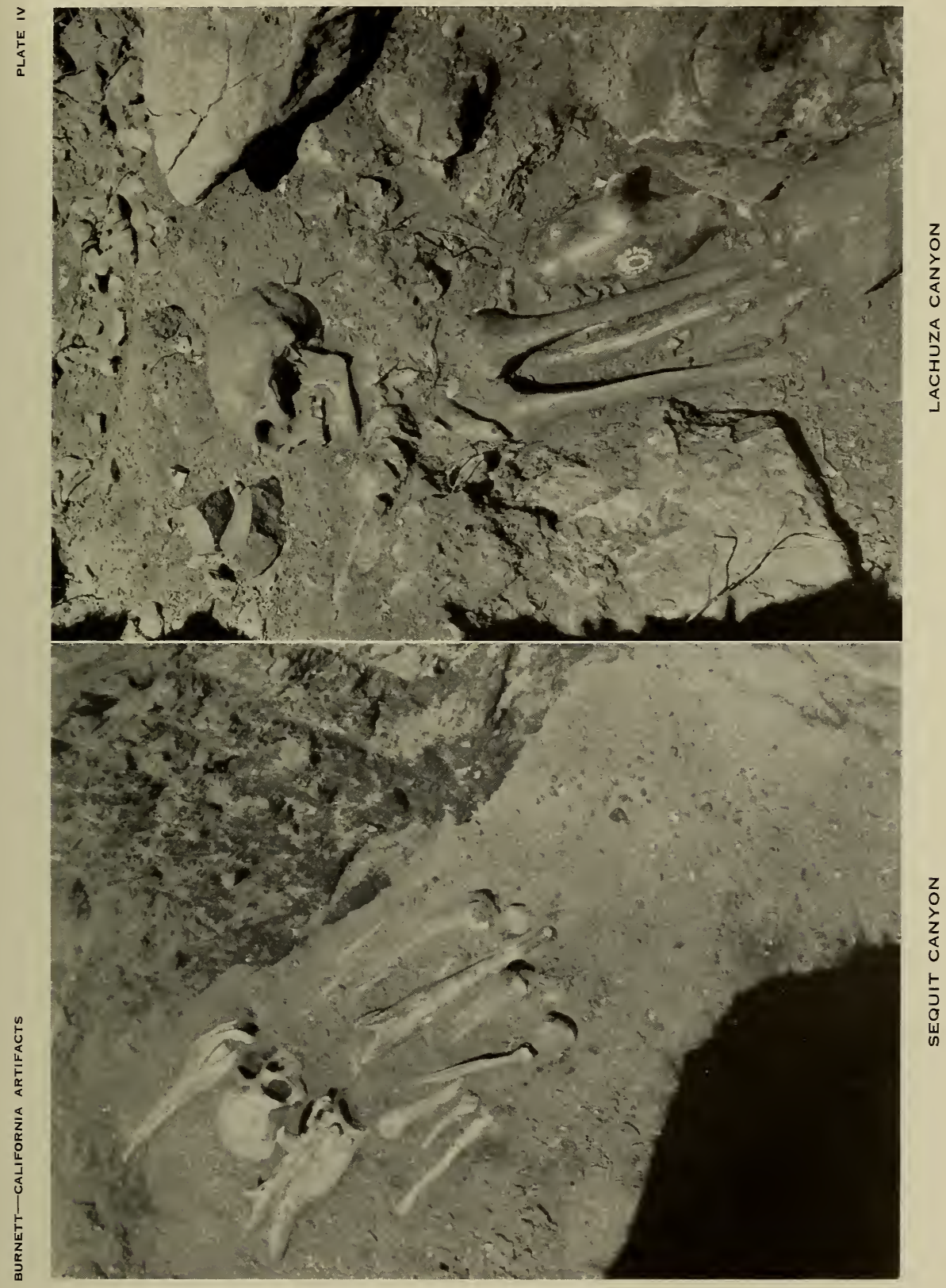




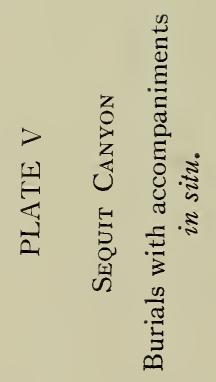



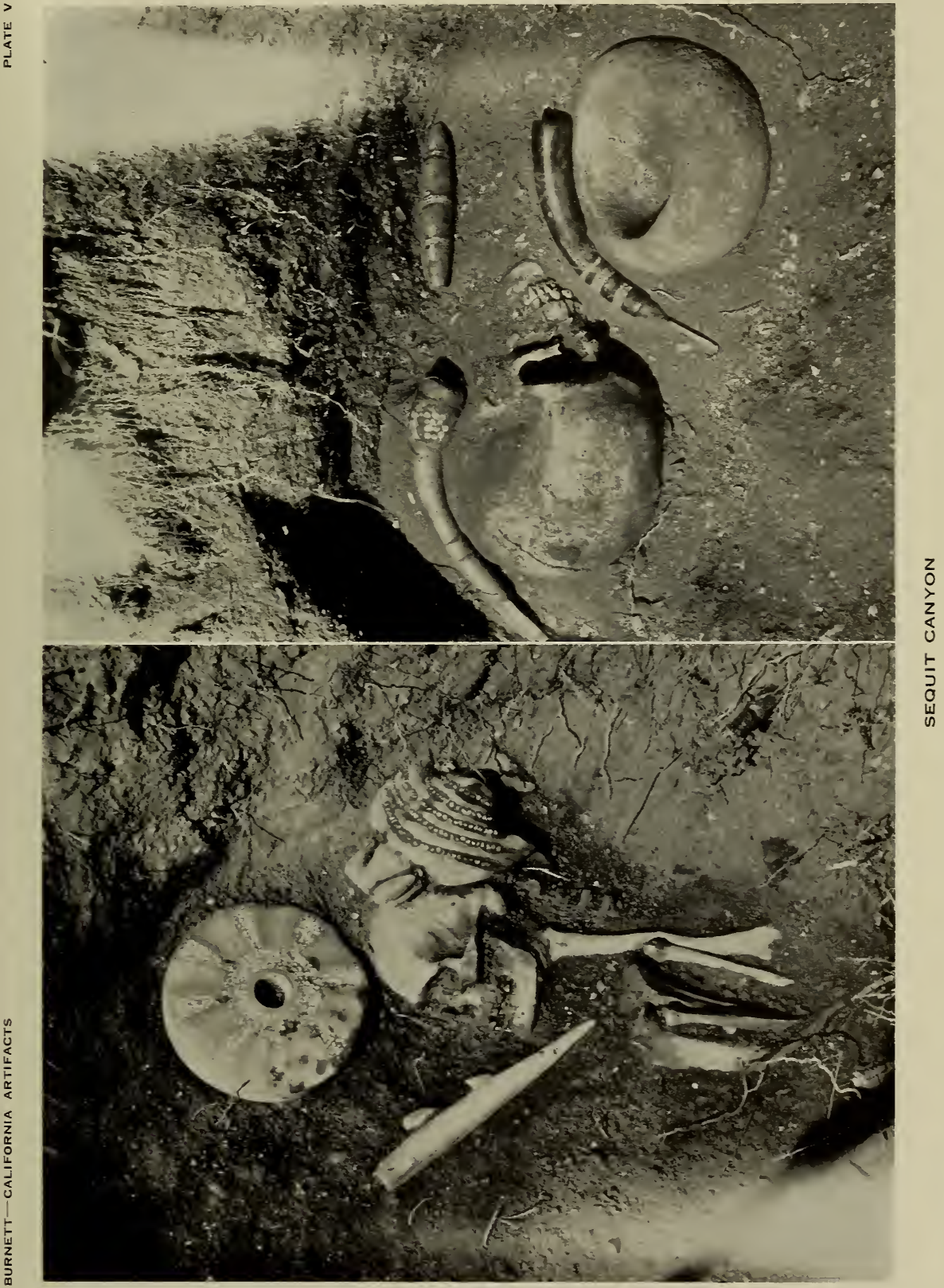


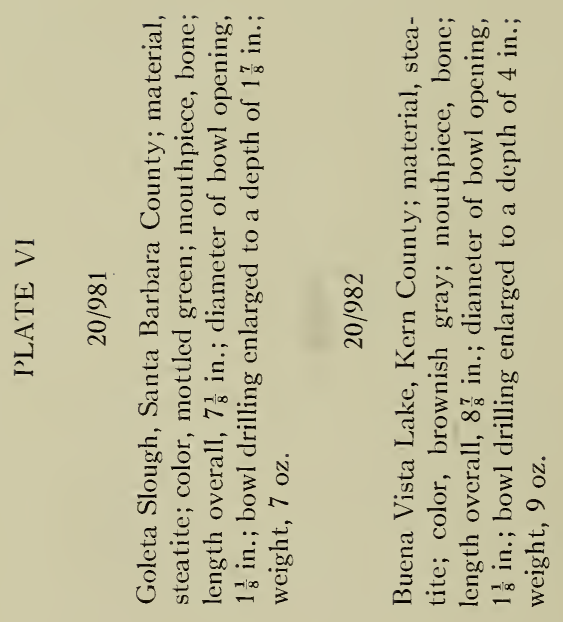


5

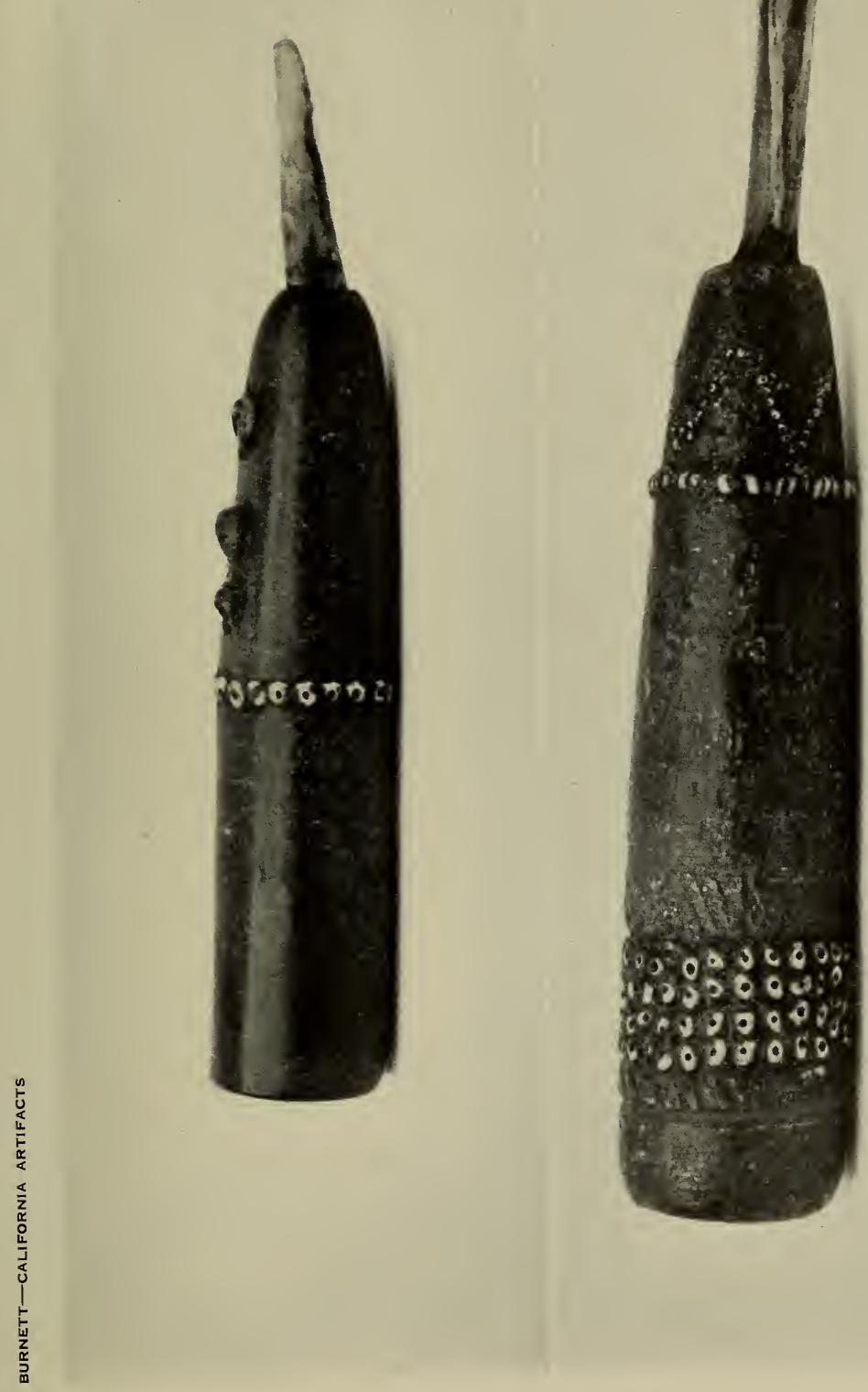

$\begin{array}{cc}\bar{\infty} & \infty \\ \stackrel{2}{2} & \infty \\ \stackrel{2}{2}\end{array}$ 


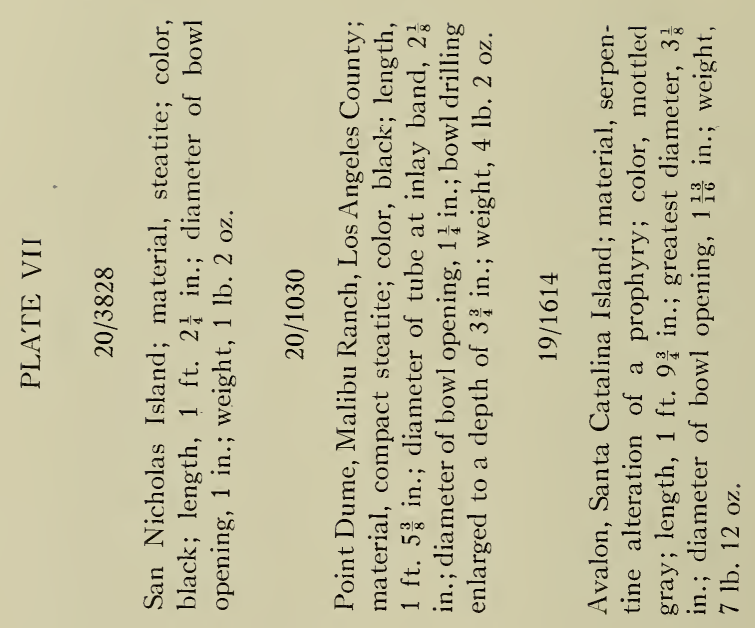


5
$\frac{5}{5}$
$\frac{5}{2}$

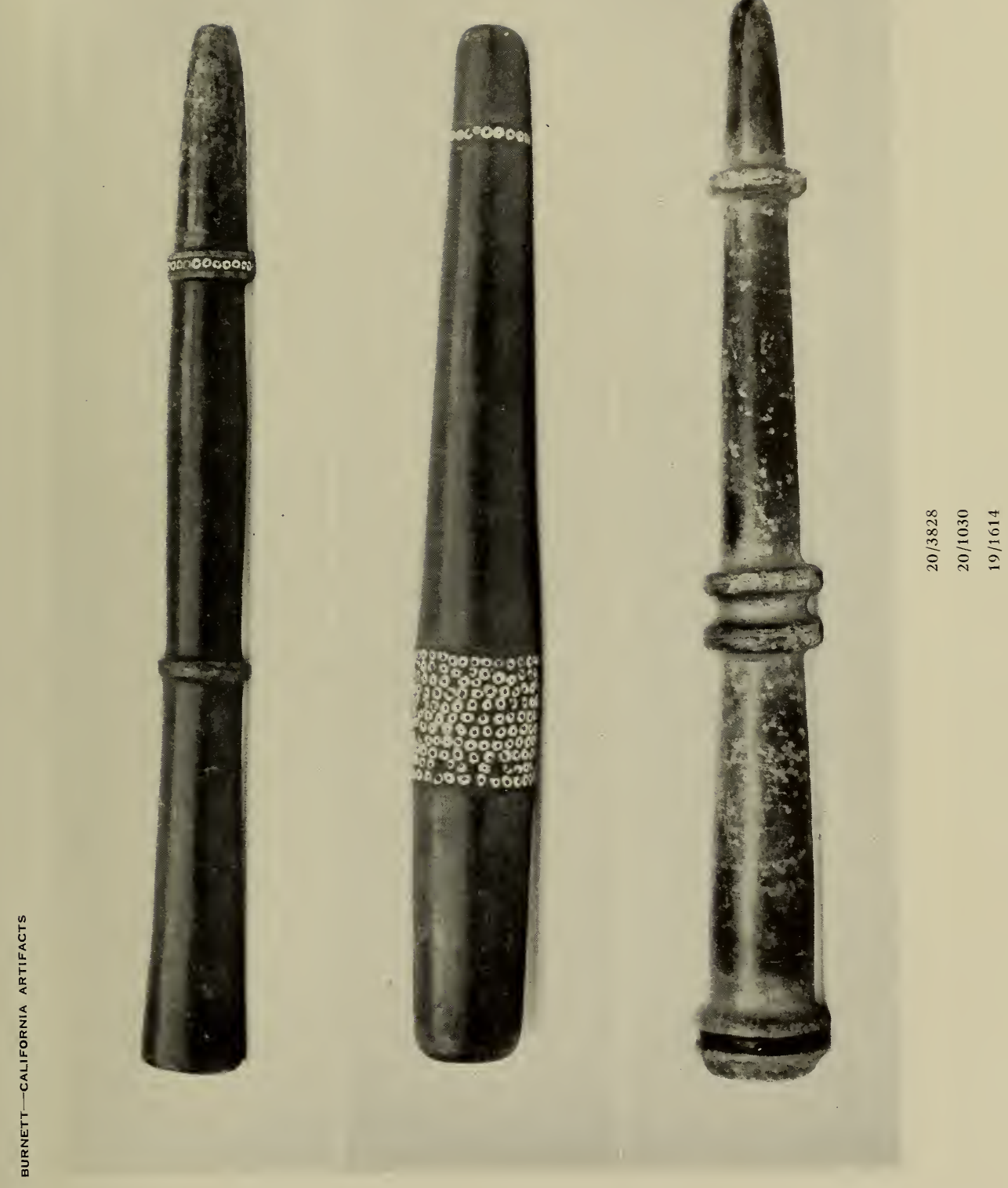




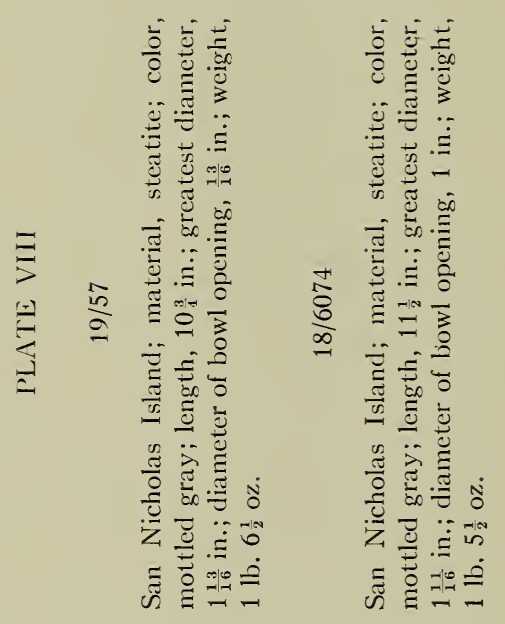




$$
11
$$




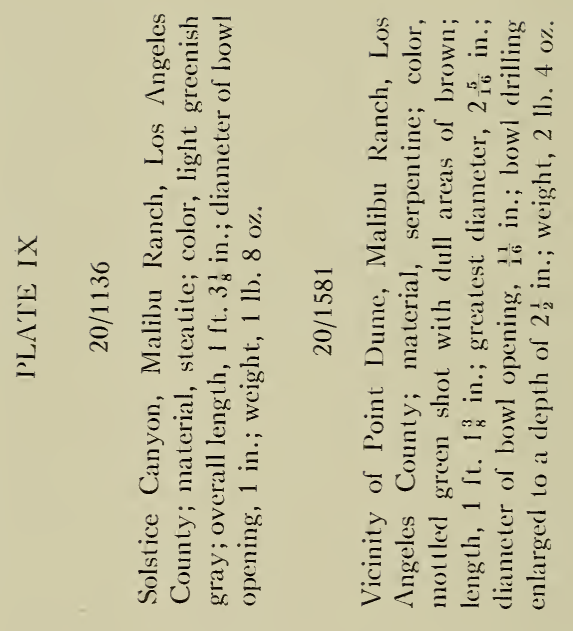




$$
11
$$




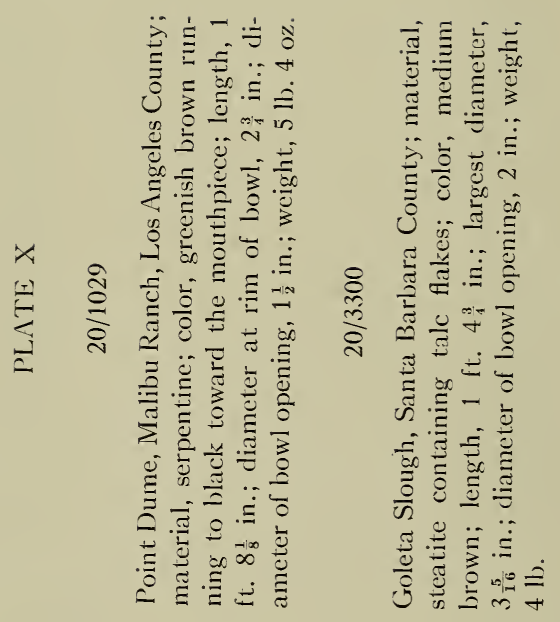


$x$
$\frac{1}{5}$
$\frac{5}{a}$

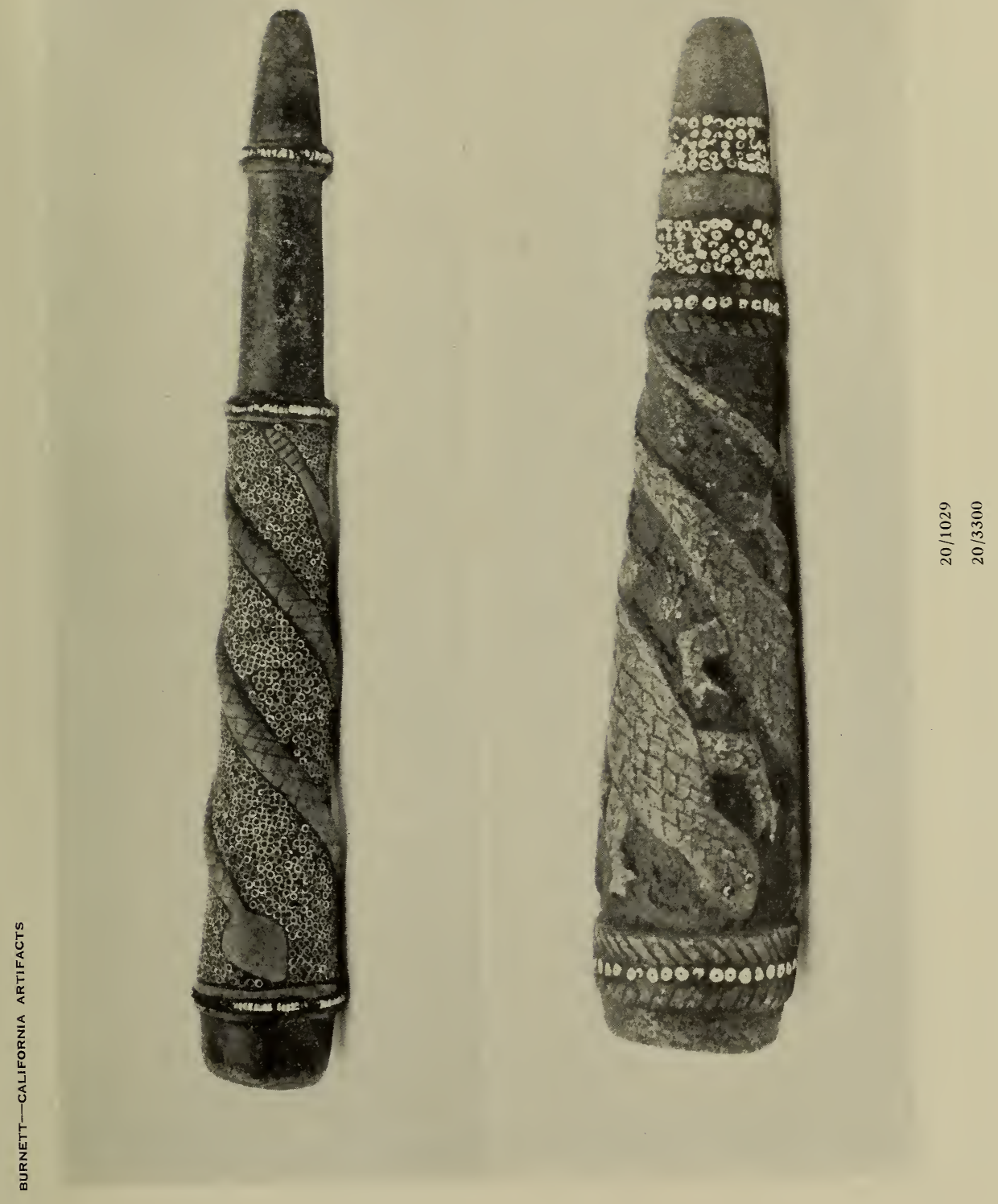




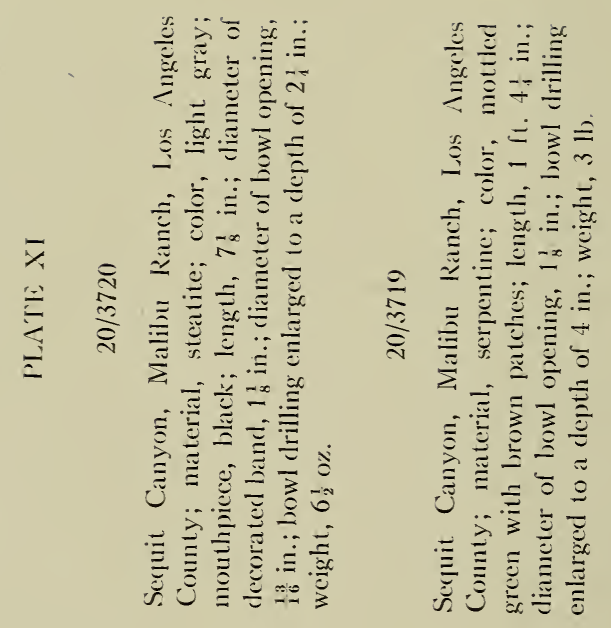




$$
H
$$




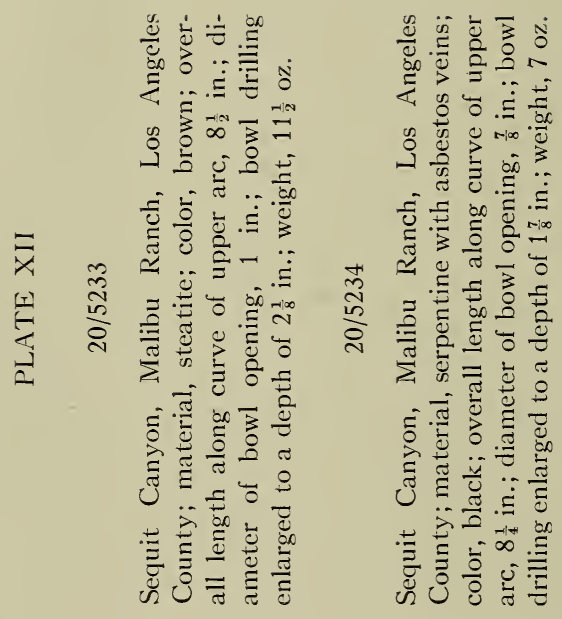




$$
\text { d) }
$$




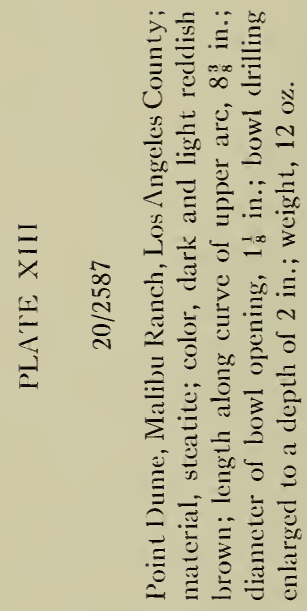


$\overline{\bar{x}}$
$\frac{\mathrm{a}}{5}$
$\frac{5}{a}$

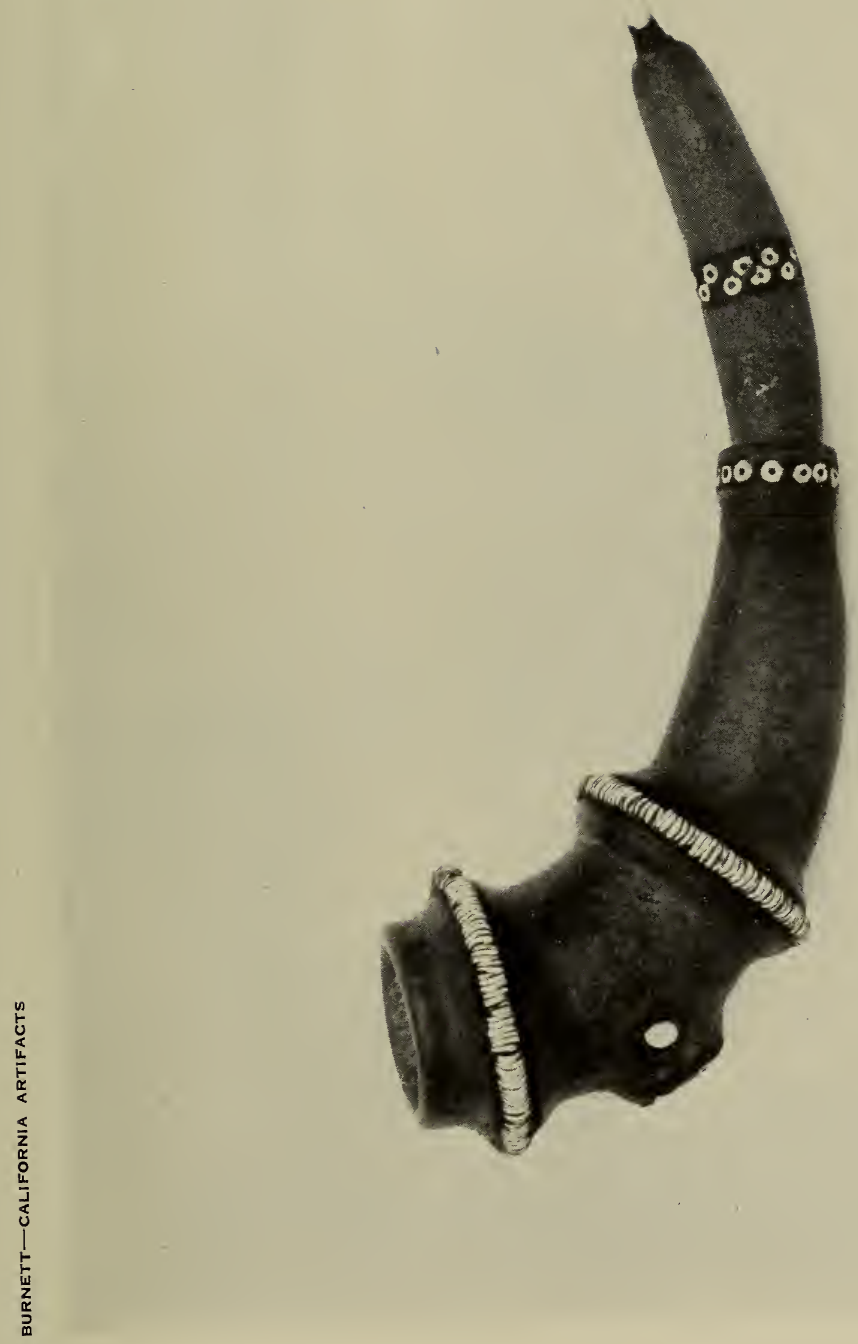

$n$
$\infty$
$i$
0
0 


\section{PLATE XIV}

\section{$20 / 1044$}

Point Dume, Malibu Ranch, Los Angeles County; material, steatite; overall length along upper arc, $8 \frac{1}{4}$ in.; diameter of bowl opening $1 \frac{1}{8}$ in.; bowl drilling enlarged to a depth of $2 \frac{1}{2}$ in.; weight, $13 \mathrm{oz}$.

\section{0/977}

San Nicholas Island; material, steatite; color, light gray; length, rim to elbow, $3 \frac{7}{8}$ in., elbow to tip of stem, $5 \frac{1}{4}$ in.; diameter of bowl opening $\frac{13}{16}$ in.; the bore being a gradual cone to the region of the elbow; weight, $12 \frac{1}{2} \mathrm{oz}$. 

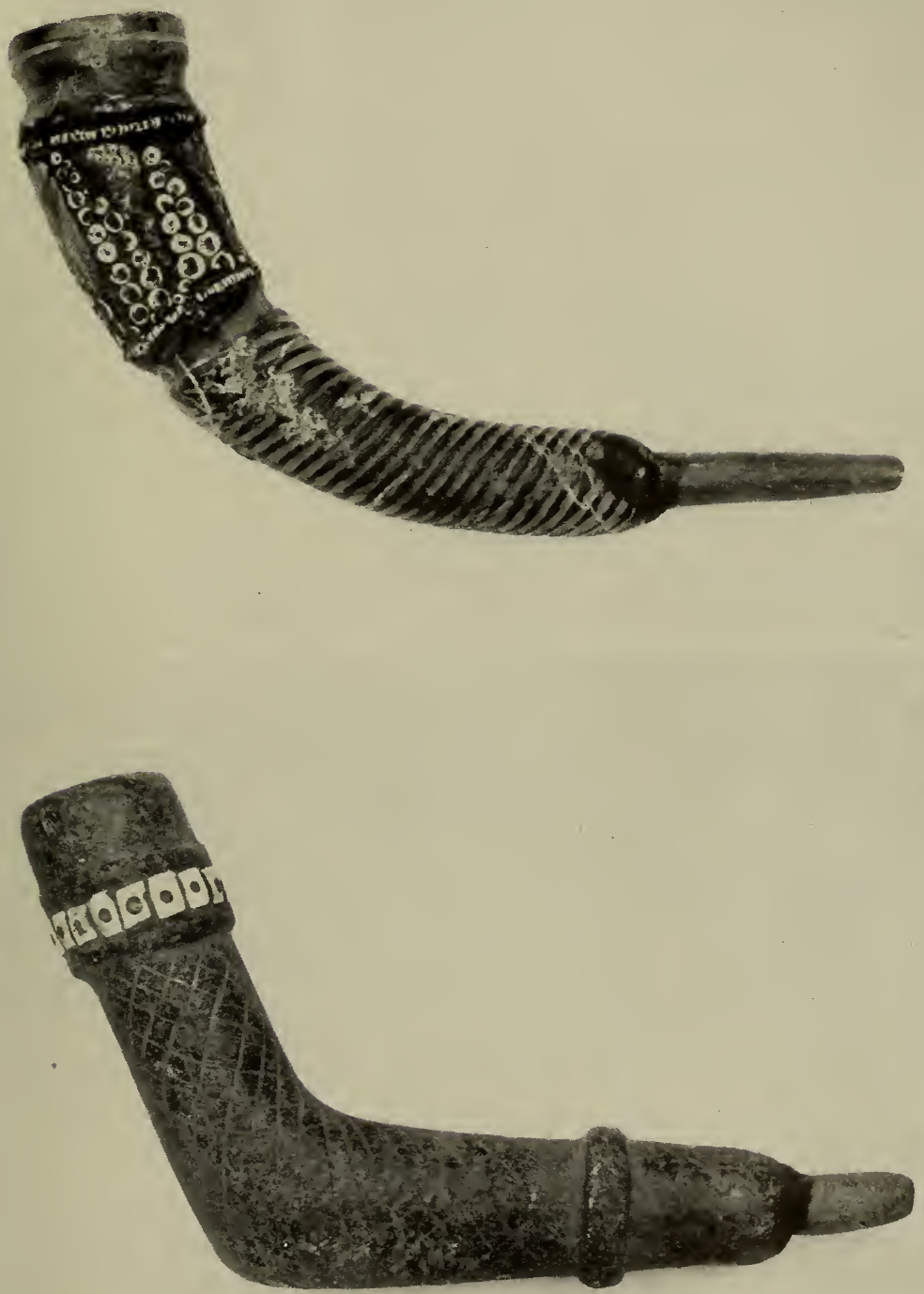

$20 / 1044$

$20 / 977$ 


\section{PLATE XV}

$20 / 5222$

Sequit Canyon, Malibu Ranch, Los Angeles County; material, steatite; color, dark gray; length, rim to elbow, 3 in., elbow to mouthpiece, 6 in.; diameter of bowl opening, 1 in., the bore showing a tapering enlargement to a depth of $1 \frac{7}{16}$ in.; weight, $10 \mathrm{oz}$.

\section{$20 / 3830$}

San Nicholas Island; material, steatite; color, gray completely painted over with asphaltum; length, rim to elbow, $4 \frac{3}{8}$ in., elbow to mouthpiece, $6 \frac{1}{8}$ in.; diameter of bowl opening, $1 \frac{1}{8}$ in., the bore being a gradual cone to the region of the elbow; weight, $1 \mathrm{lb}$. 

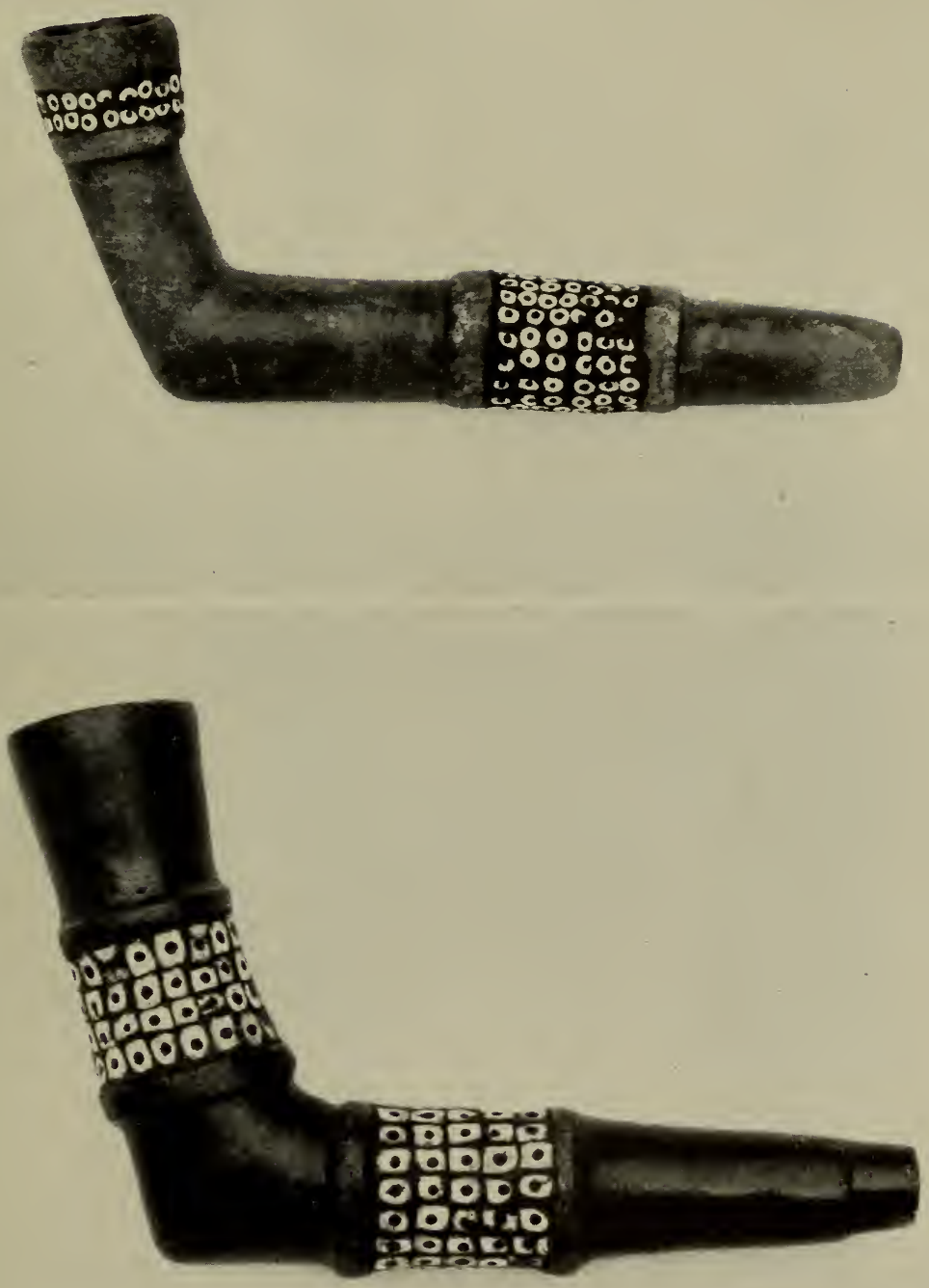

$20 / 5222$

$20 / 3830$ 


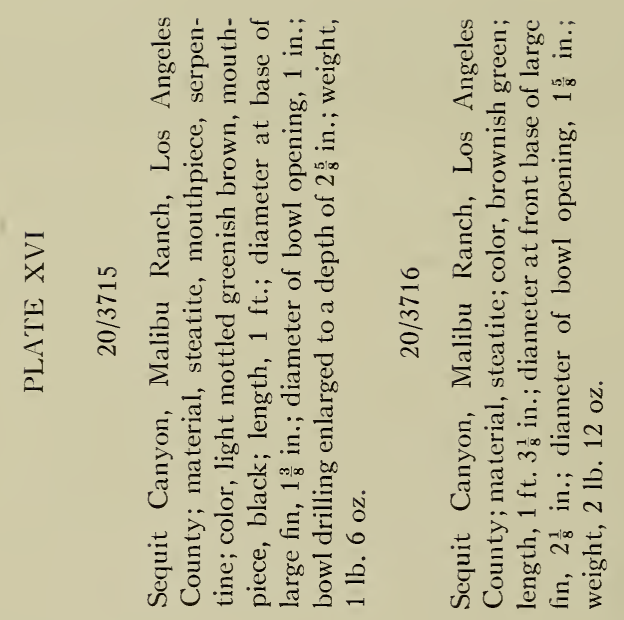


$\bar{x}$
$\frac{1}{b}$
$\frac{5}{a}$
$\frac{1}{a}$
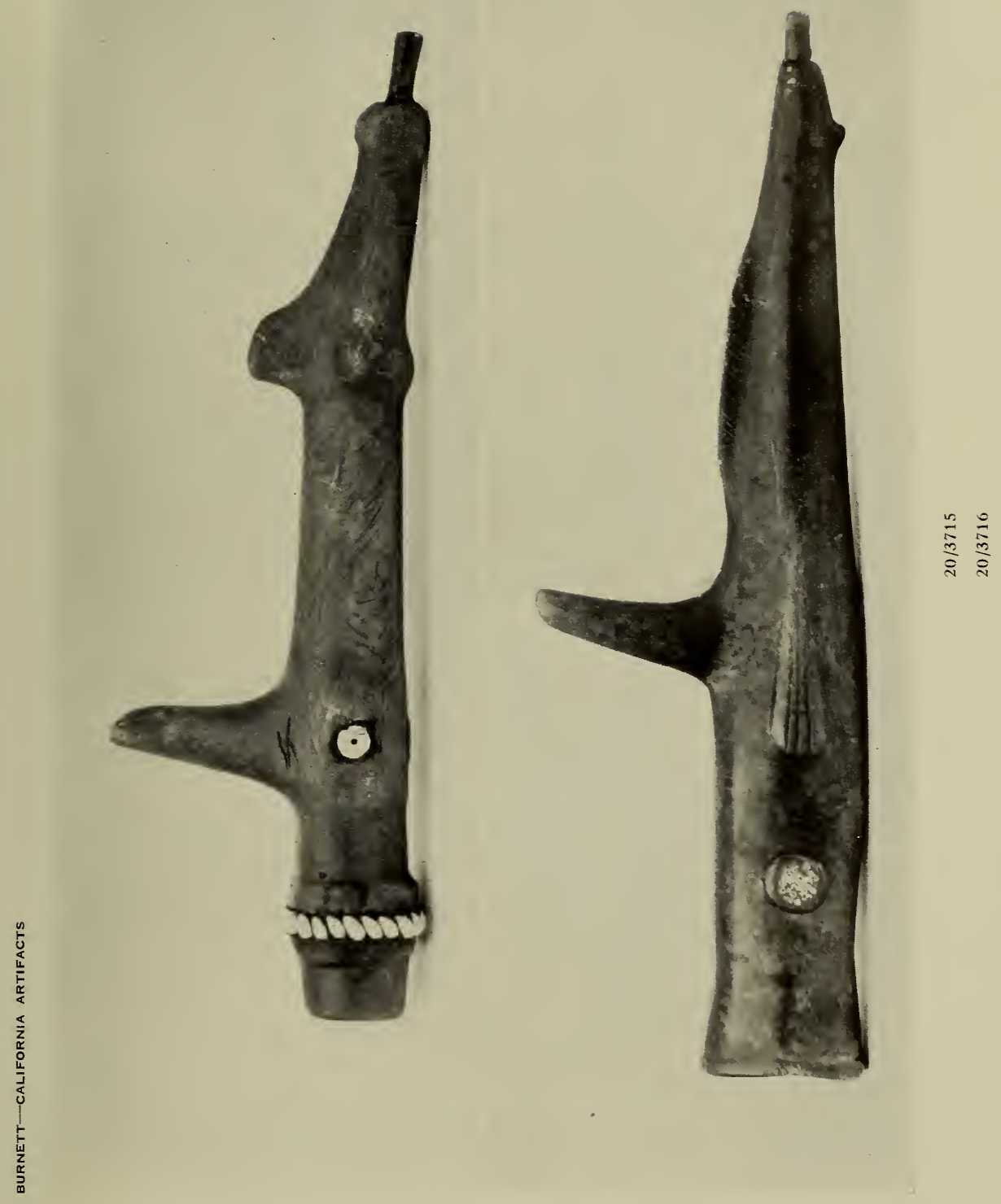


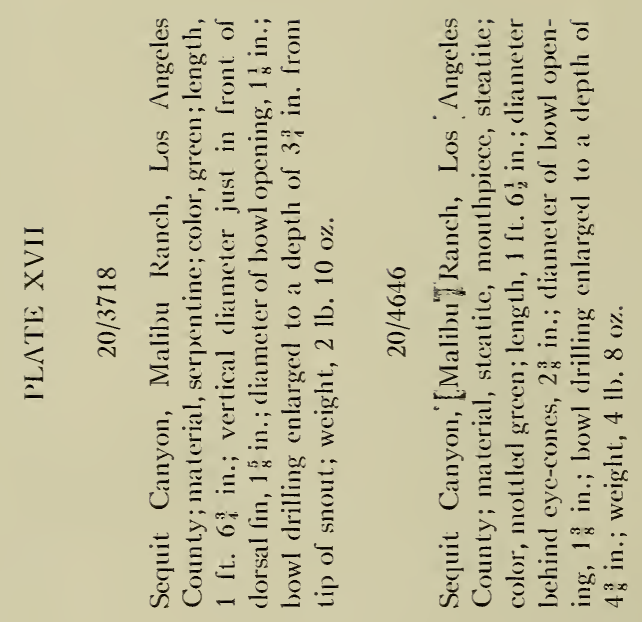




$$
\text { H }
$$




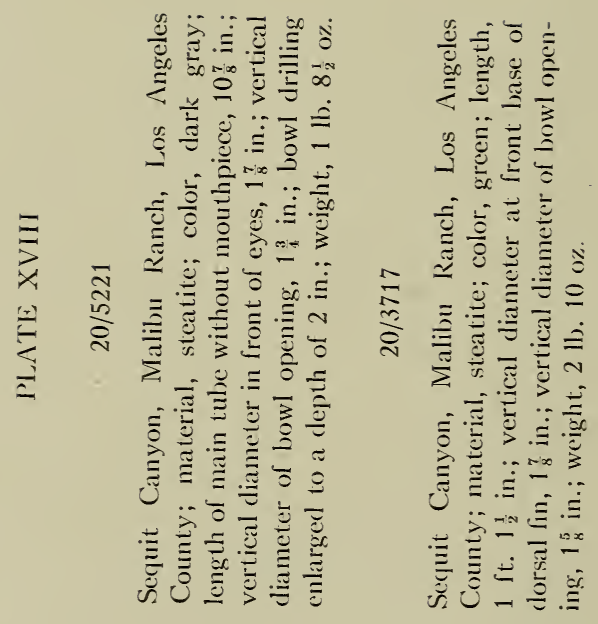


$\overline{3}$
$\mathbf{x}$
$\mathbf{w}$
$\frac{1}{2}$
$\frac{1}{2}$
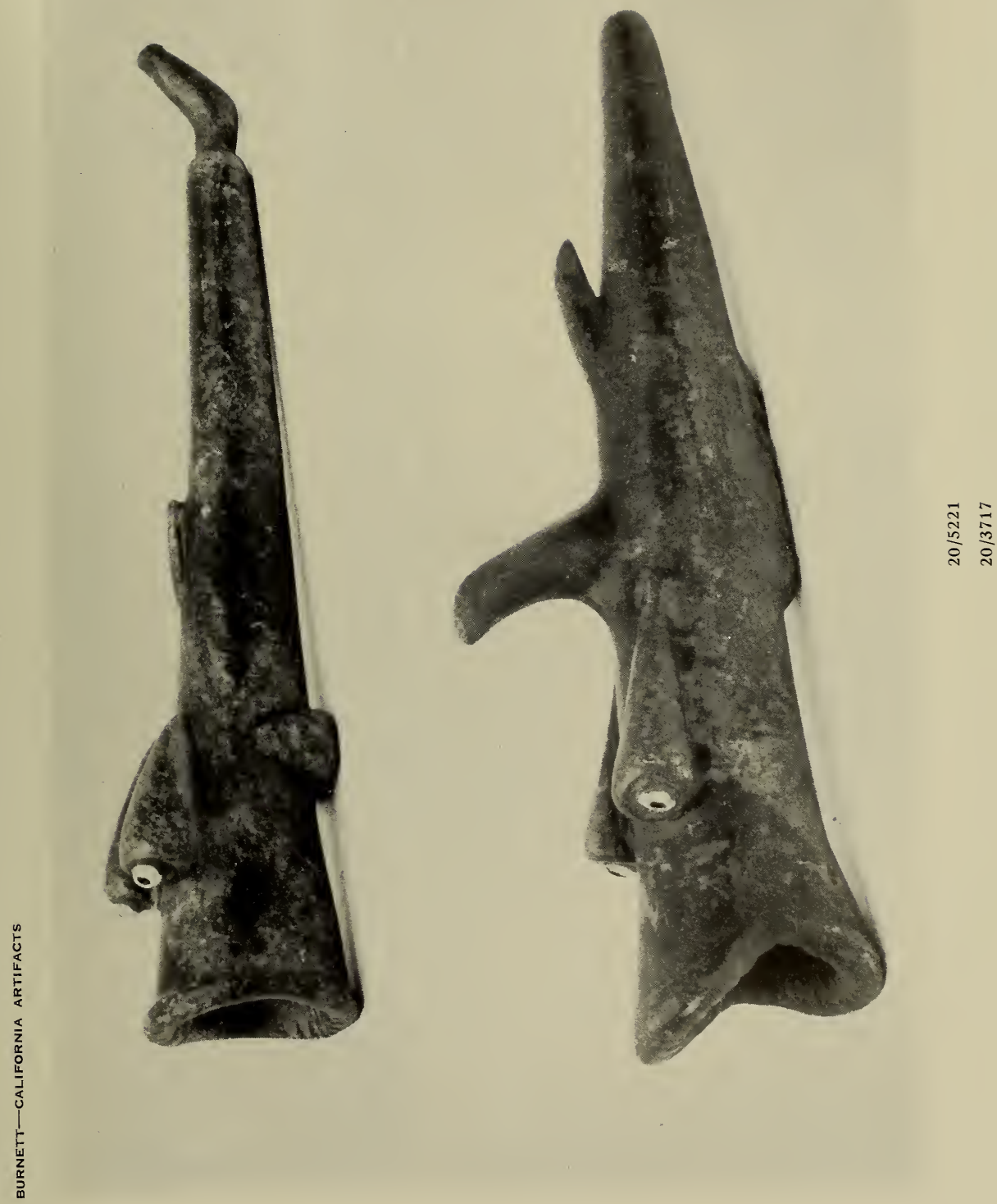


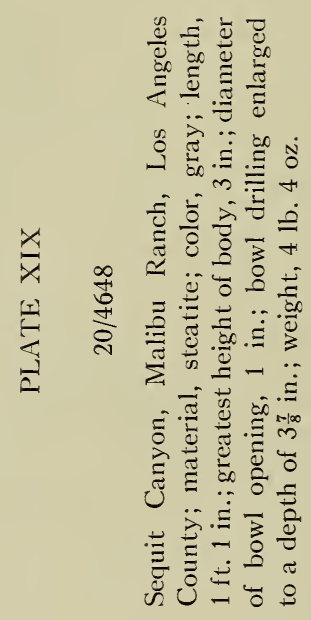




$$
\text { I }
$$




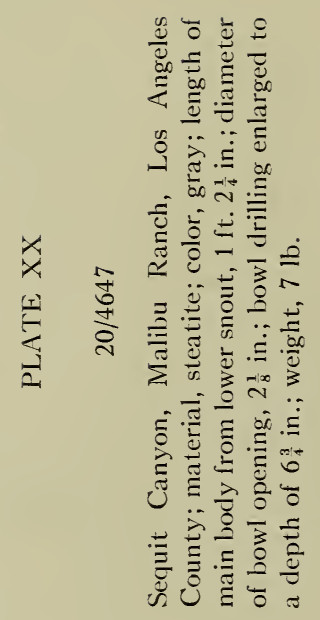




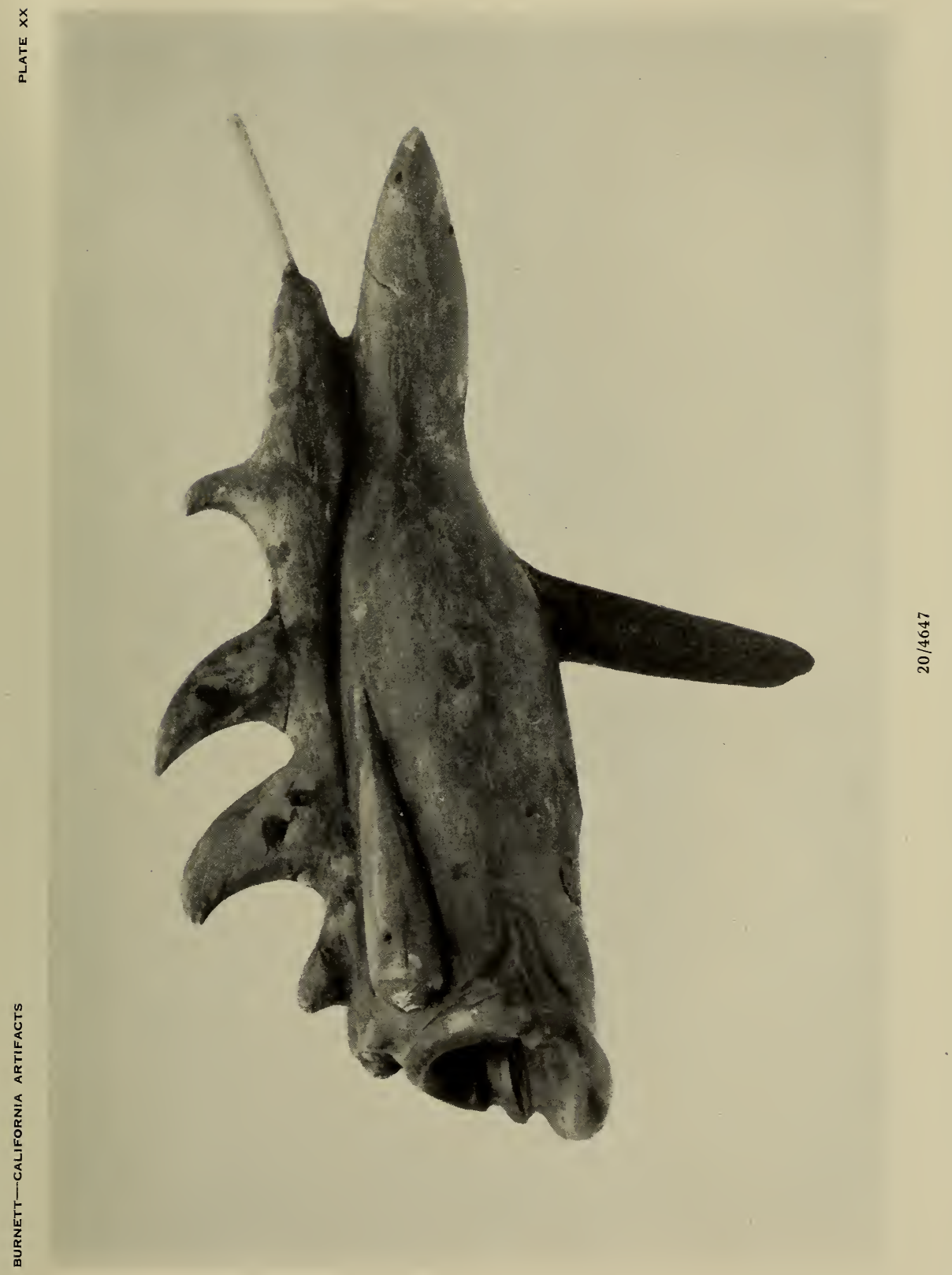




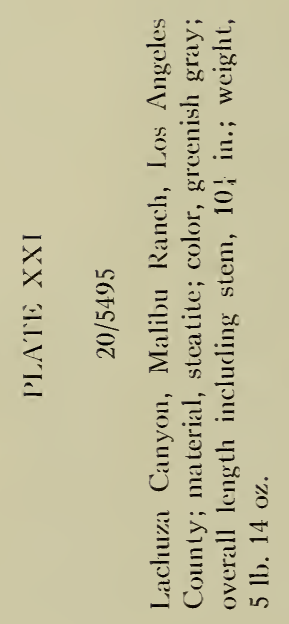


$\bar{x}$
$x$
$\frac{w}{5}$
$\frac{j}{a}$ 


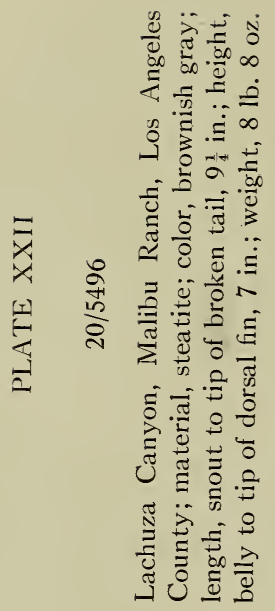




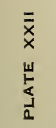

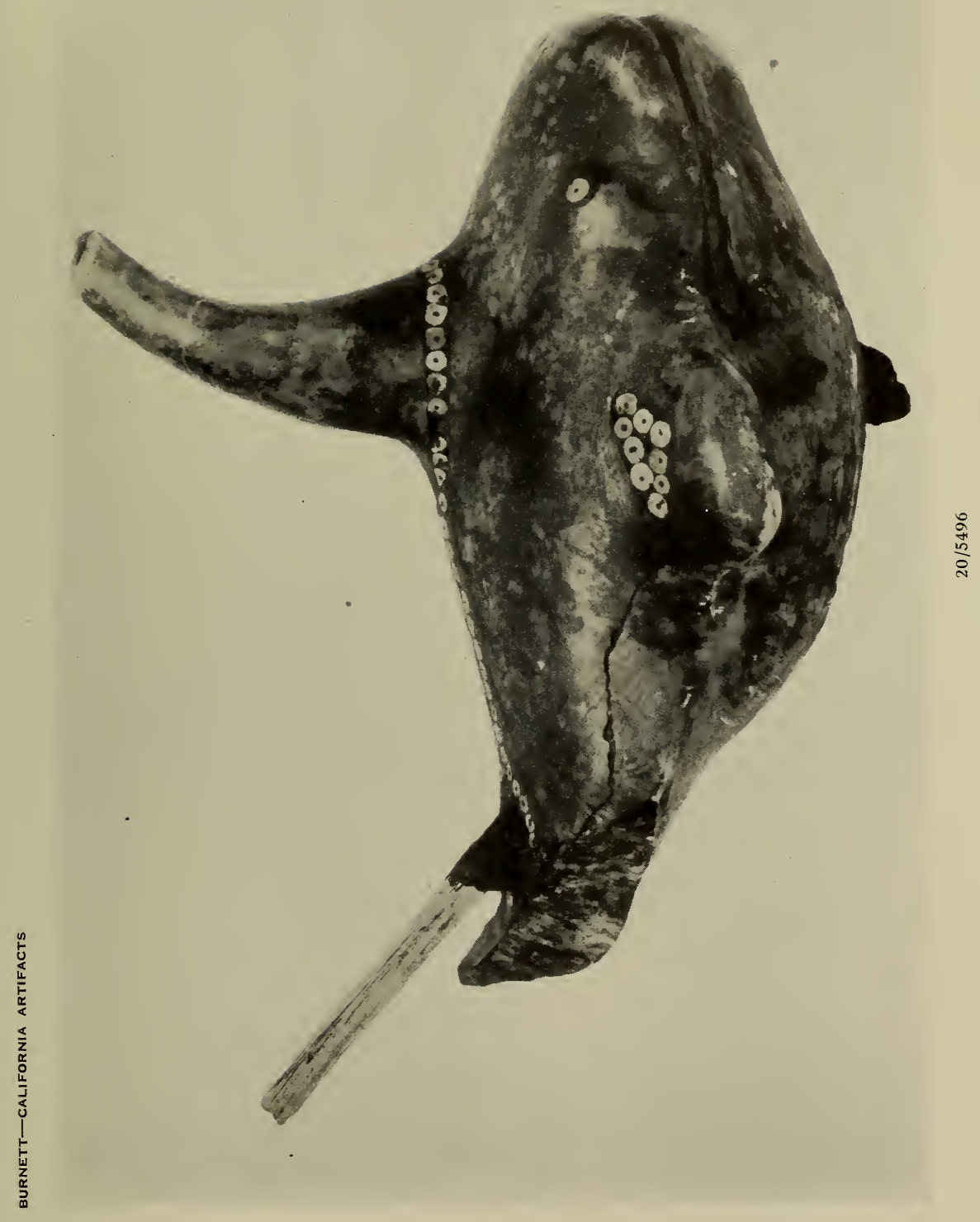


PLATE XXIII

20/5 496

Front view. 


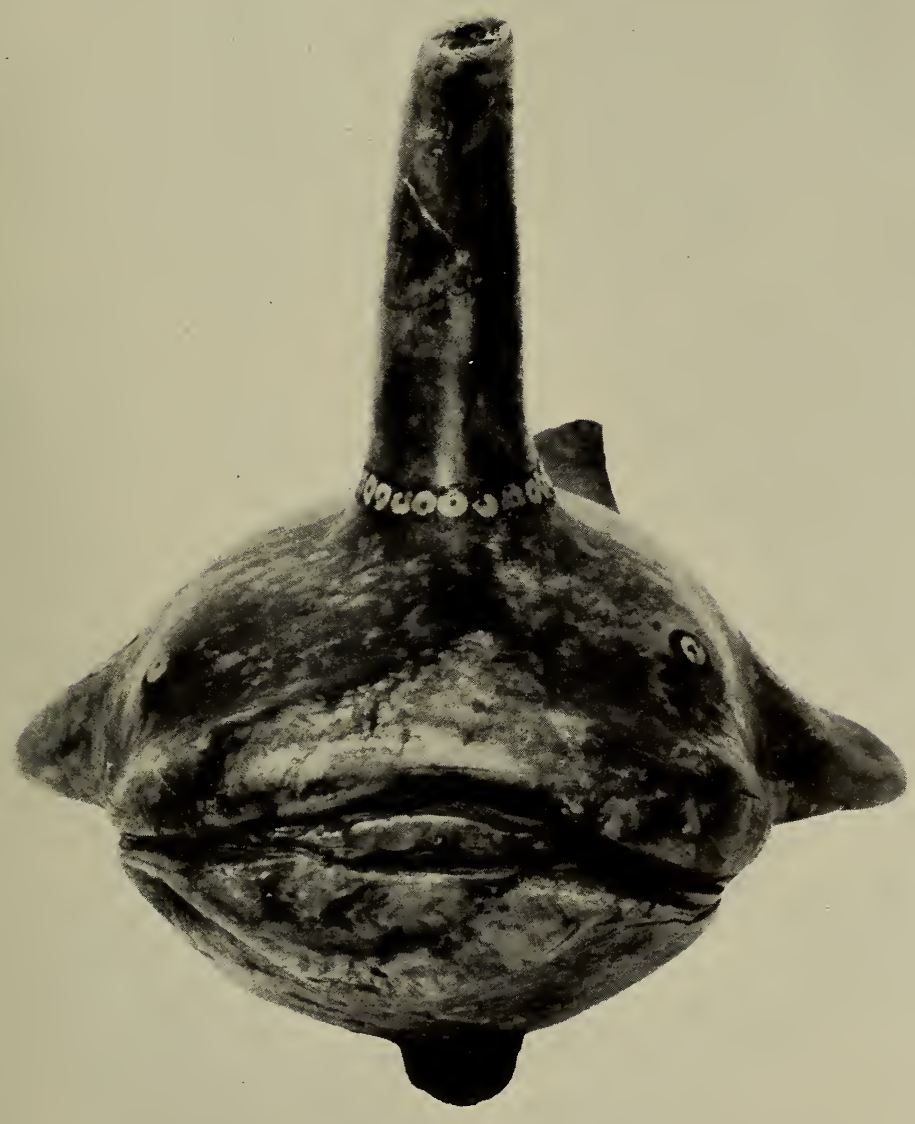


PLATE XXIV

20/5495

$20 / 5196$

Drawings showing drilling 


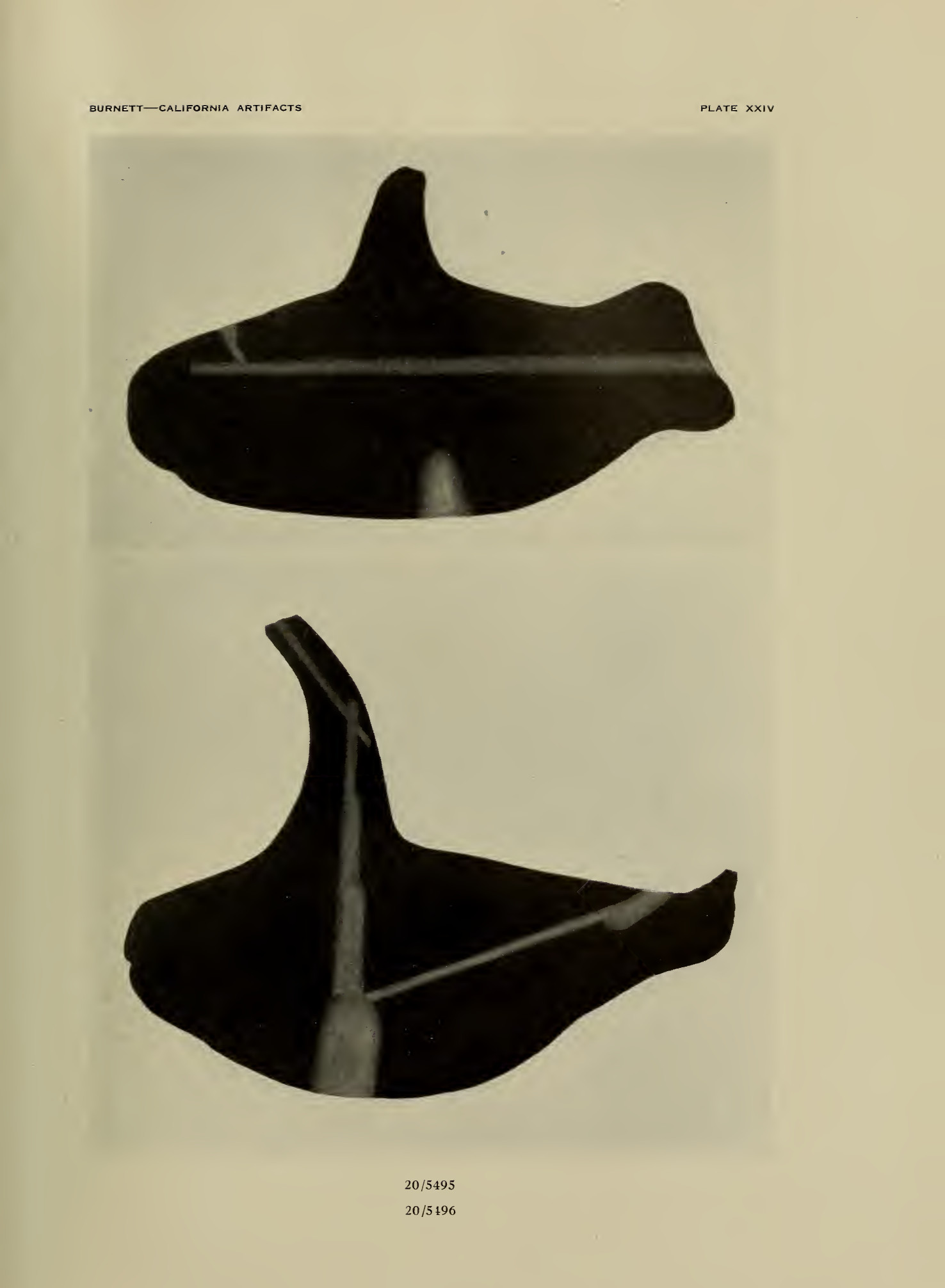




\section{PLATE XXV}

$20 / 4891$

Sequit Canyon, Malibu Ranch, Los Angeles County; material, steatite; color, grayish brown; greatest length, snout to tail, $10 \frac{7}{8}$ in.; width between fintips, $7 \frac{3}{8}$ in.; greatest thickness of body, $2 \frac{3}{4}$ in.; bowl drilling enlarged to a depth of $5 \frac{1}{4}$ in.; weight, $6 \mathrm{lb} .4 \mathrm{oz}$. 

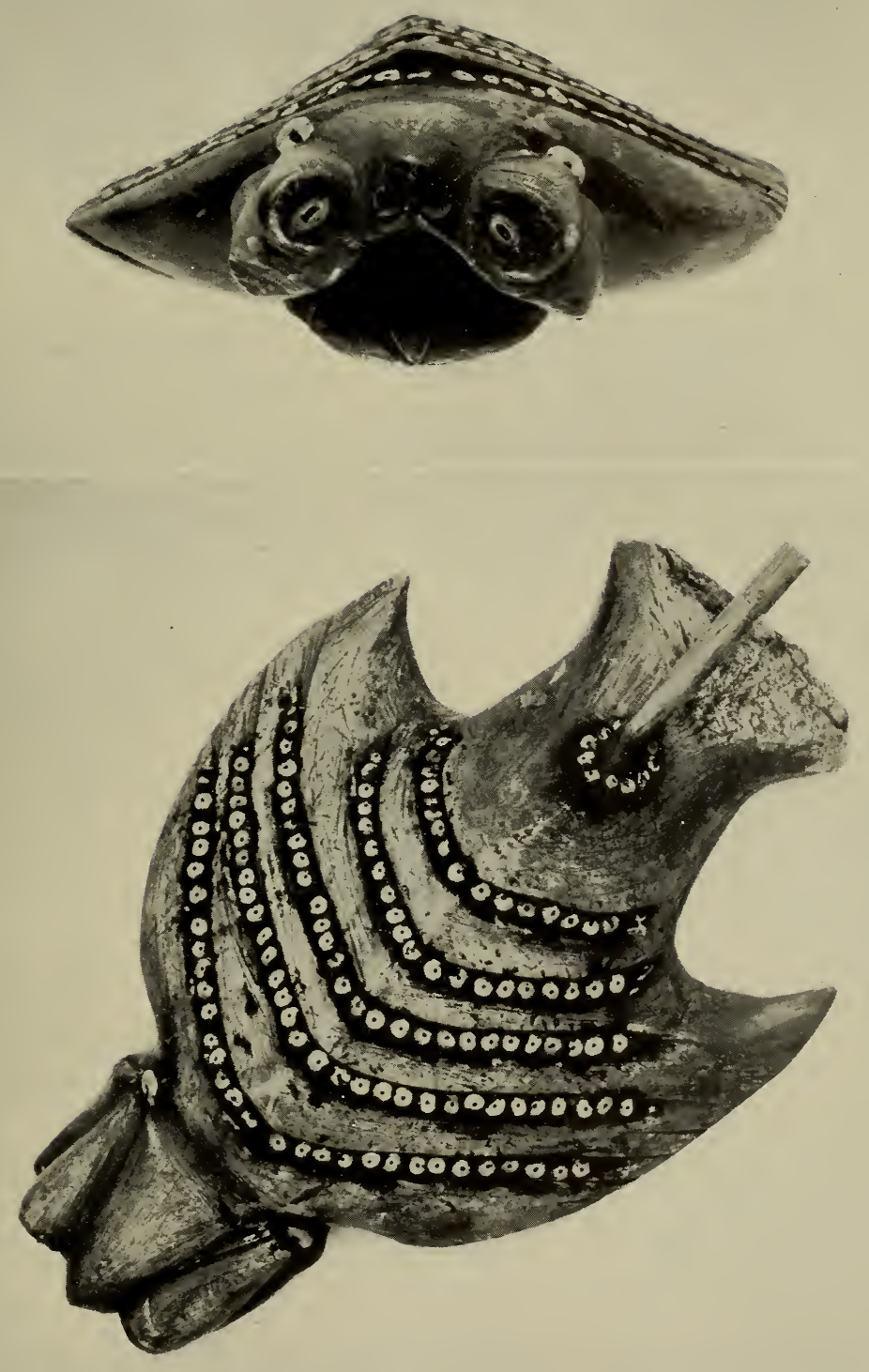

$20 / 4891$ 


\section{PLATE XXVI}

$20 / 1123$

Solstice Canyon, Malibu Ranch, Los Angeles County; material, steatite; color, light brownish gray; length, $5 \frac{3}{4}$ in.; weight, $10 \frac{1}{2} \mathrm{oz}$.

\section{$20 / 1855$}

Vicinity of Point Dume, Malibu Ranch, Los Angeles County; material, steatite; color, light mottled greenish gray; greatest length, $4 \frac{1}{4}$ in.; greatest width, $4 \frac{1}{2}$ in.; weight, $11 \frac{1}{2} \mathrm{oz}$. 

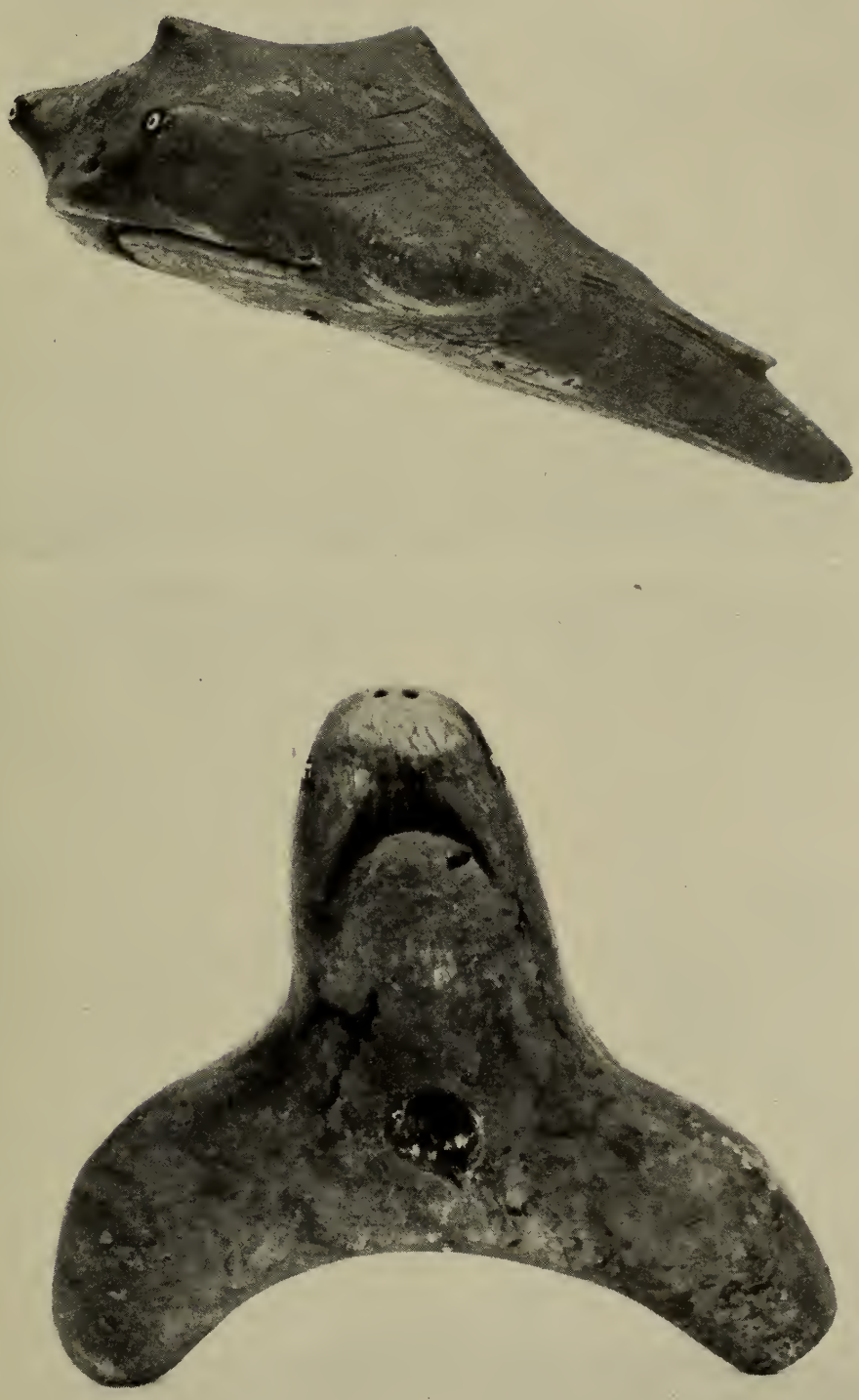

$20 / 1123$

20/1855 


\section{PLATE XXVII}

\section{$20 / 3727$}

Sequit Canyon, Malibu Ranch, Los Angeles County; material, serpentine; color, light bluish gray; length, $3 \frac{3}{4}$ in.; height, to tip of dorsal fin, $2 \frac{5}{8}$ in.; weight, $6 \frac{1}{2} \mathrm{oz}$.

\section{$20 / 1856$}

Vicinity of Point Dume, Malibu Ranch, Los Angeles County; material, steatite; color, greenish brown; overall length, 5 in.; weight, $9 \frac{1}{2} \mathrm{oz}$. 

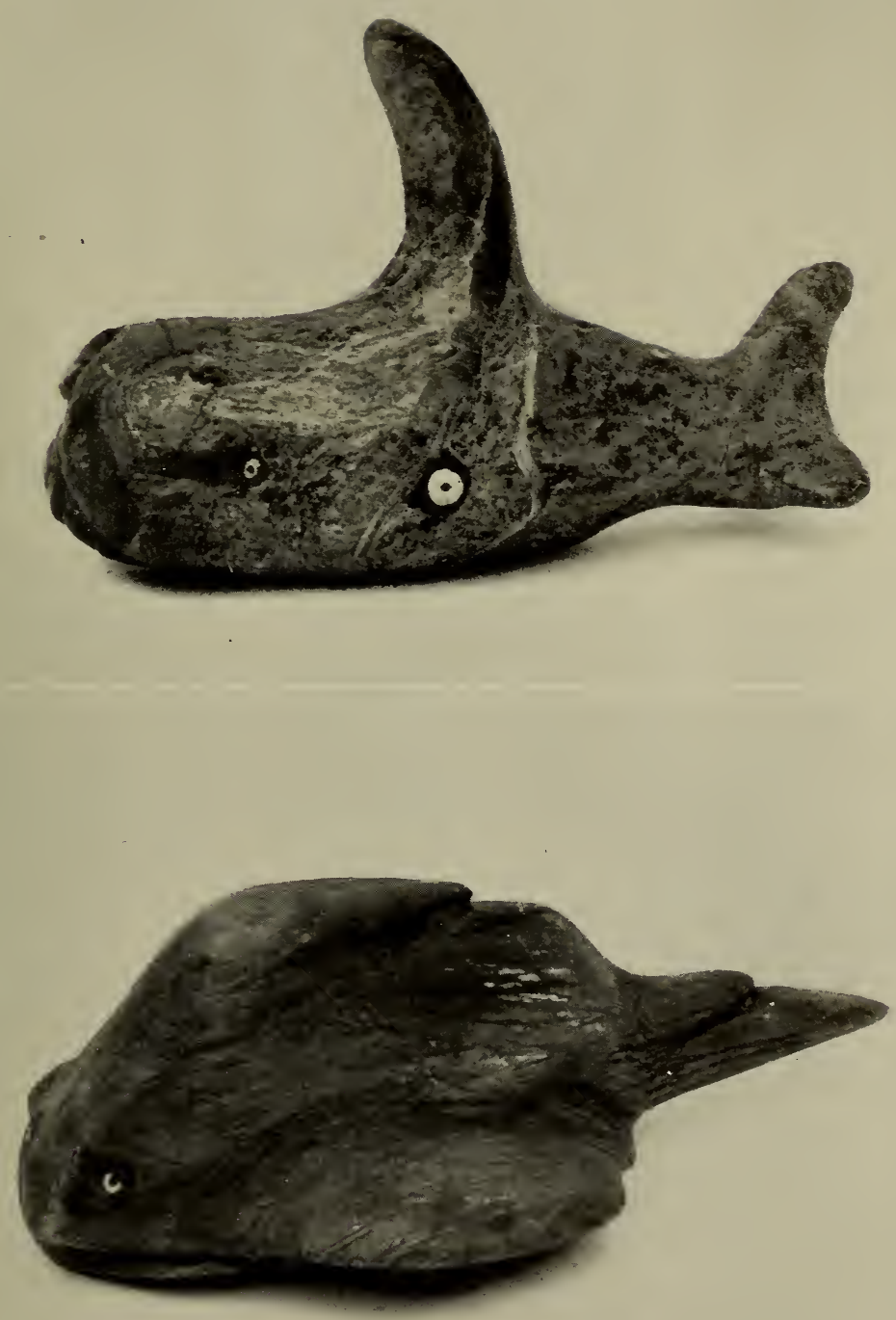

$20 / 3727$

$20 / 1856$ 


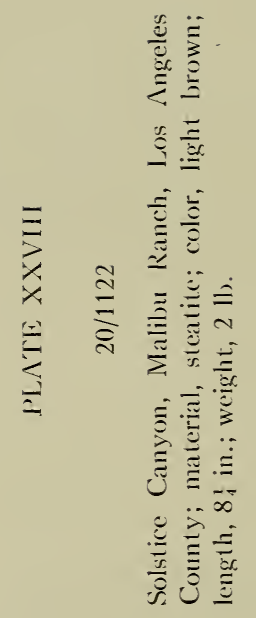




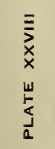

$\stackrel{\text { ลิ }}{\stackrel{2}{8}}$ 


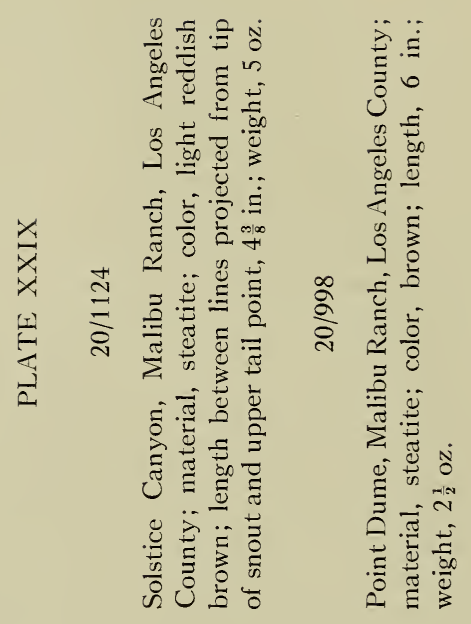




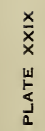

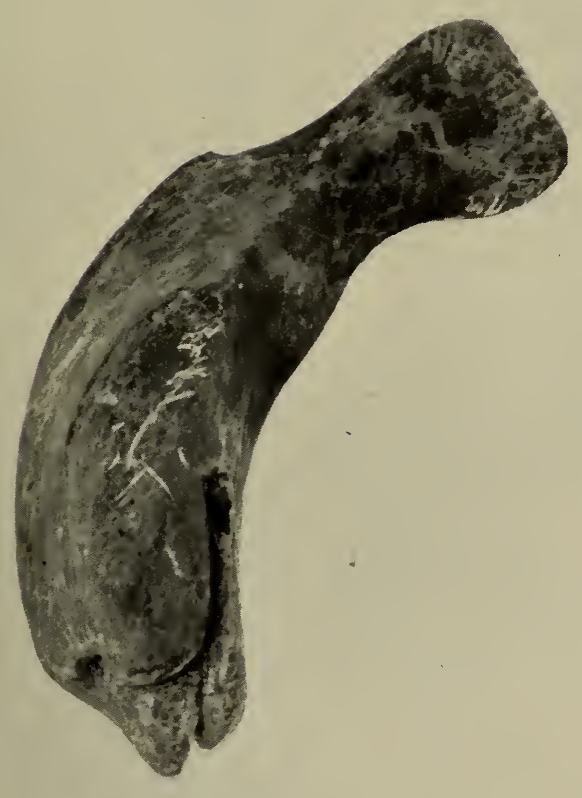

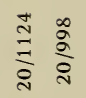

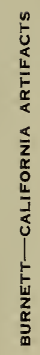




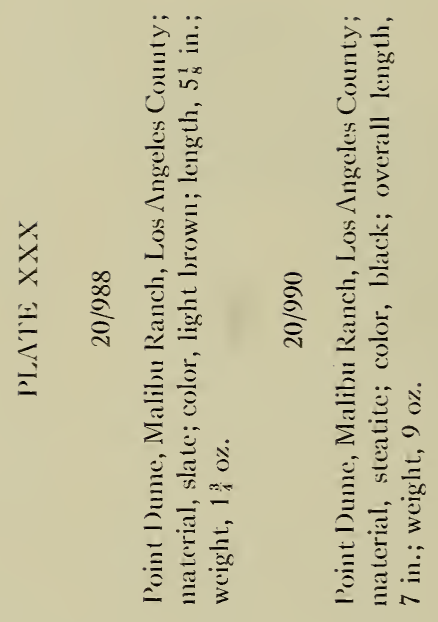


$x$
$x$
$x$
$u$
5
$\frac{a}{a}$
$a$
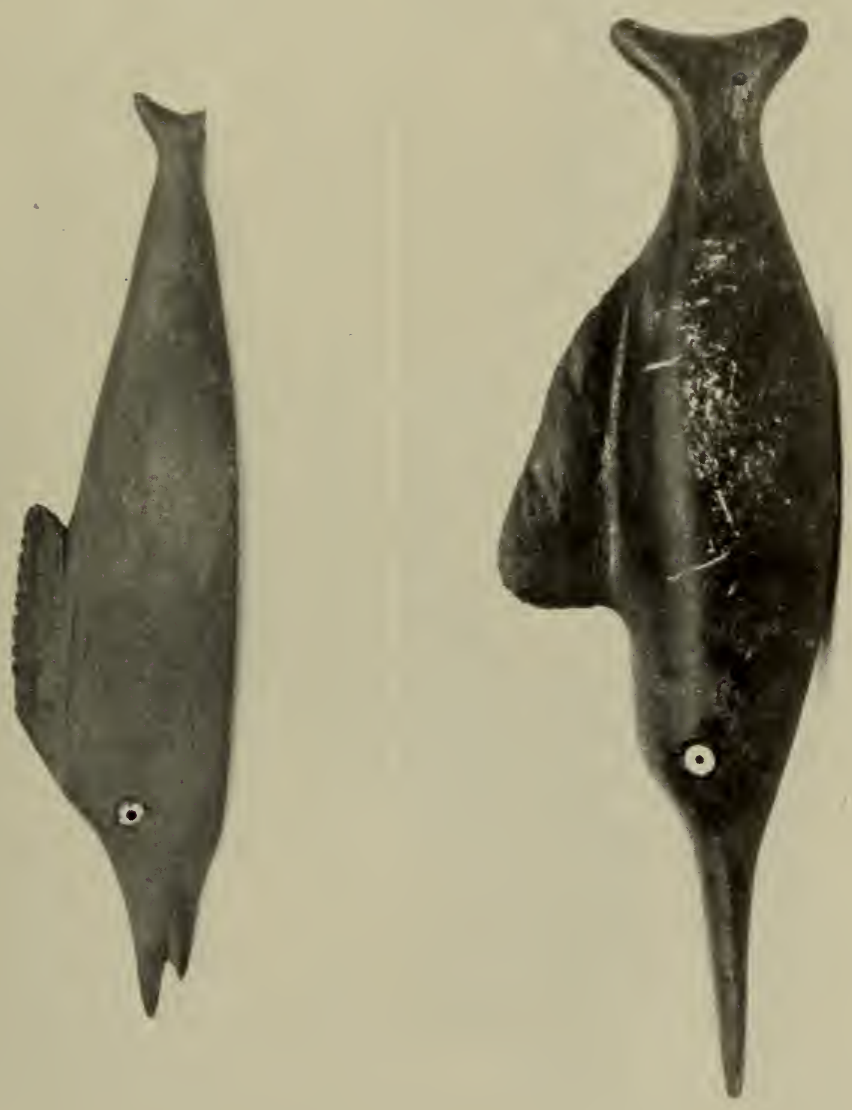

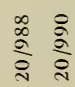

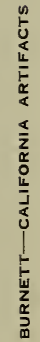




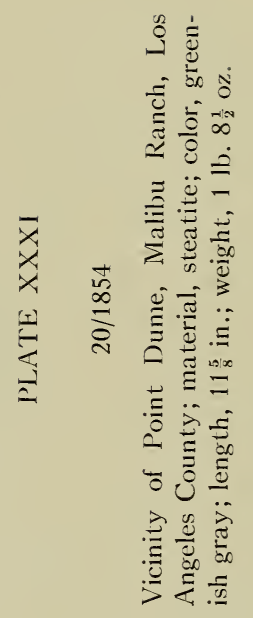


$\bar{x}$
$x$
$x$
$w$
$\frac{5}{2}$
$\frac{a}{2}$

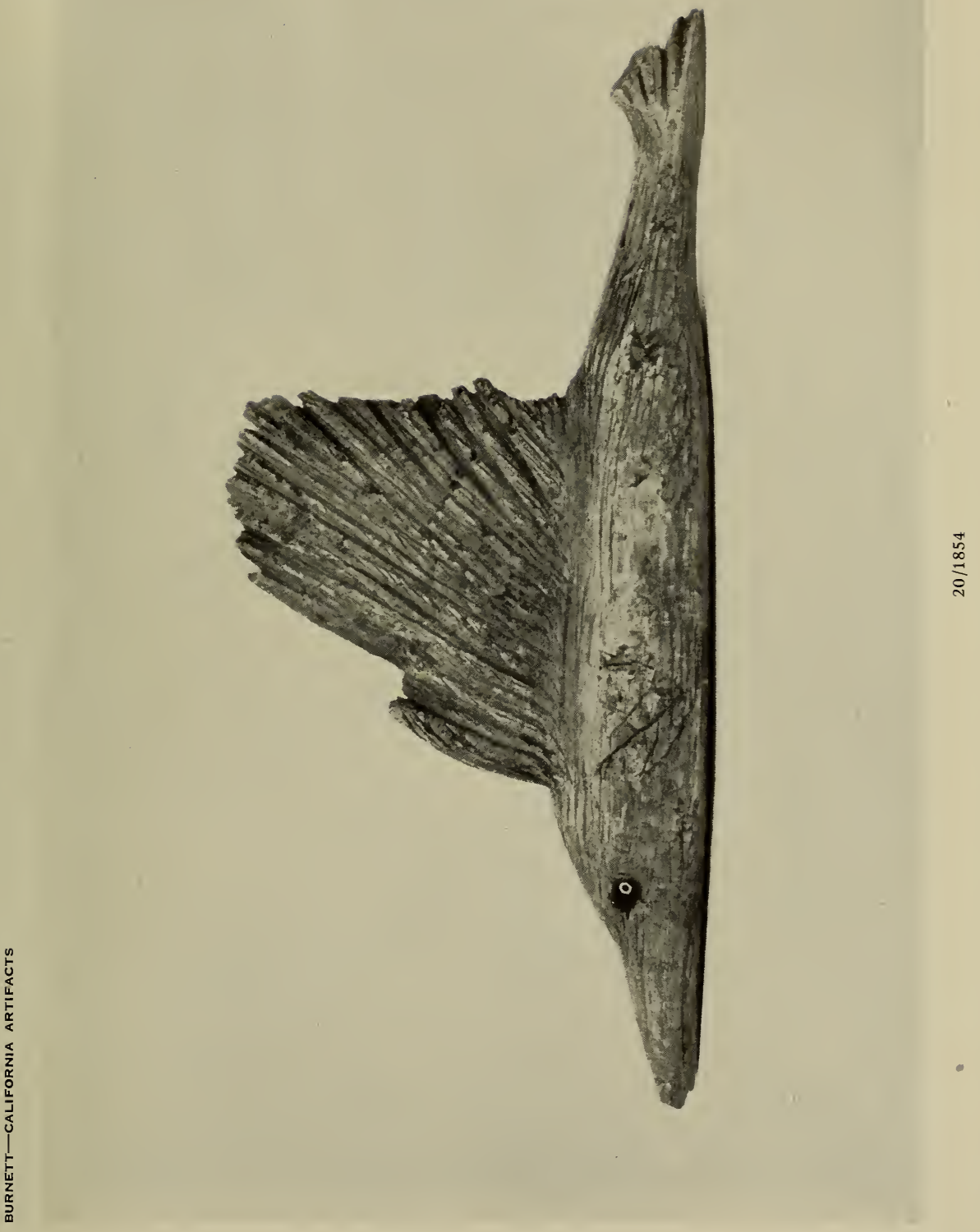




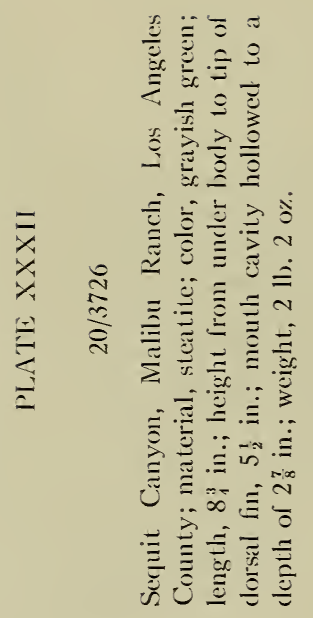




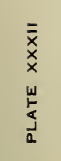

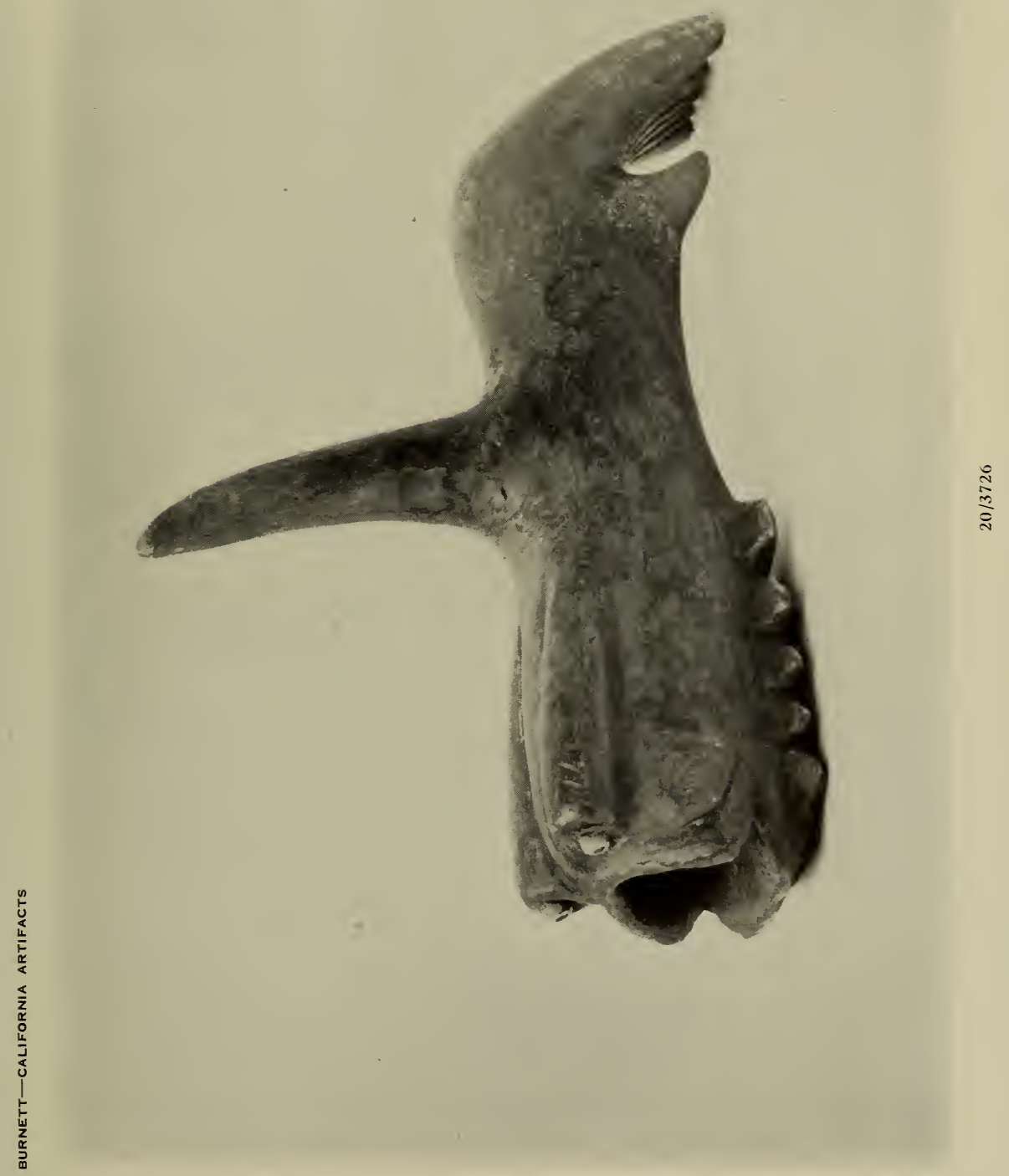




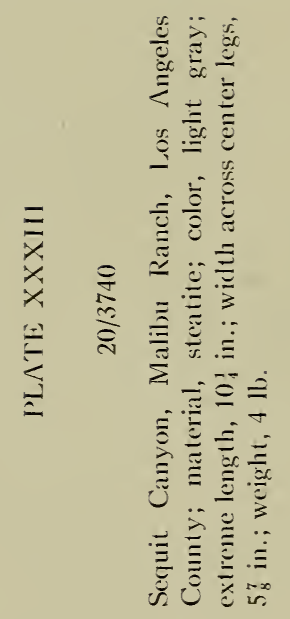




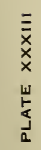
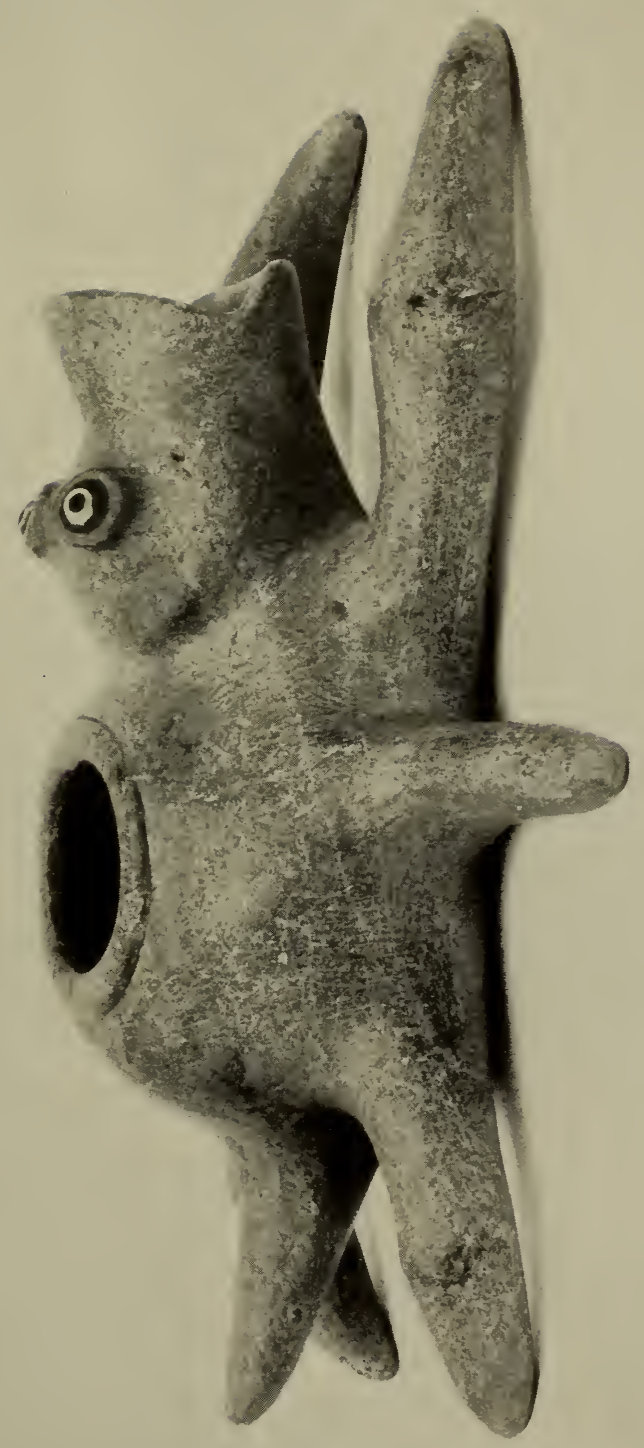

$\frac{\text { d }}{\frac{1}{2}}$ 


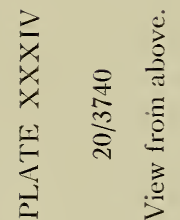


2
$x$
$x$
$x$
$w$
$\frac{w}{5}$
5
$a$

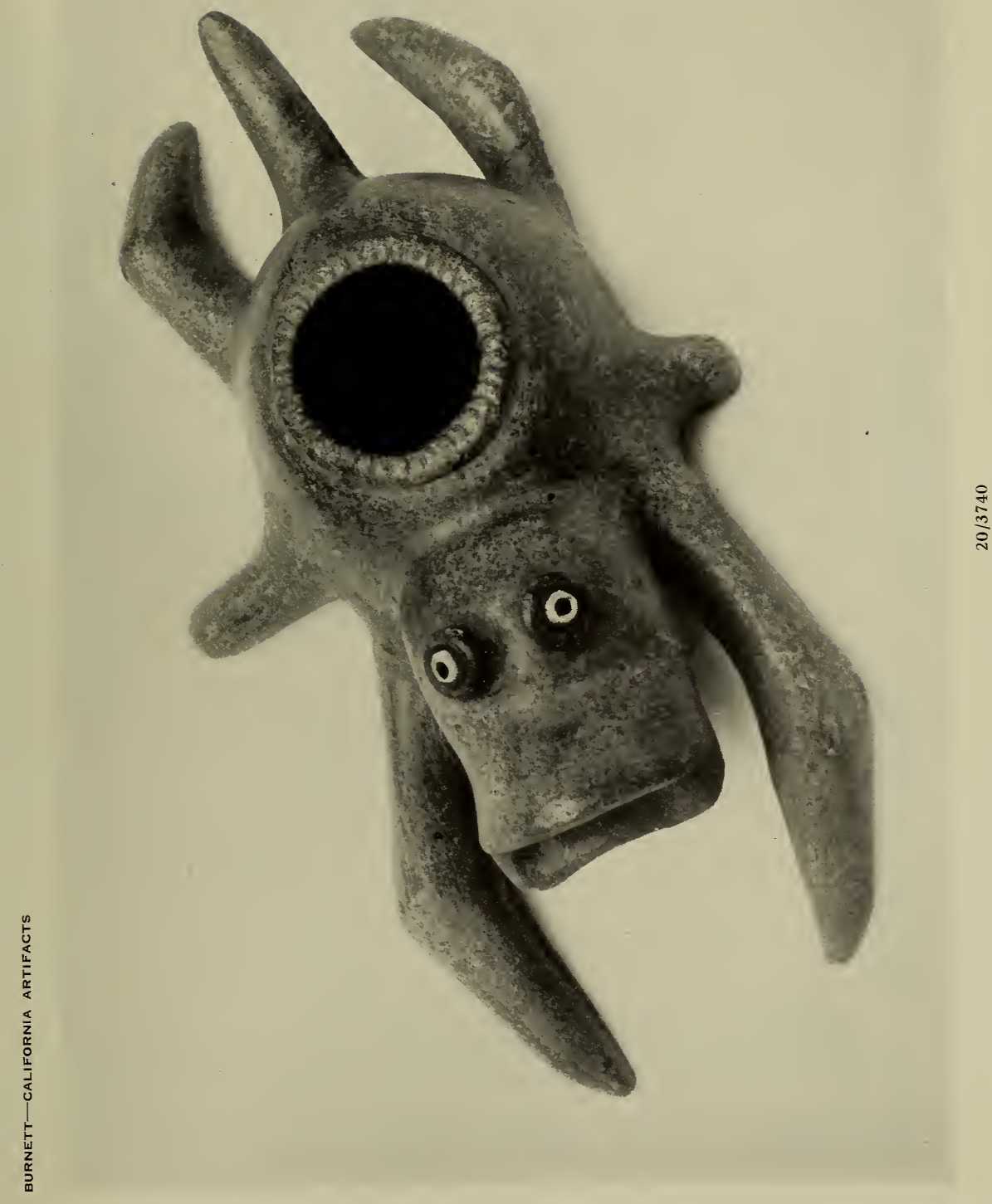




\section{PLATE XXXY}

\section{0/3776}

Lower Ramera Canyon, Malibu Ranch, Los Angeles County; material, steatite; color, gray with areas of brown mottling; length, 4 in.; greatest height, $1 \frac{3}{8}$ in.; weight, $3 \frac{1}{2} \mathrm{oz}$.

\section{0/999}

Point Dume, Malibu Ranch, Los Angeles County; material, steatite; color, light brown; length, between lines projected from snout to tip of tail, $3 \frac{7}{8}$ in.; weight, $1 \frac{1}{2} \mathrm{oz}$.

\section{$20 / 3731$}

Sequit Canyon, Malibu Ranch, Los Angeles County; material, steatite; color, brown; length, $4 \frac{1}{8}$ in.; greatest height, $1 \frac{3}{4}$ in.; weight, $2 \frac{1}{2}$ oz. 


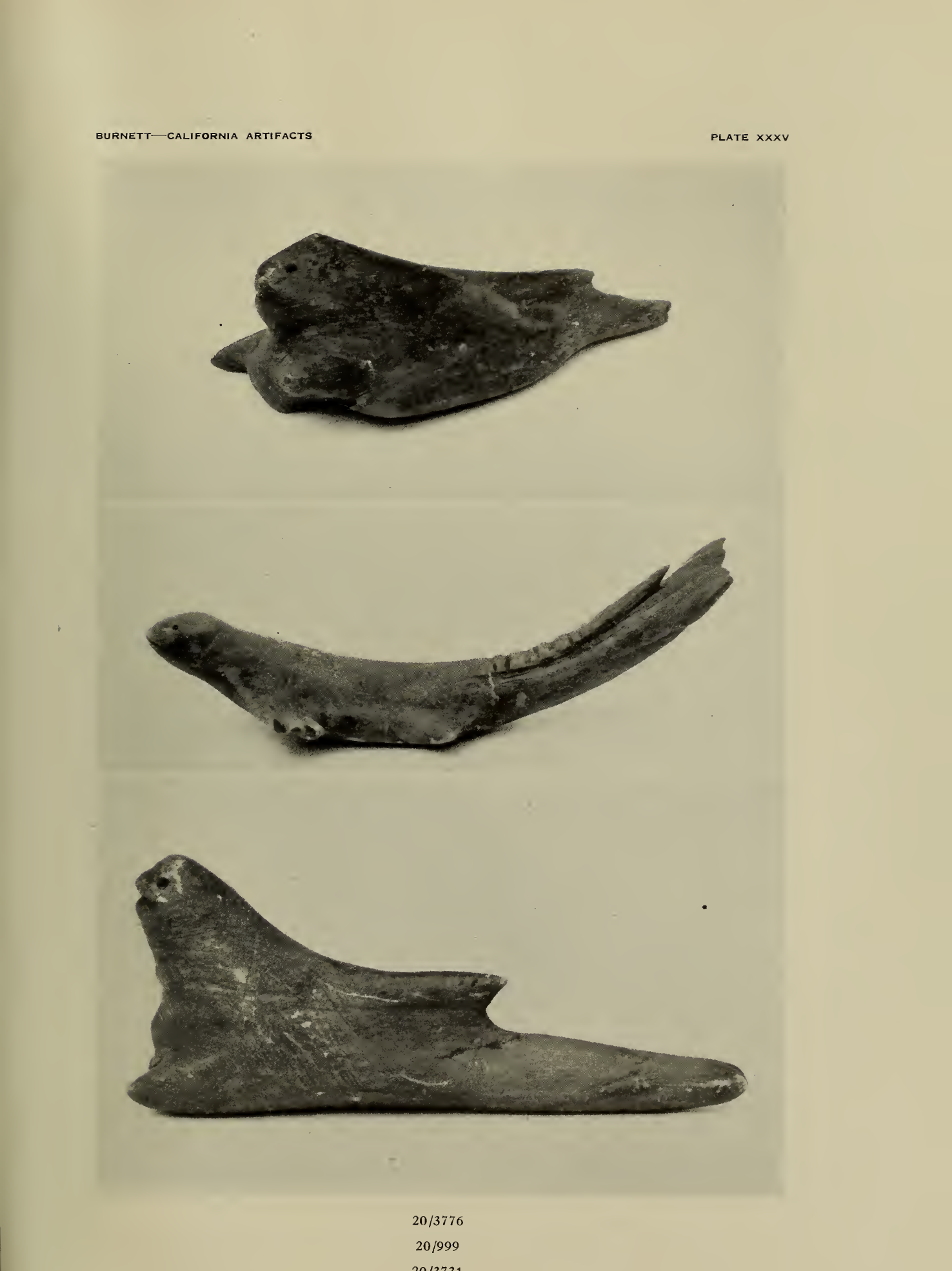




\section{PLATE XXXVI}

\section{$14 / 8851$}

San Nicholas Island; material, slate; color, dark reddish brown; length, $3 \frac{3}{4}$ in.; weight, $5 \frac{1}{2} \mathrm{oz}$.

\section{$20 / 3728$}

Sequit Canyon, Malibu Ranch, Los Angeles County; material, steatite; color, brownish gray; length, 6 in.; height from ground line to dome of head, $3 \frac{1}{4}$ in.; weight, $15 \frac{1}{2} \mathrm{oz}$. 

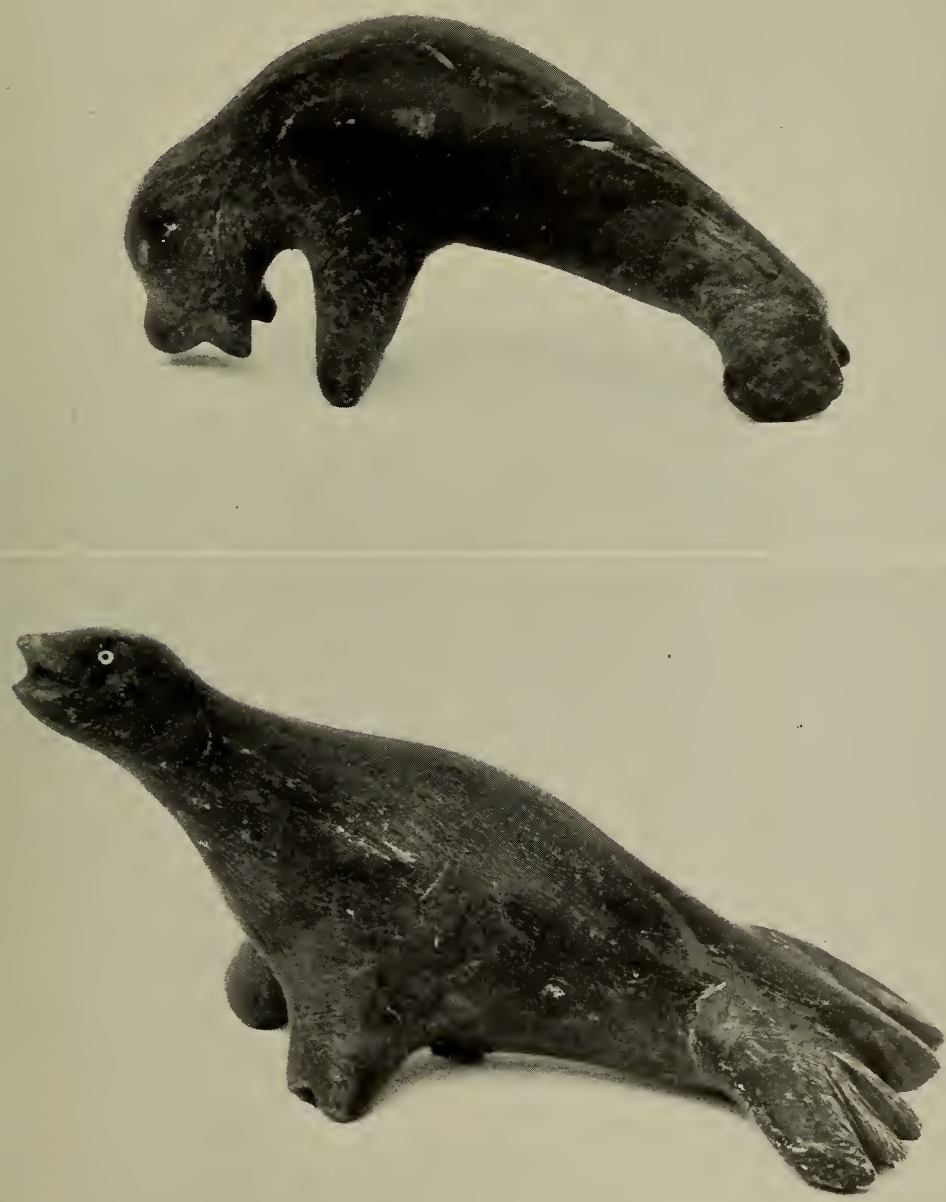

$14 / 8851$

$20 / 3728$ 


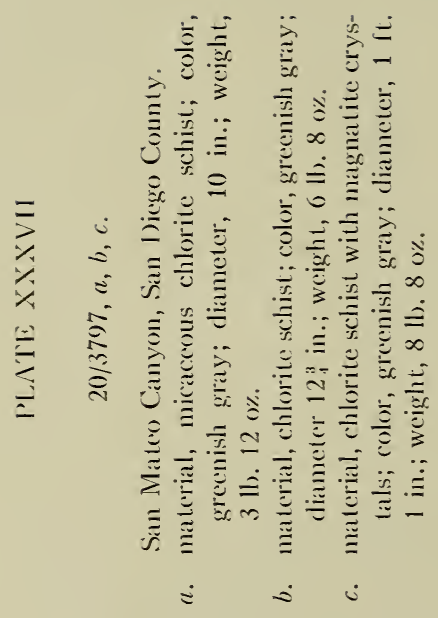




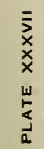

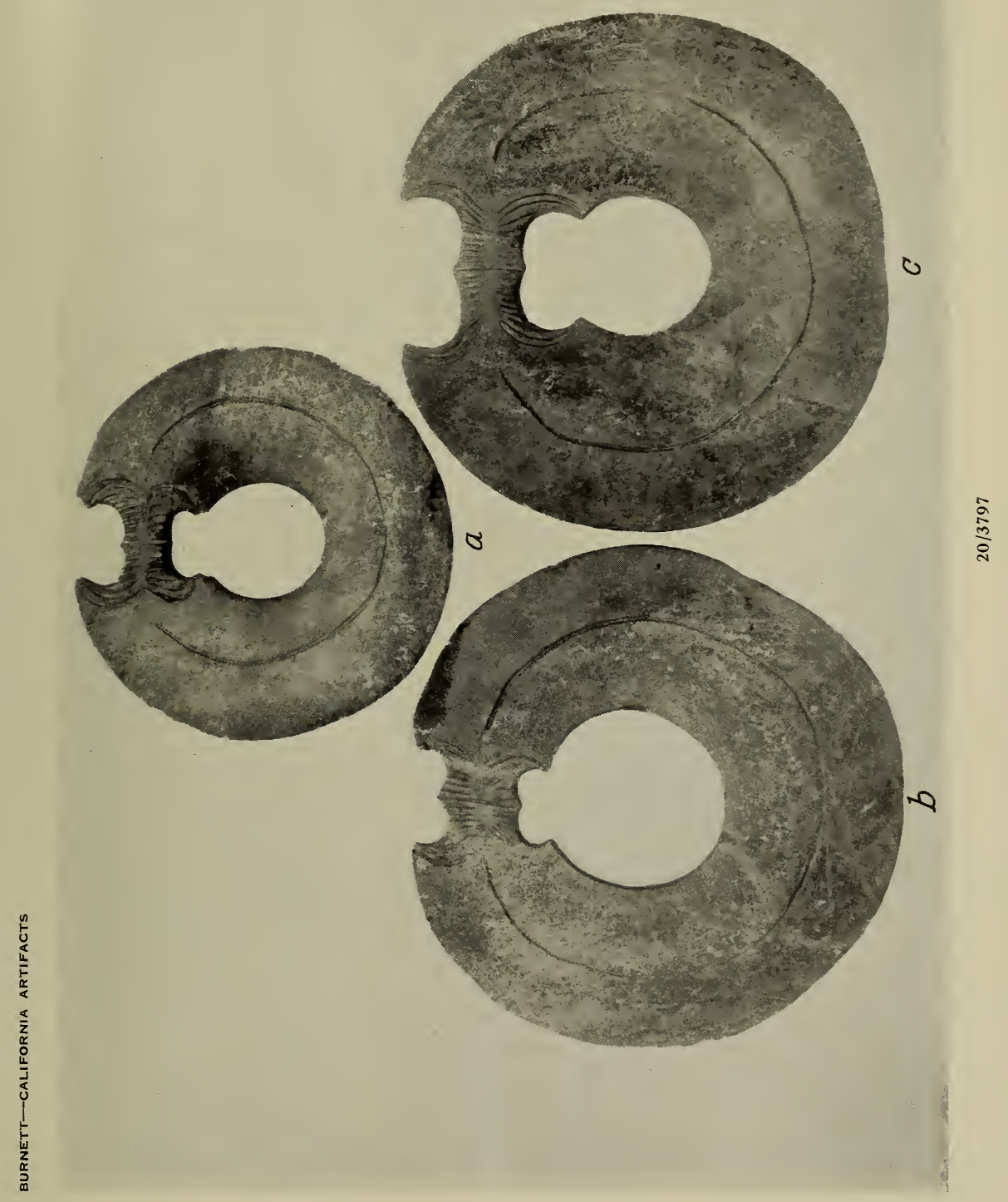




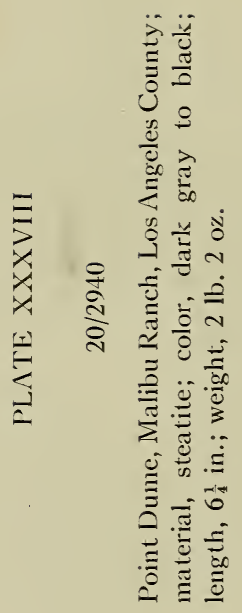




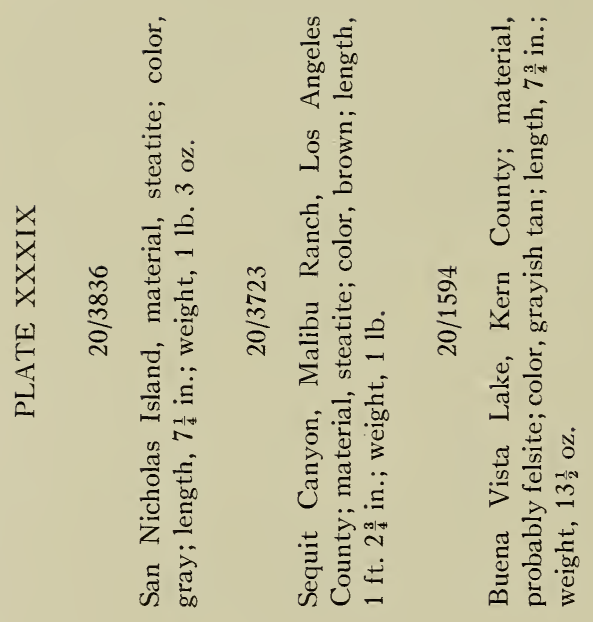




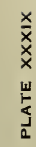
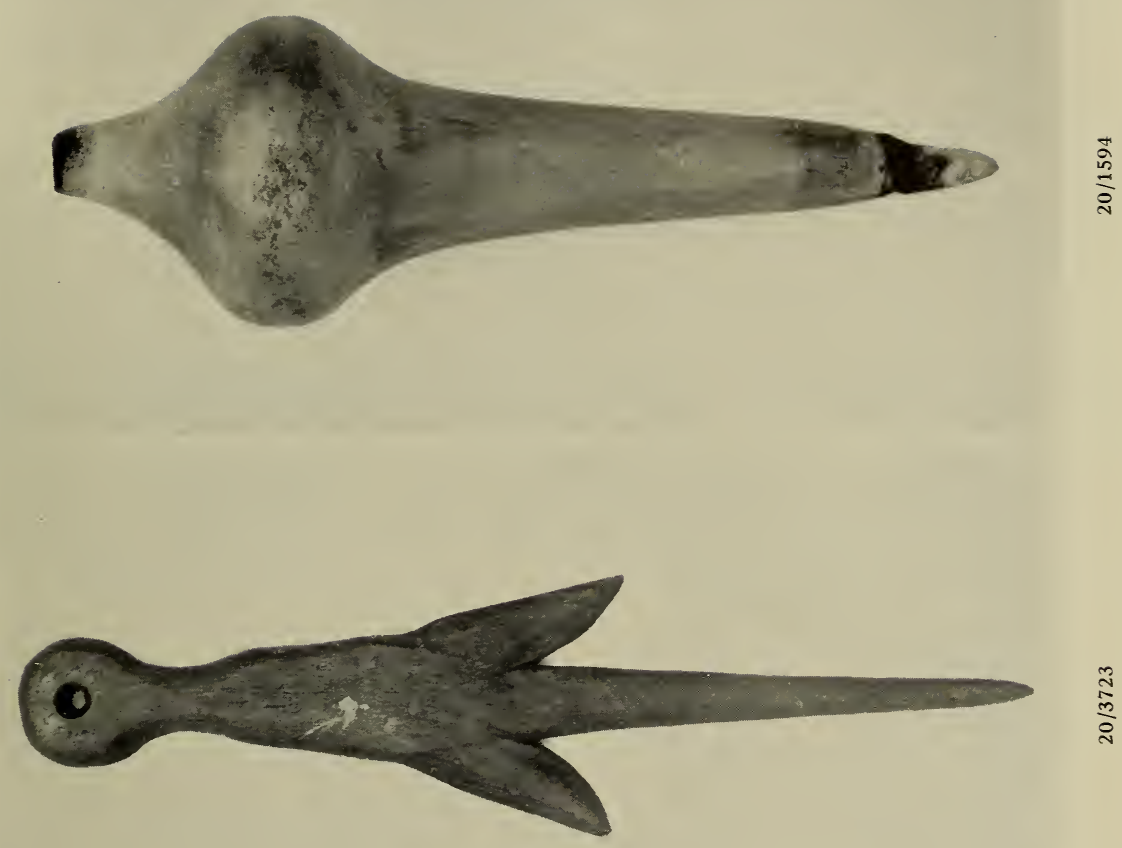

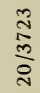

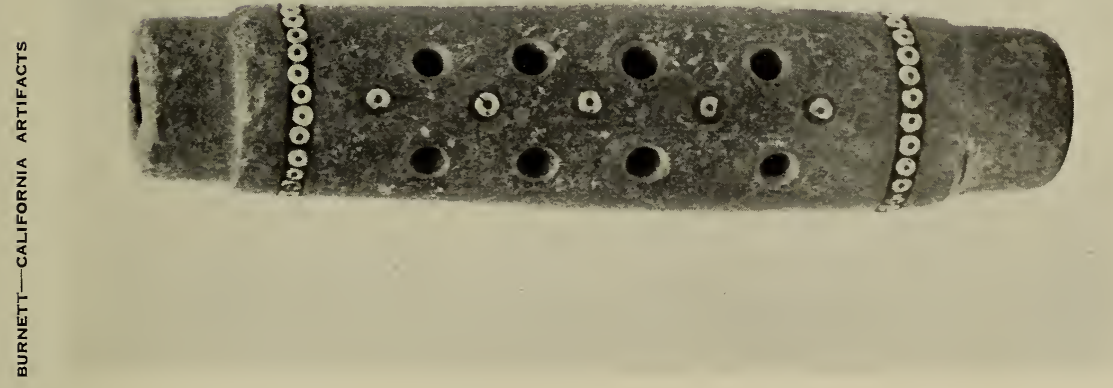

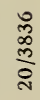




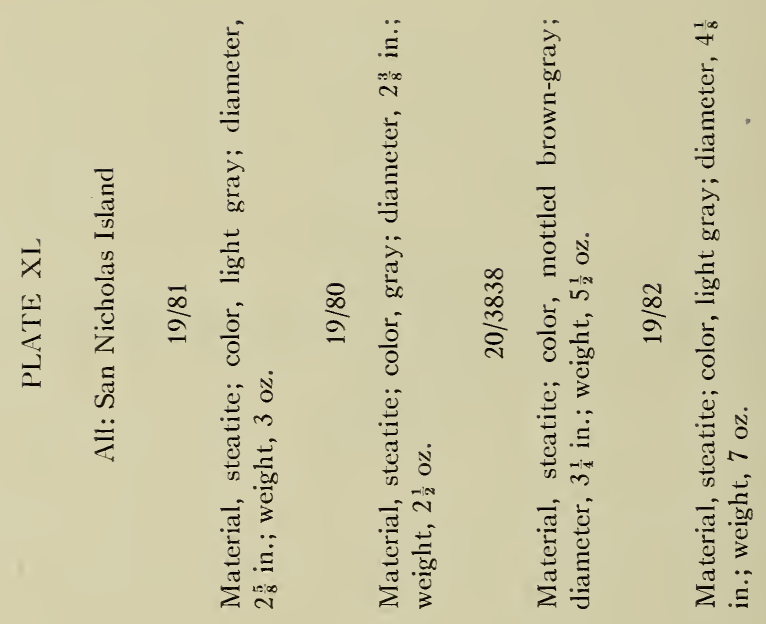


$\overrightarrow{1}$
$\frac{1}{5}$
$\frac{5}{a}$
$\frac{5}{a}$
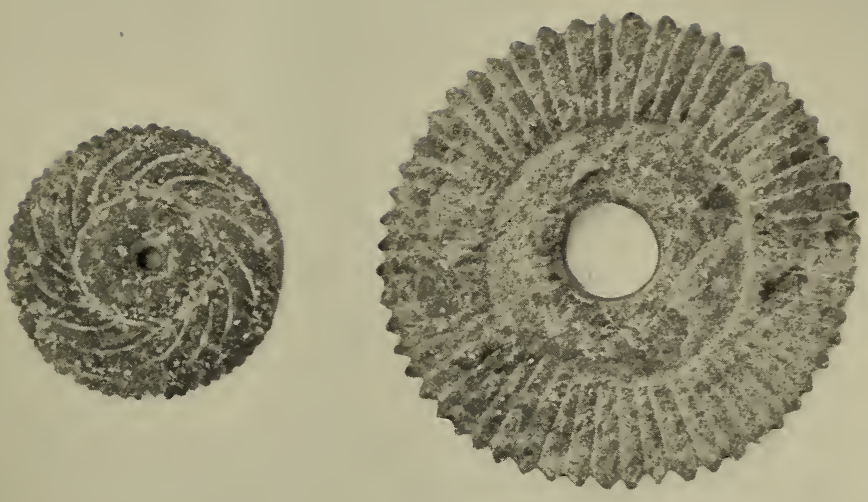

$\frac{\infty}{2} \stackrel{\infty}{\varrho}$
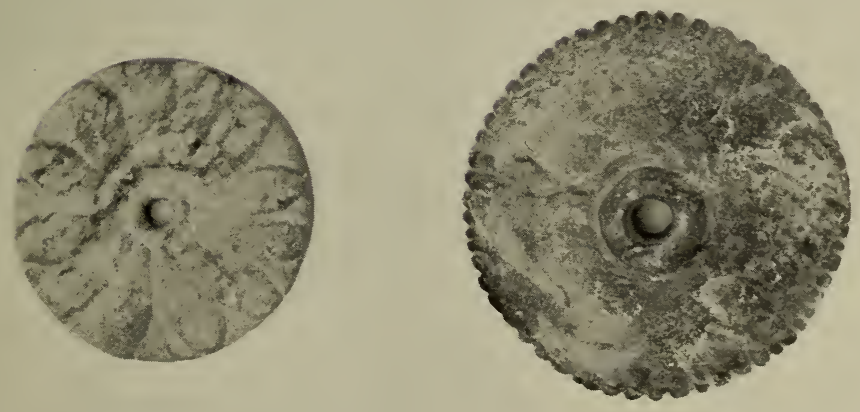

$\vec{\infty} \stackrel{\substack{\infty \\ \infty}}{\infty}$ 


\section{PLATE XLI}

Both: Sequit Canyon, Malibu Ranch, Los Angeles County.

\section{$20 / 5770$}

Material, steatite; color, light gray; greatest diameter through lugs, $2 \frac{3}{4}$ in.; thickness, $1 \frac{7}{16}$ in.; weight, $9 \frac{1}{2} \mathrm{oz}$.

\section{$20 / 4893$}

Material, sandstone; color, brown; diameter, $8 \frac{7}{8}$ in.; thickness at edge, $1 \frac{3}{4}$ in.; diameter of central well, $1 \frac{7}{16}$ in.; depth of well, $1 \frac{1}{4}$ in.; weight, $9 \mathrm{lb} .6 \mathrm{oz}$. 

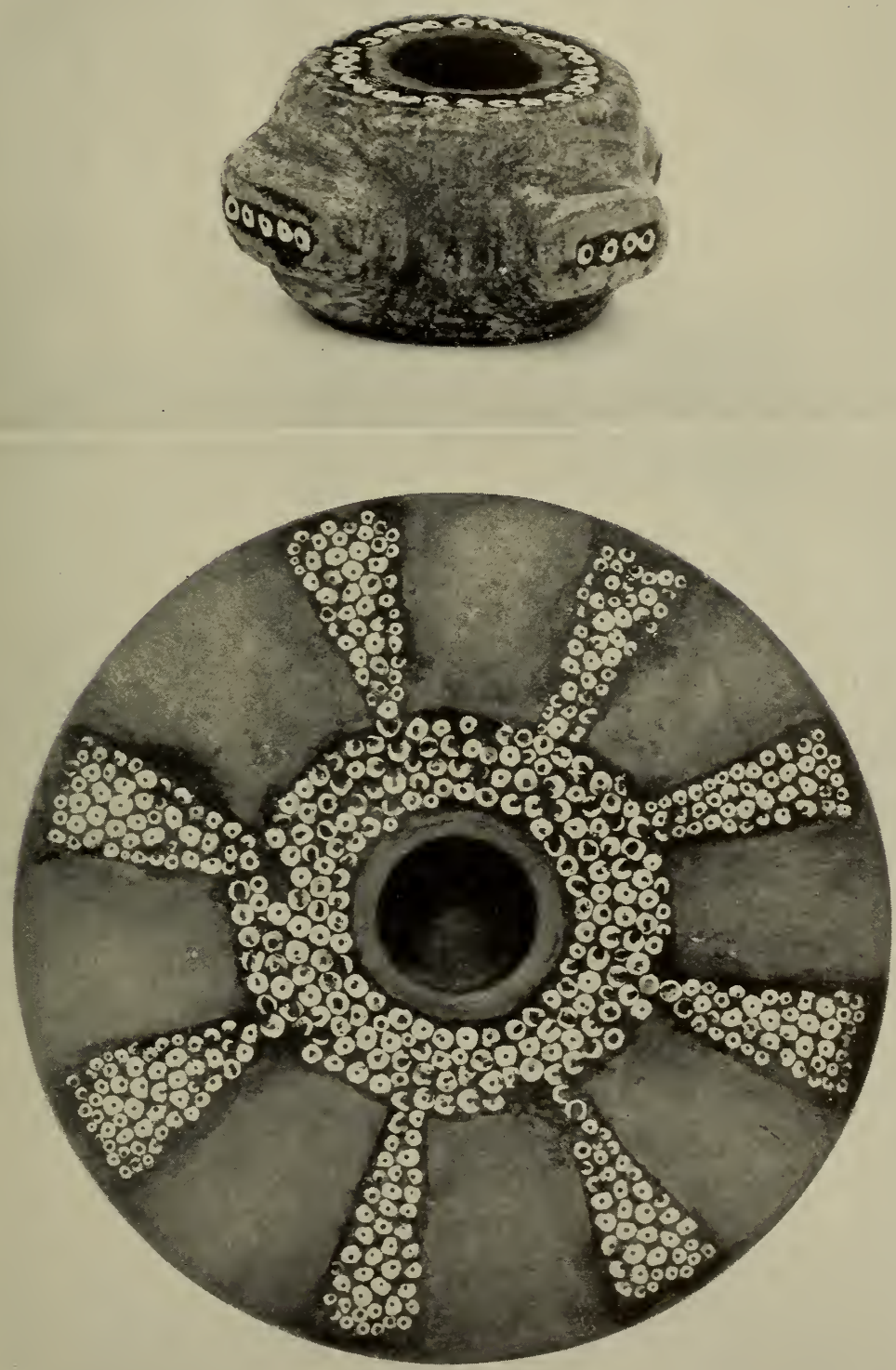

$20 / 5770$

$20 / 4893$ 


\section{PLATE XLII}

\section{All: Sequit Canyon, Malibu Ranch,} Los Angeles County.

\section{$20 / 5230$}

Material, steatite; color, gray; length, 7 in.; greatest diameter, $1 \frac{3}{4}$ in.; diameter of base at inlay end, $1 \frac{1}{8}$ in.; weight, $1 \mathrm{lb} .4 \mathrm{oz}$.

\section{$20 / 3746$}

Material, steatite; color, gray; length, $7 \frac{1}{2}$ in.; greatest diameter, $1 \frac{1}{8}$ in.; diameter of base, $\frac{5}{8}$ in.; weight, $9 \frac{1}{2} \mathrm{oz}$.

$$
20 / 37+5
$$

Material, steatite; color, gray; length, $7 \frac{5}{8}$ in.; greatest diameter, $2 \frac{1}{2}$ in.; diameter of base, irregularly $1 \frac{1}{2}$ in.; weight, $2 \mathrm{lb} .2 \mathrm{oz}$. 

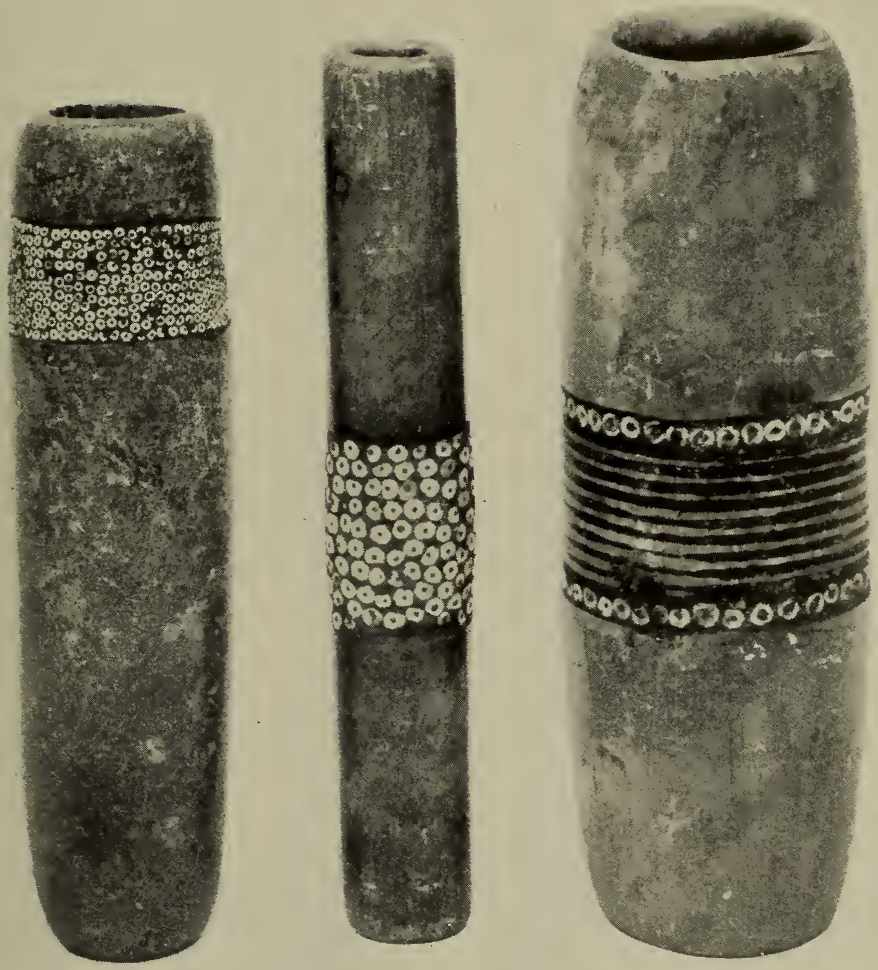


\section{PLATE XLIII}

\section{$20 / 1028$}

Point Dume, Malibu Ranch, Los Angeles County; color, light tan; length, 2 ft. $2 \frac{1}{8}$ in.; weight, $8 \mathrm{lb}$. $8 \mathrm{oz}$.

$$
\text { 20/2585 }
$$

Boney Mountain, Ventura County; length, $1 \mathrm{ft}$. 9 in.; weight, 2 lb. 4 oz.

\section{$18 / 9182$}

Baldwin Hills, Los Angeles County; color, brown; length, $1 \mathrm{ft}$. $10 \frac{1}{2}$ in.; weight, $5 \mathrm{lb}$.

\section{$20 / 2584$}

Boney Mountain, Ventura County; color, dark brown; length, 2 ft. $6 \frac{1}{4}$ in.; weight, $5 \mathrm{lb}$. $14 \mathrm{oz}$. 
PLATE XLIII

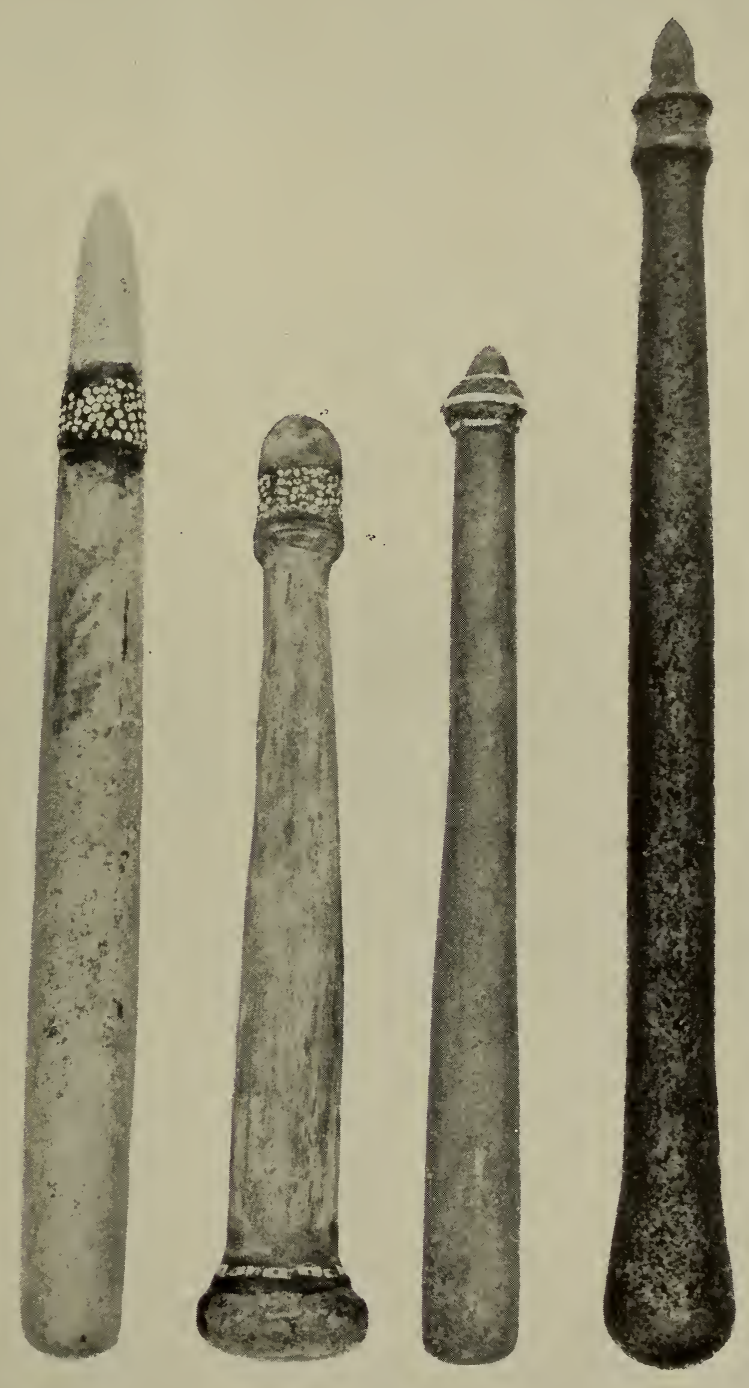




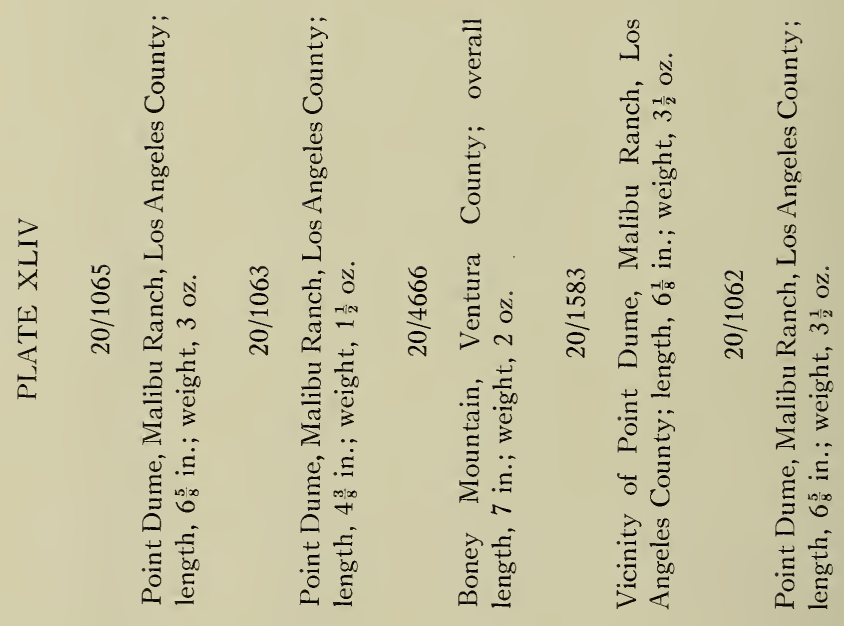




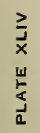

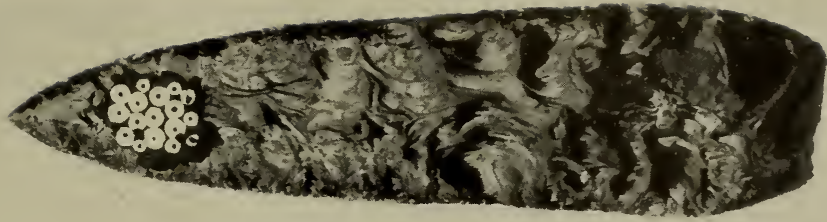

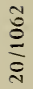

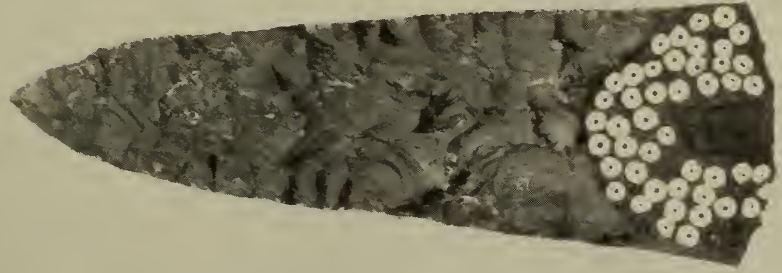

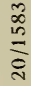

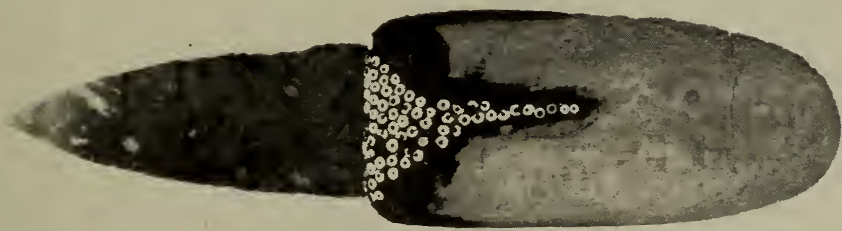

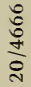
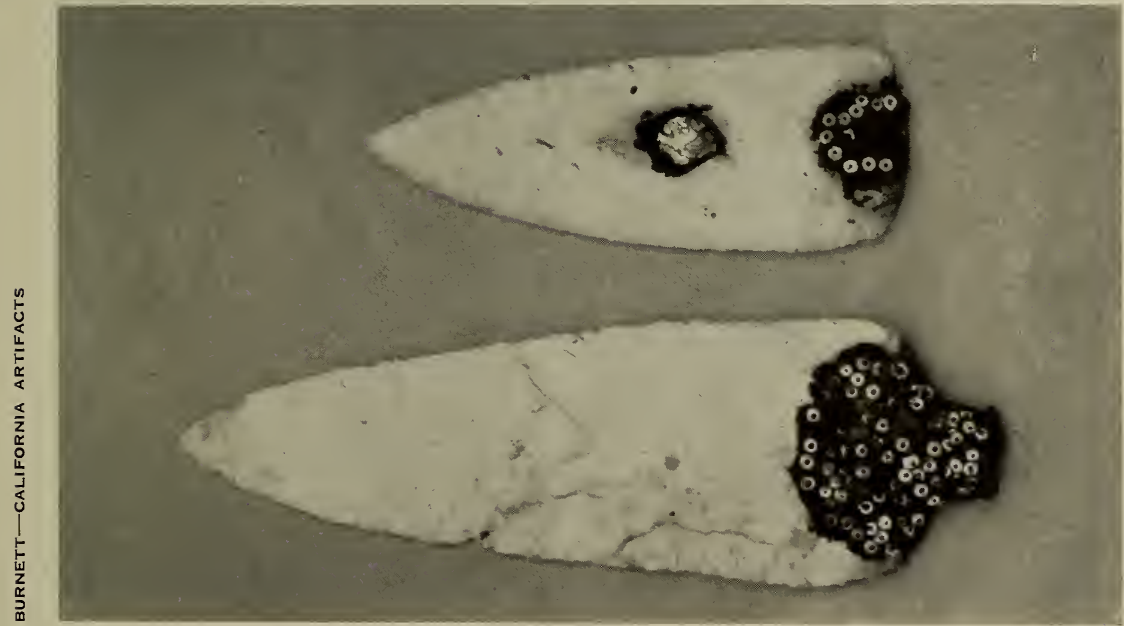

$\stackrel{\overbrace{}}{8}$

$\frac{2}{8}$ 


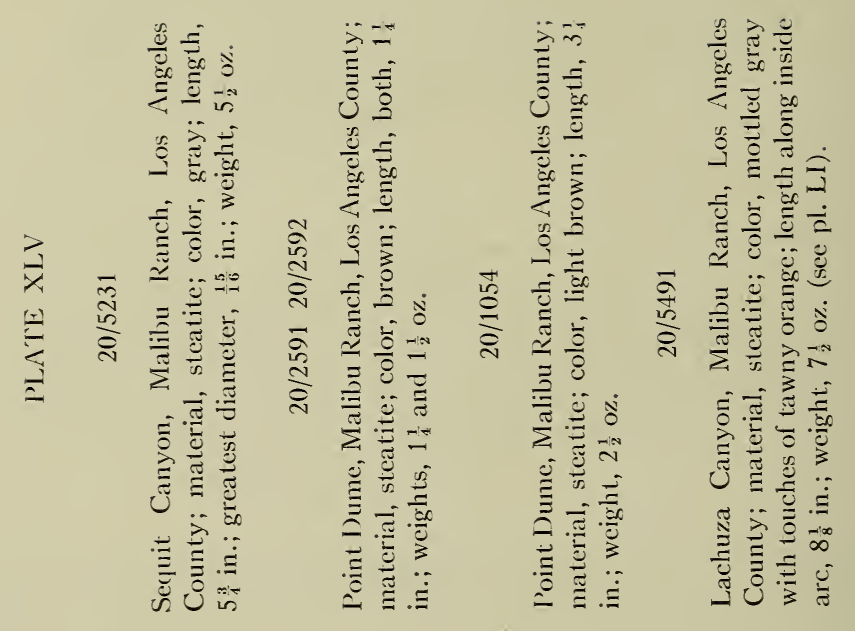


$\vec{J}$
$\vec{x}$
$\frac{w}{5}$
$\frac{a}{a}$
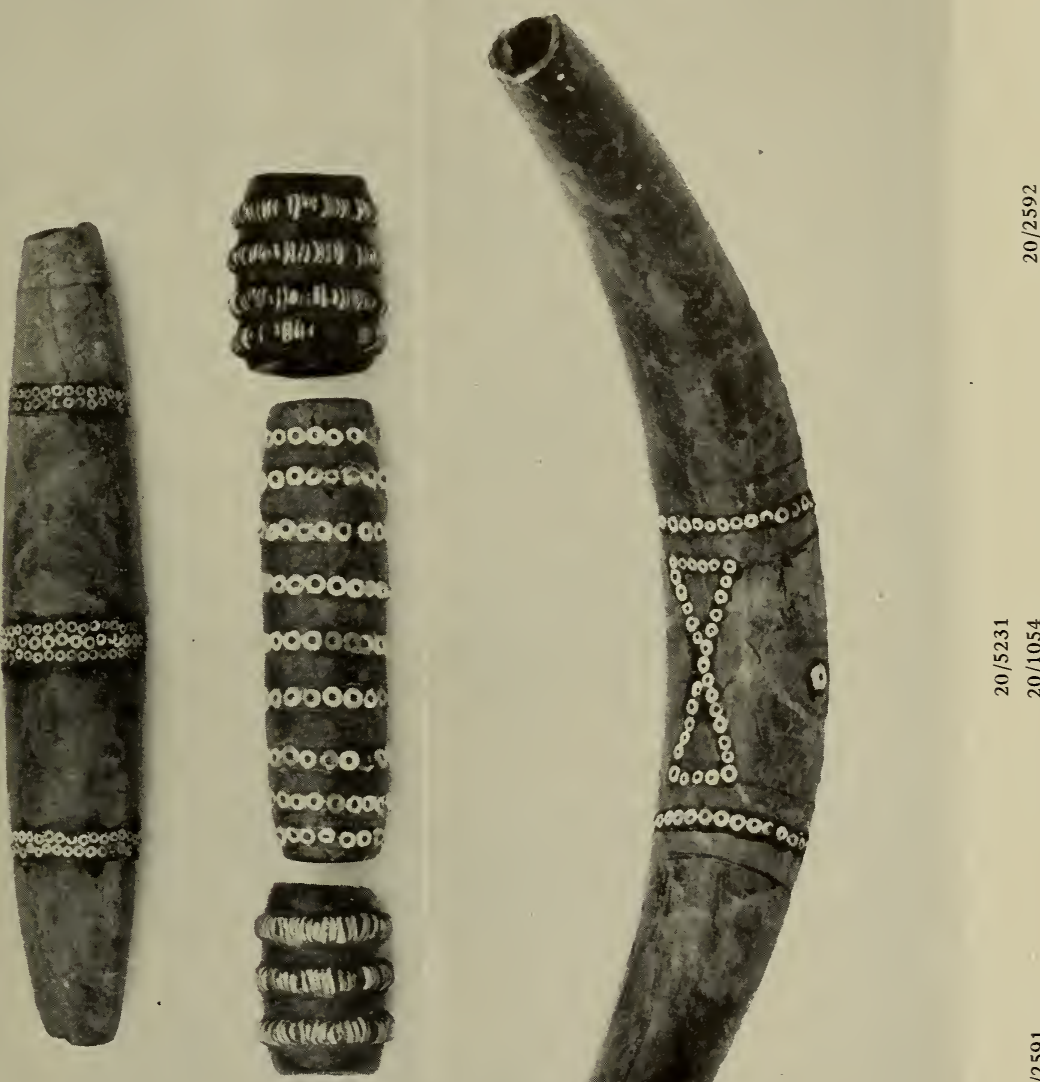

ลัก

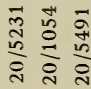

ำ 


\section{PLATE XLVI}

\section{$19 / 9453$}

Buena Vista Lake, Kern County; material, steatite; color, gray; length of units from $1 \frac{7}{8}$ to $3 \frac{5}{8}$ in.; collective weight, $7 \mathrm{oz}$. 

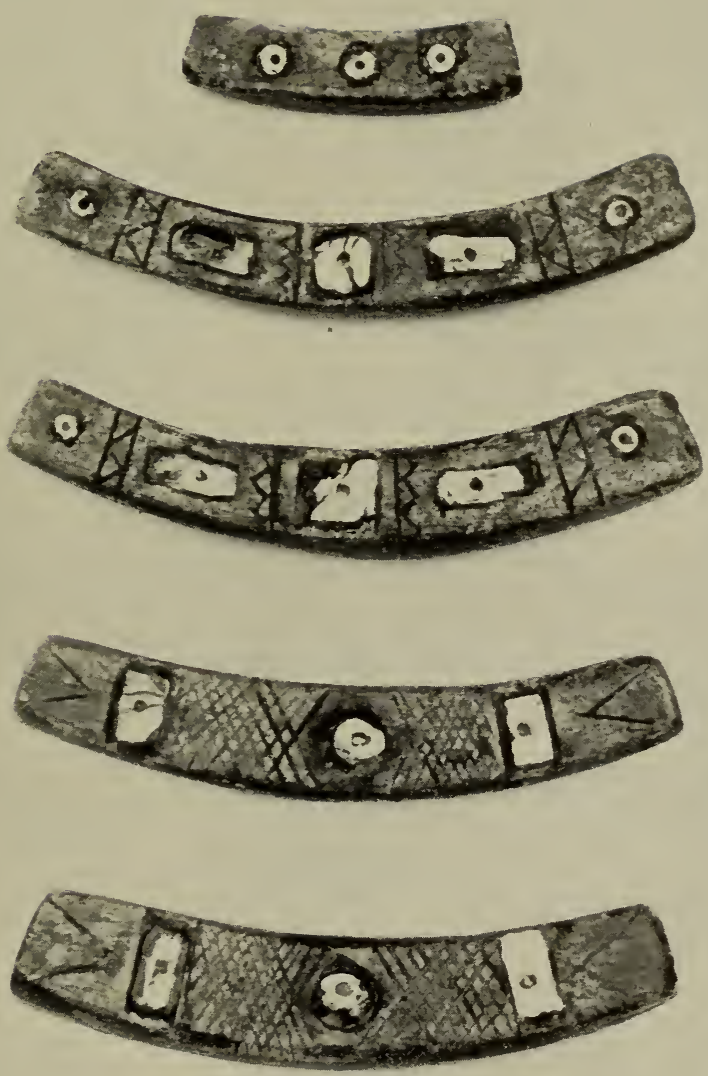

$19 / 9453$ 


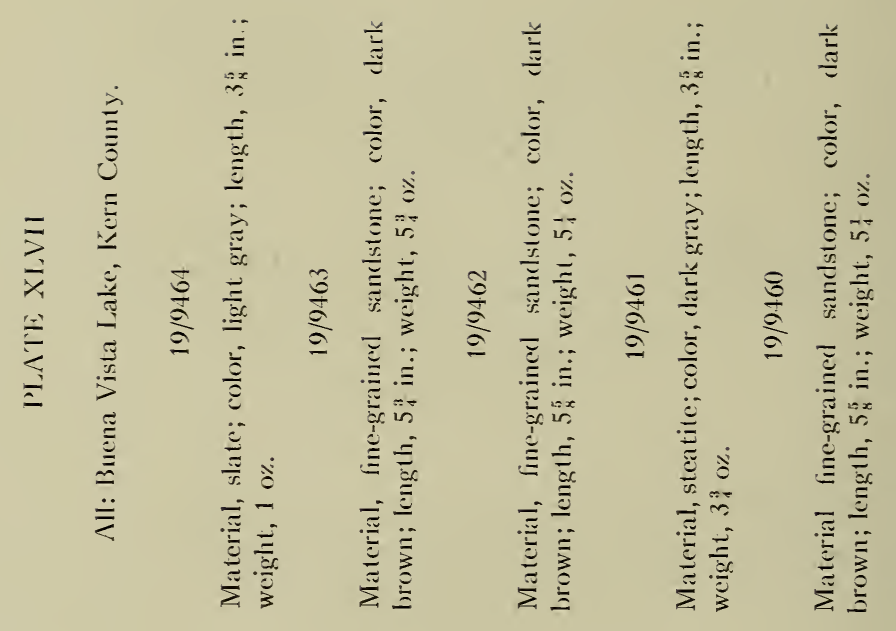


$\bar{j}$
$\frac{3}{x}$
$\frac{1}{5}$
$\frac{1}{2}$
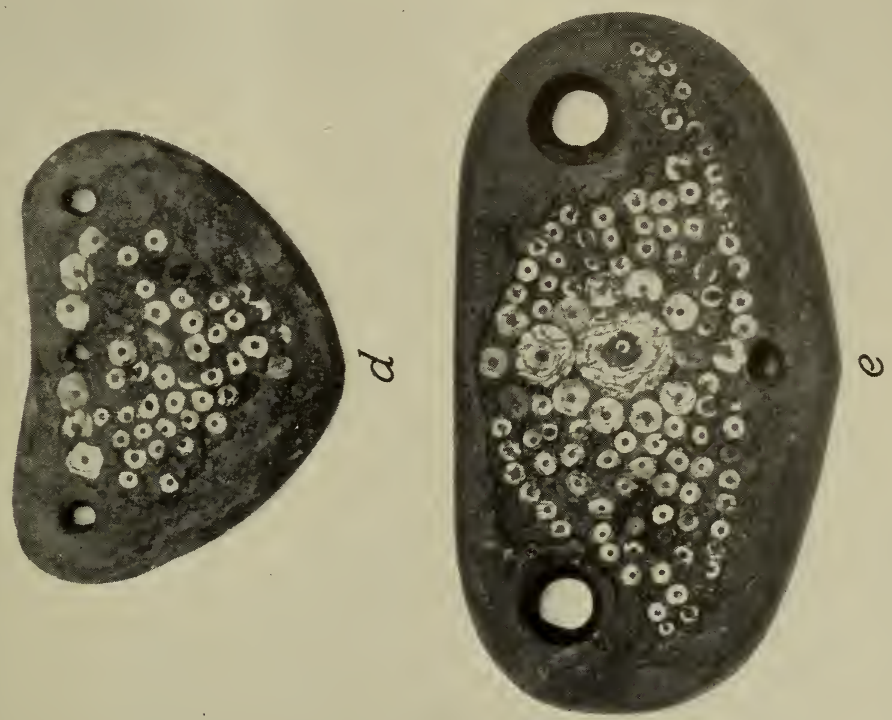

$\begin{array}{ll}\overrightarrow{0} & 0 \\ +1 & +1 \\ 0 & 0 \\ 0 & 0\end{array}$

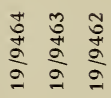

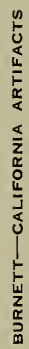
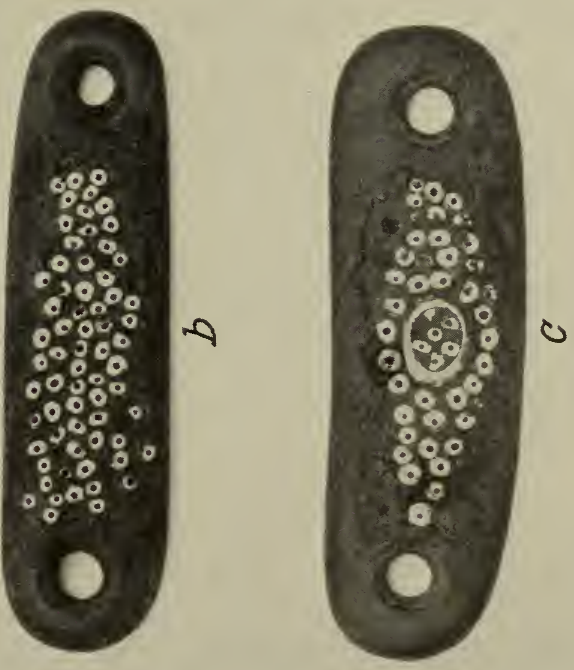


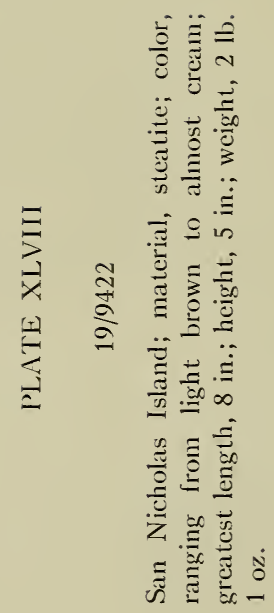




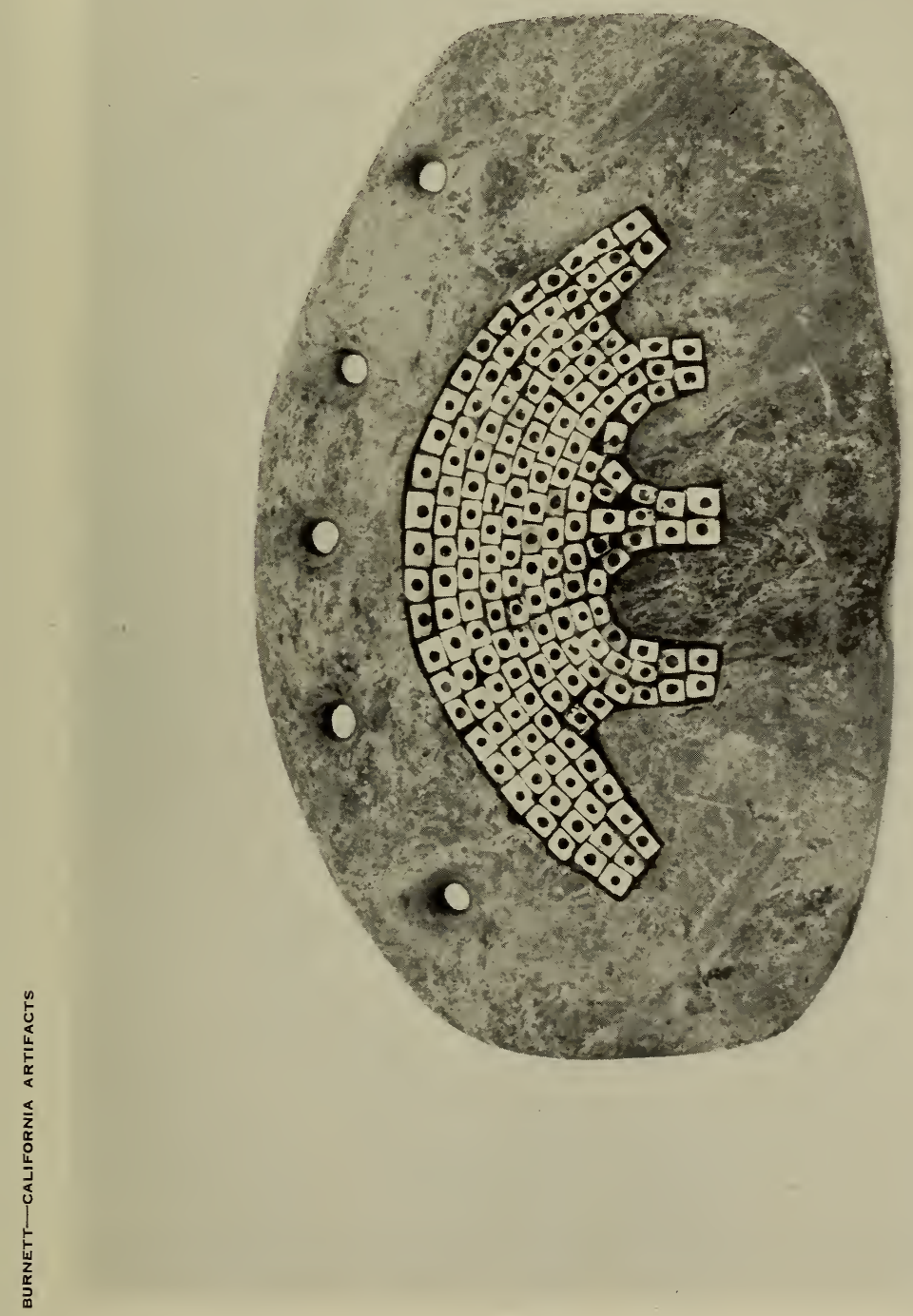




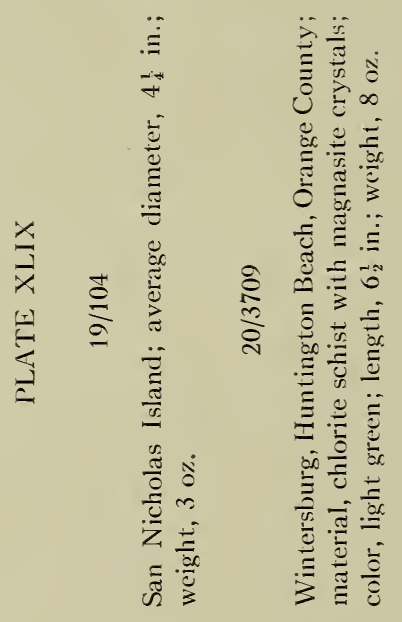


$x$
$\frac{x}{x}$
$\frac{x}{5}$
$\frac{a}{2}$
$\frac{a}{2}$

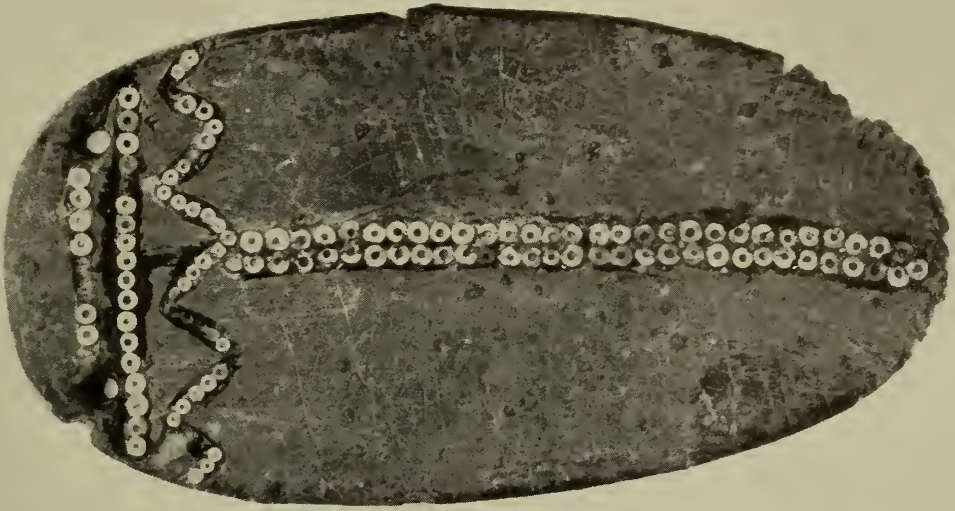

ca

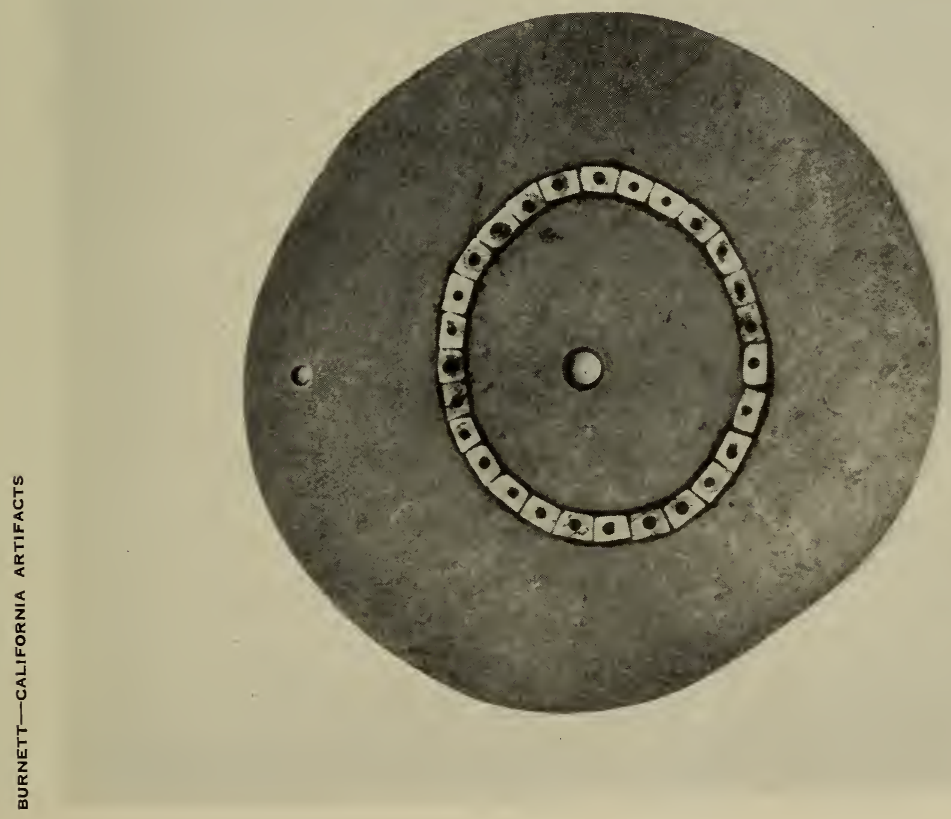

$\stackrel{+}{\circ}$ 


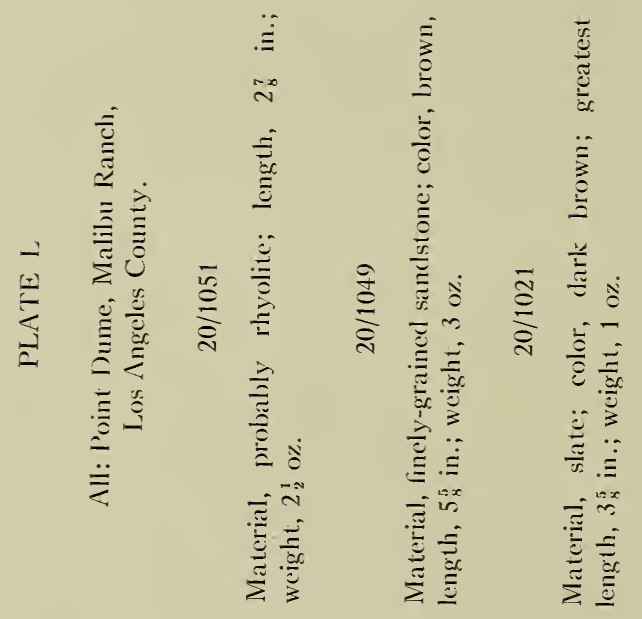




$$
\frac{\infty}{0}
$$




\section{PLATE LI}

\section{$20 / 5+91$}

Lachuza Canyon, Malibu Ranch, Los Angeles County; material, steatite; color, mottled gray with touches of tawny orange; length of inside arc of curved segment, $8 \frac{1}{8}$ in.; weight complete, $14 \frac{1}{2}$ oz. (see pl. XLV). 


$$
\text { Q }
$$


PLATE LII

20/3301-2-3-4-5

Colorado River, north of Needles, San Bernardino County; material, steatite; color, light brown; distance between points of uppermost unit, $7 \frac{7}{8}$ in.; thickness of this unit, $\frac{11}{16}$ to $\frac{7}{8} \mathrm{in}$.; combined weight, $4 \mathrm{lb}$. 


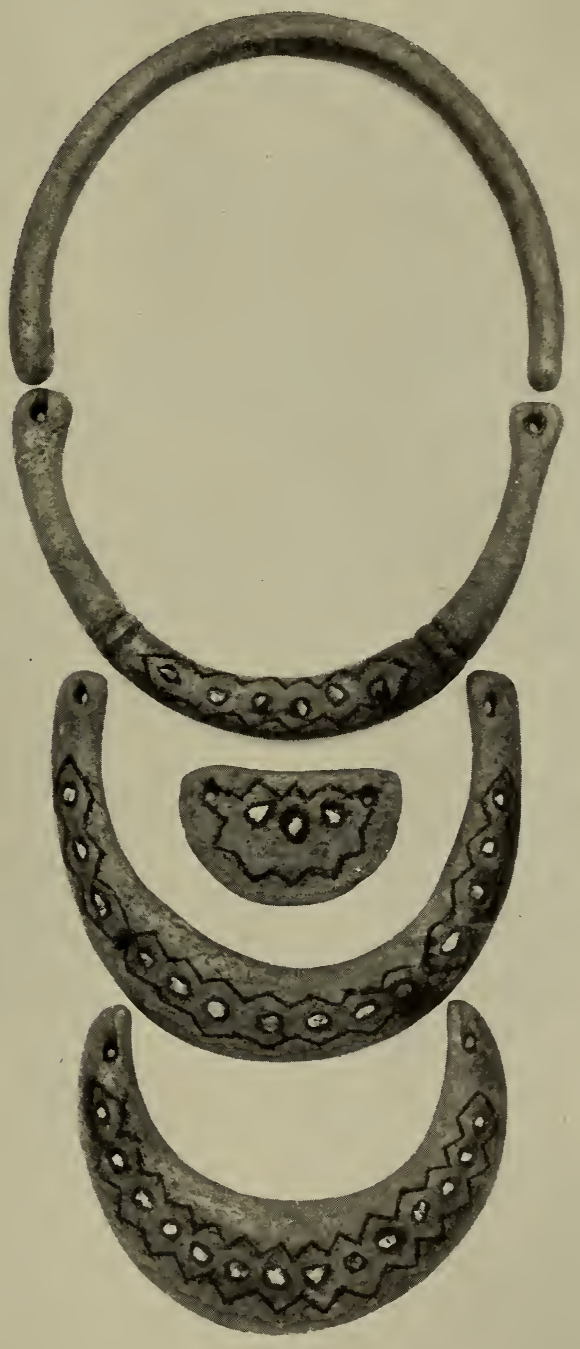

20/3301-02--03-04-05 


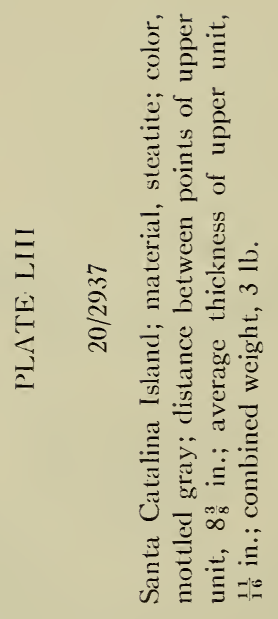


$\vdots$
$\vdots$
$\frac{\omega}{5}$
$\vdots$
$\vdots$

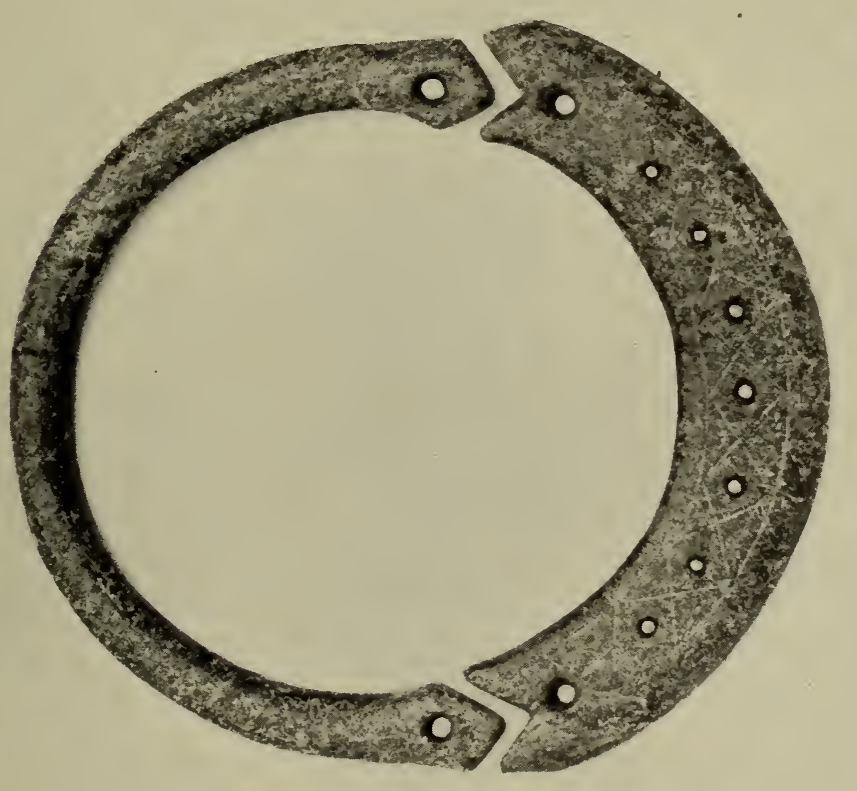

ำ

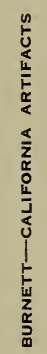




\section{PLATE LIV}

\section{$20 / 5768$}

Sequit Canyon, Nalibu Ranch, Los Angeles County; length, $11 \frac{1}{8}$ in.; width at top, $4 \frac{5}{8}$ in.; weight, $8 \mathrm{oz}$. 


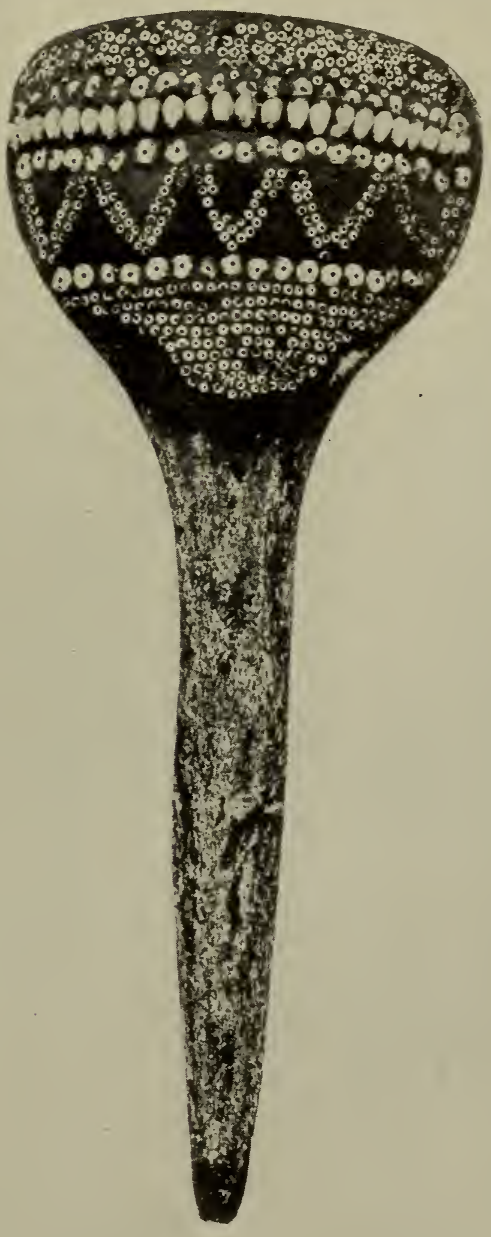

$20 / 5768$ 


\section{PLATE LV}

\section{$19 / 9425$}

San Nicholas Island; length, $1 \mathrm{ft} .3$ in.; weight, $3 \mathrm{oz}$.

$$
20 / 3761
$$

Sequit Canyon, Malibu Ranch, Los Angeles County; length, $9 \frac{7}{8}$ in.; weight, $\frac{1}{2} \mathrm{oz}$.

\section{$20 / 1129$}

Vicinity of Point Dume, Malibu Ranch, Los Angeles County; length, $11 \frac{3}{8}$ in.; weight, $1 \frac{3}{4} \mathrm{oz}$.

\section{$20 / 4654$}

Sequit Canyon, Malibu Ranch, Los Angeles County; length, $10^{\frac{3}{4}}$ in.; weight, $1 \frac{3}{4} \mathrm{oz}$. 

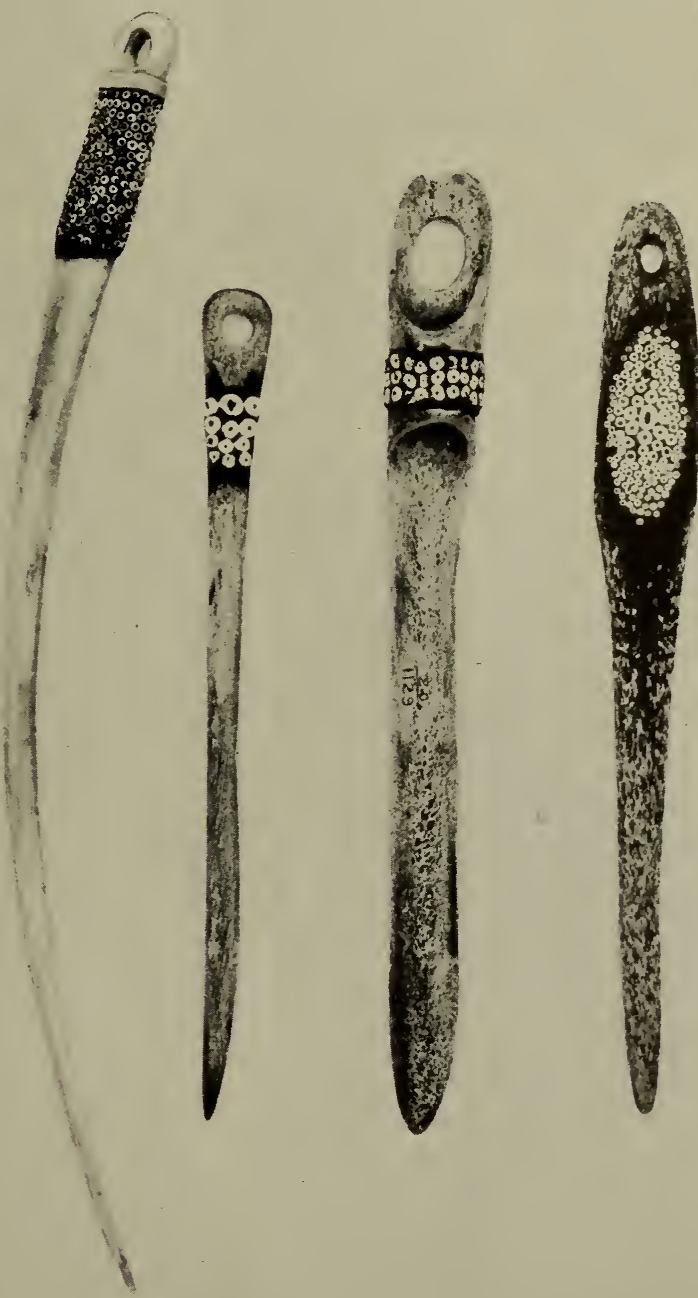

$19 / 9425$

$20 / 3761$

$20 / 1129$

$20 / 4654$ 


\section{PLATE LVI}

\section{$20 / 3762$}

Sequit Canyon, Malibu Ranch, Los Angeles County; length, $10 \frac{1}{8}$ in.; weight, $2 \frac{1}{2} \mathrm{oz}$.

\section{$20 / 1848$}

Vicinity of Point Dume, Malibu Ranch, Los Angeles County; length, $10 \frac{5}{8}$ in.; weight, $2 \frac{1}{2} \mathrm{oz}$.

\section{$20 / 1849$}

Vicinity of Point Dume, Malibu Ranch, Los Angeles County; length, $11 \frac{3}{8}$ in.; weight $2 \frac{3}{4} \mathrm{oz}$. 

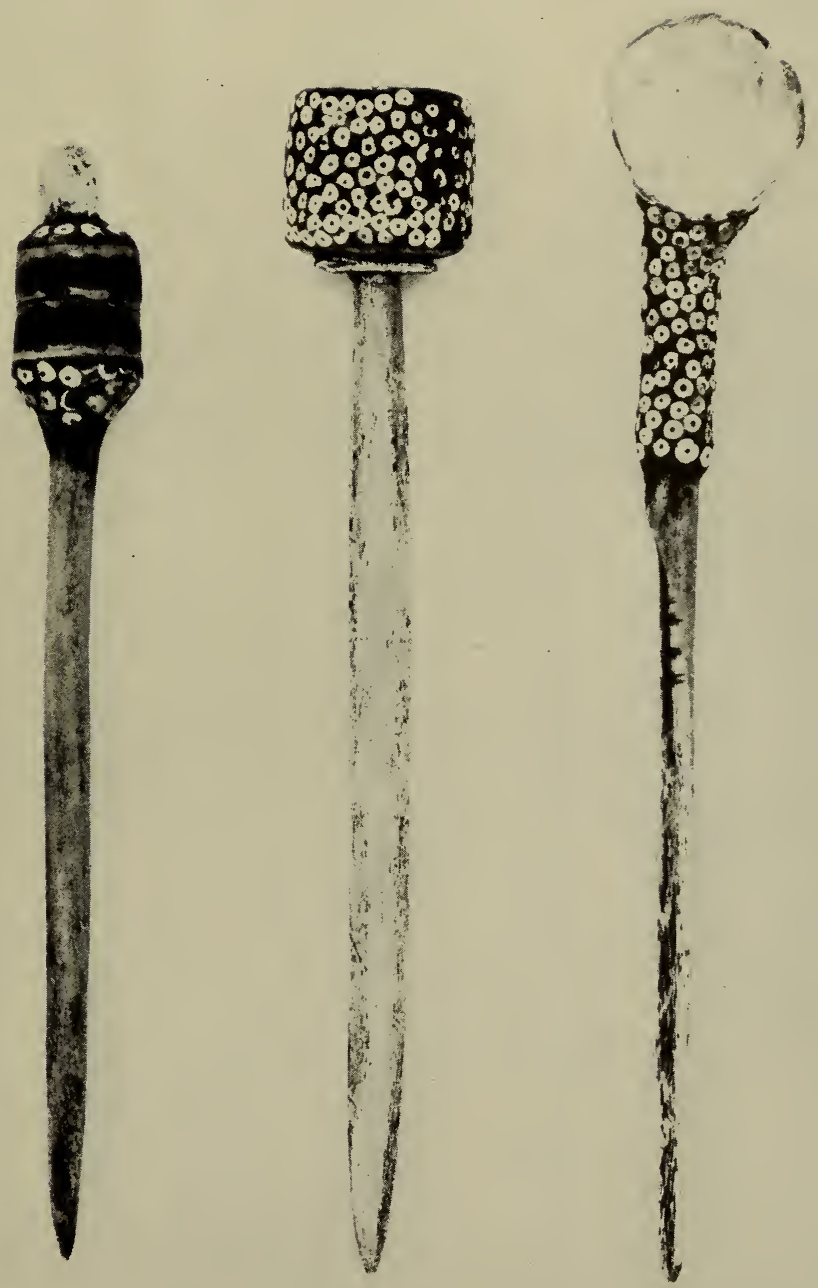


\section{PLATE LVII}

\section{$20 / 3763$}

Sequit Canyon, Malibu Ranch, Los Angeles County; length, $9 \frac{5}{8}$ in.; weight, $1 \frac{1}{2} \mathrm{oz}$.

\section{$20 / 1036$}

Point Dume, Malibu Ranch, Los Angeles County; length, $11 \frac{3}{8}$ in.; weight, $3 \frac{1}{4} \mathrm{oz}$.

\section{$20 / 3760$}

Sequit Canyon, Malibu Ranch, Los Angeles County; length, $12 \frac{1}{8}$ in.; weight, $2 \frac{1}{4} \mathrm{oz}$. 

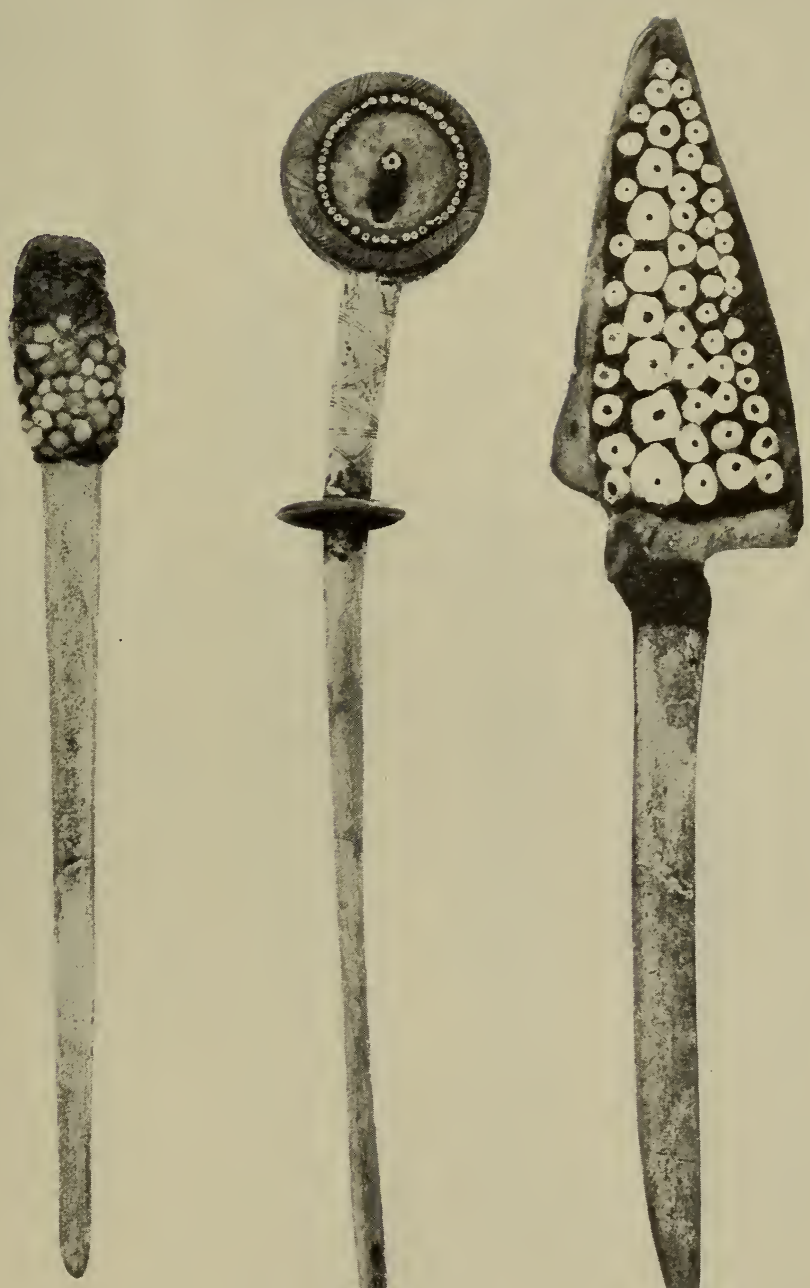


\section{PLATE LVIII}

\section{$20 / 3764$}

Sequit Canyon, Malibu Ranch, Los Angeles County; length, 9 in.; weight, $1 \frac{1}{2} \mathrm{oz}$.

$20 / 1130$

Vicinity of Point Dume, Malibu Ranch, Los Angeles County; length, $9 \frac{1}{4}$ in.; weight, $1 \frac{3}{4} \mathrm{oz}$.

$11 / 8428$

Redondo Beach, Los Angeles County; length, $10 \frac{1}{4}$ in.; weight, $1 \frac{1}{4} \mathrm{oz}$.

$19 / 9442$

Barstow, San Bernardino County; length, $10_{\frac{3}{3}}^{3}$ in.; weight, $1 \frac{1}{4} \mathrm{oz}$. 

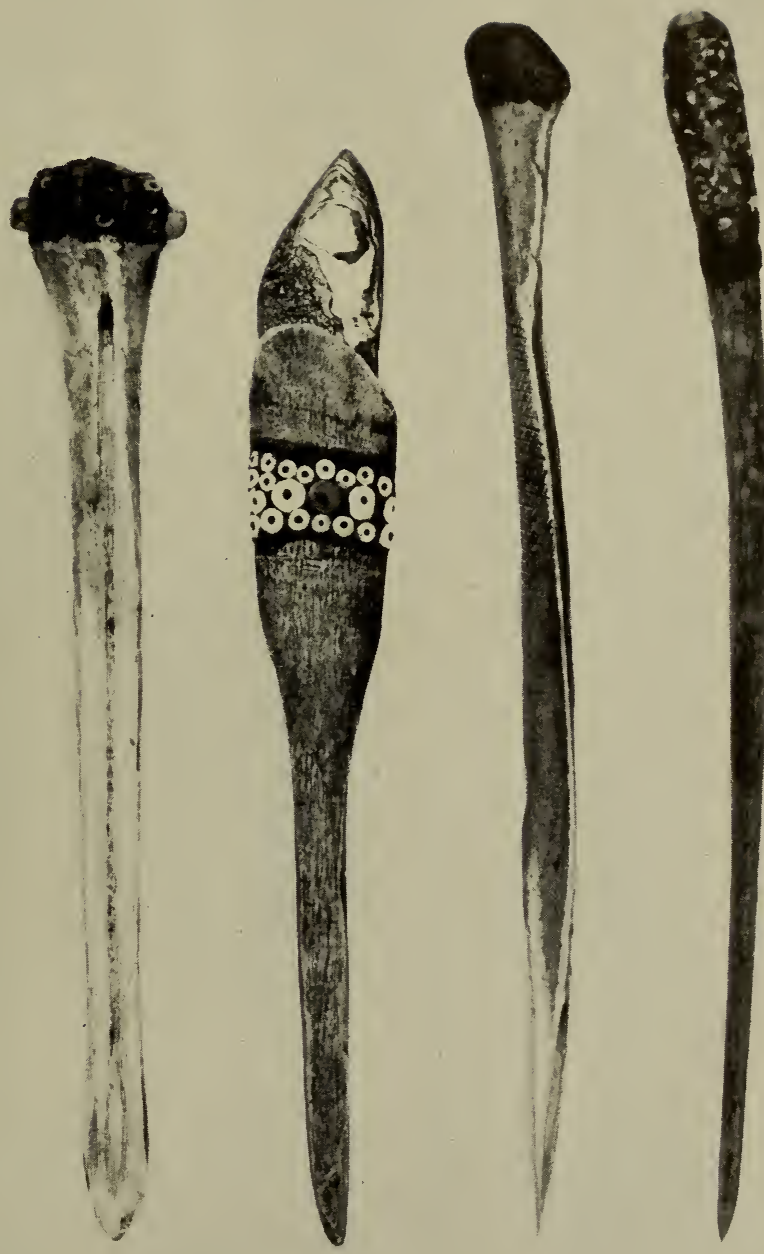

$20 / 3764$

$20 / 1130$

$11 / 8428$

$19 / 9442$ 


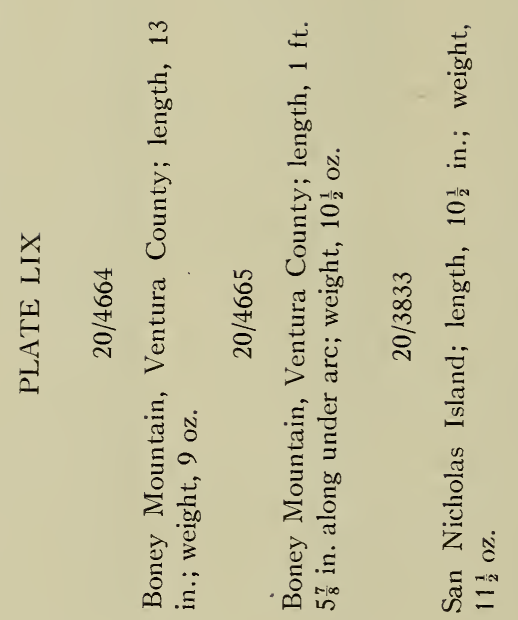


$\frac{x}{J}$
$\frac{w}{5}$
$\frac{d}{a}$

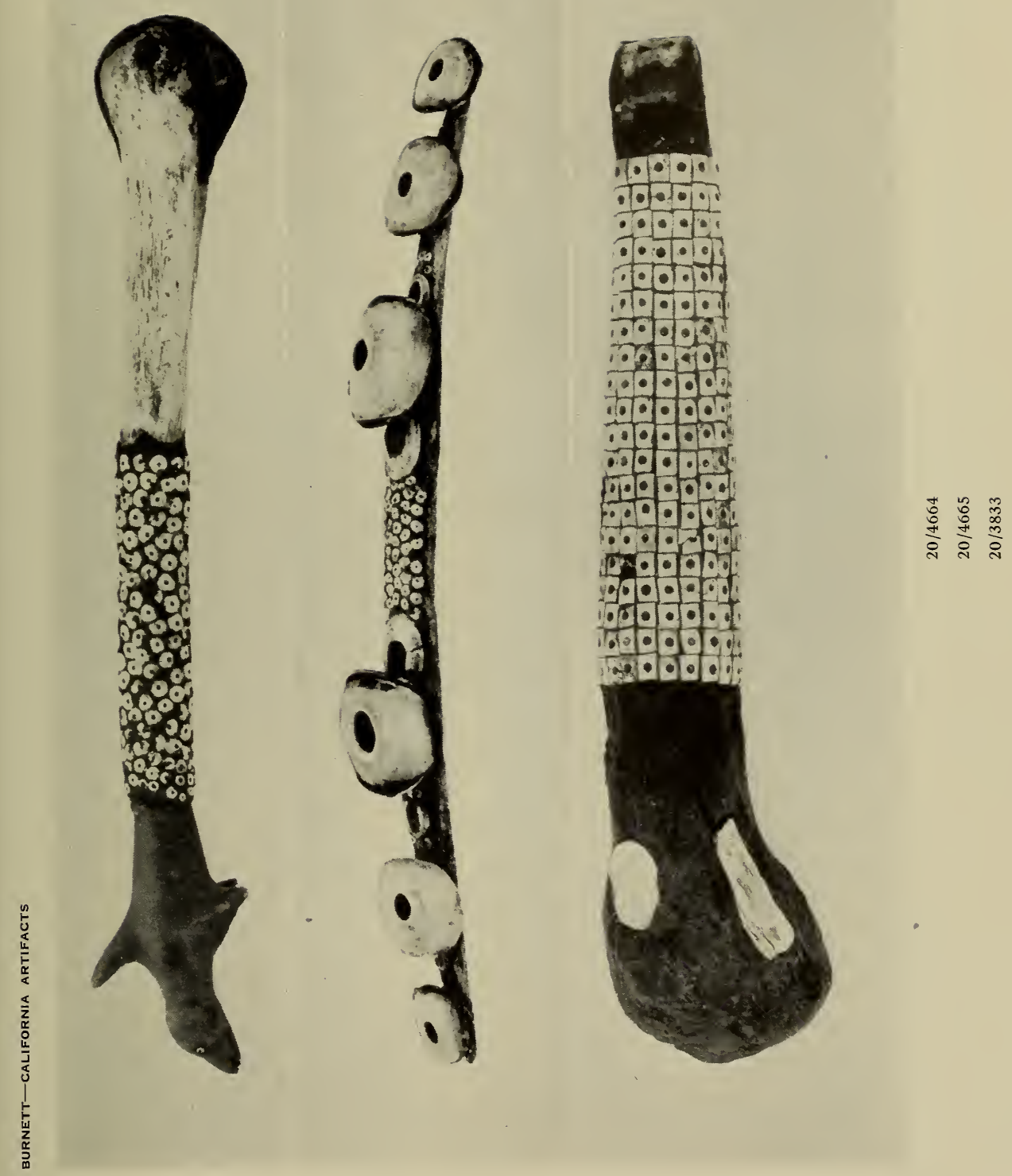




\section{PLATE LX}

All: Yaqui IVells, San Diego County

$$
\text { 19/9512-B }
$$

Length overall, $1 \mathrm{ft}$. 7 in.

$$
\text { 19/9512-A }
$$

Length overall, $1 \mathrm{ft} .8$ in.

$$
\text { 19/9511-B }
$$

Length overall, $1 \mathrm{ft}$. $9 \frac{1}{4}$ in.

$$
19 / 9511-A
$$

Length overall, $2 \mathrm{ft}$. $\frac{1}{2}$ in. 


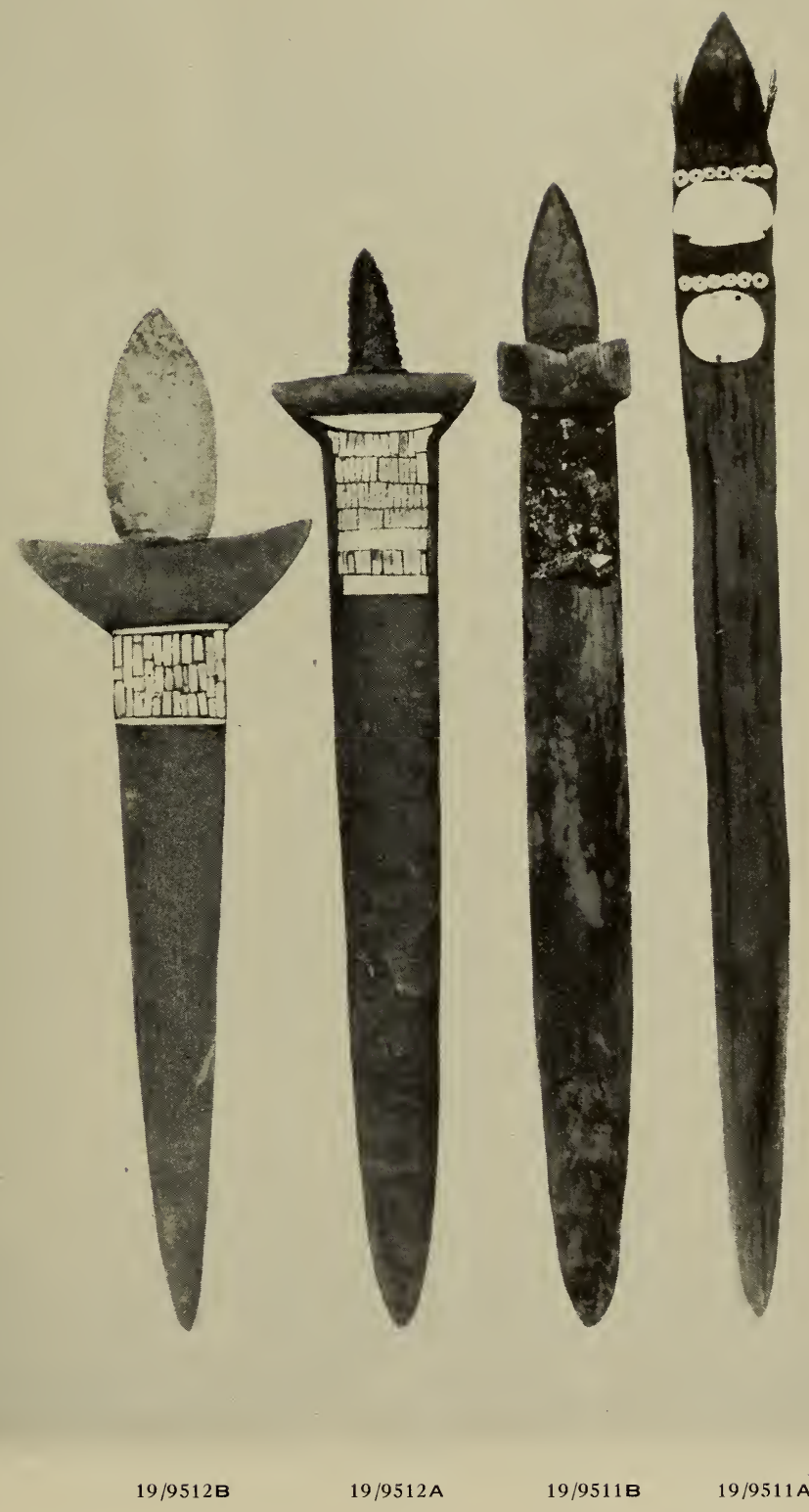




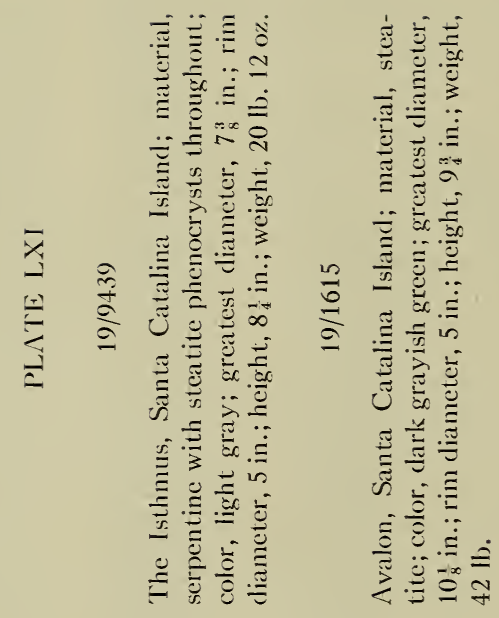




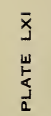

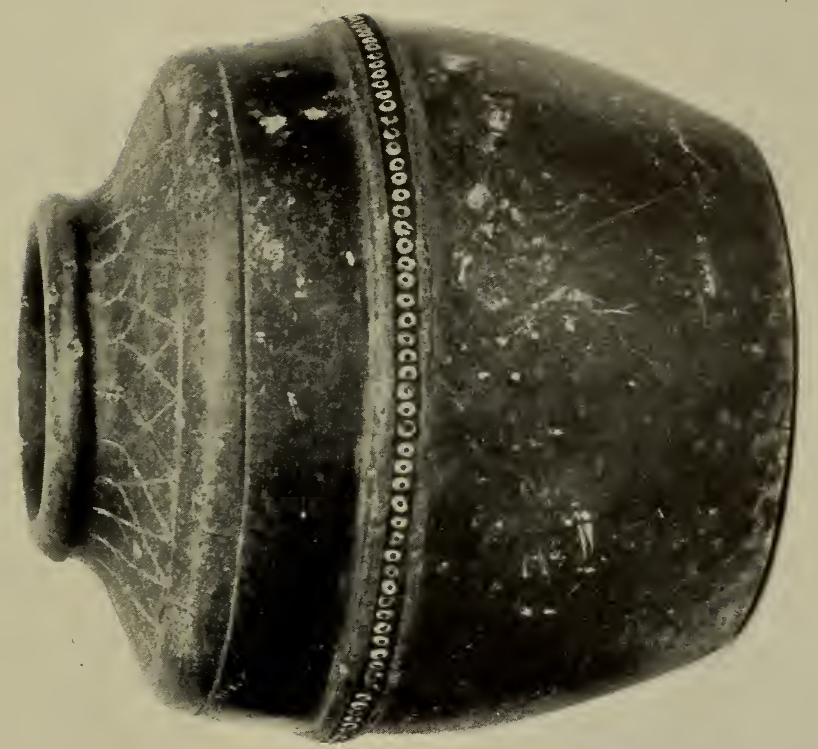

$\stackrel{\frac{n}{6}}{\frac{n}{2}}$

$\frac{9}{\frac{9}{2}}$

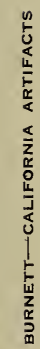




\section{PLATE LXII}

\section{$20 / 1579$}

Vicinity of Point Dume, Malibu Ranch, Los Angeles County; material, steatite; color, brown; overall length, $9 \frac{1}{2}$ in.; long rim diameter, $7 \frac{1}{2}$ in.; short rim diameter, $6 \frac{1}{2}$ in.; height, 5 in.; weight. $10 \mathrm{lb} .4 \mathrm{oz}$.

$20 / 3770$

Sequit Canyon, Malibu Ranch, Los Angeles County; material, steatite; color, light brown; long diameter, $12 \frac{1}{4}$ in.; short diameter, $11 \frac{3}{8}$ in.: height, $7 \frac{3}{8}$ in.; weight, 20 lb. $8 \mathrm{cz}$. 

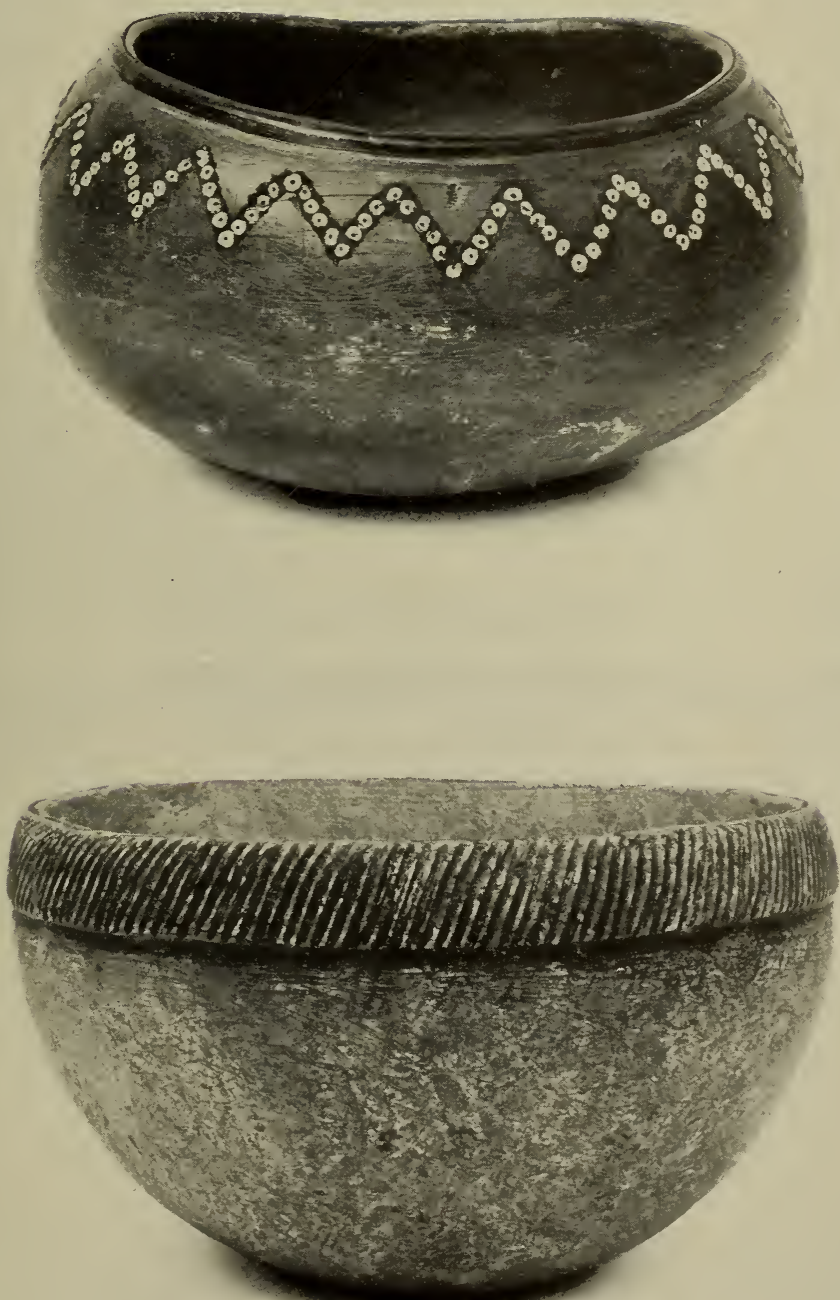

20/1579

20/3770 


\section{PLATE LXIII}

20/5 493

Lachuza Canyon, Malibu Ranch, Los Angeles County; material, steatite; color, grayish brown; diameter, $4 \frac{3}{5}$ in.; inside depth, $2 \frac{1}{4}$ in.; weight, $1 \mathrm{lb}$.

\section{$20 / 4652$}

Sequit Canyon, Malibu Ranch, Los Angeles County; material, steatite; color, light brown; diameter of rim, 4 in.; height, $3 \frac{1}{8}$ in.; weight, $1 \mathrm{lb} .12 \mathrm{oz}$.

\section{$20 / 3837$}

San Nicholas Island; material, steatite; color, gray; length, $5 \frac{3}{4}$ in.; greatest height, $2 \frac{5}{8}$ in.; weight, 1 lb. $13 \frac{1}{2} \mathrm{oz}$. 

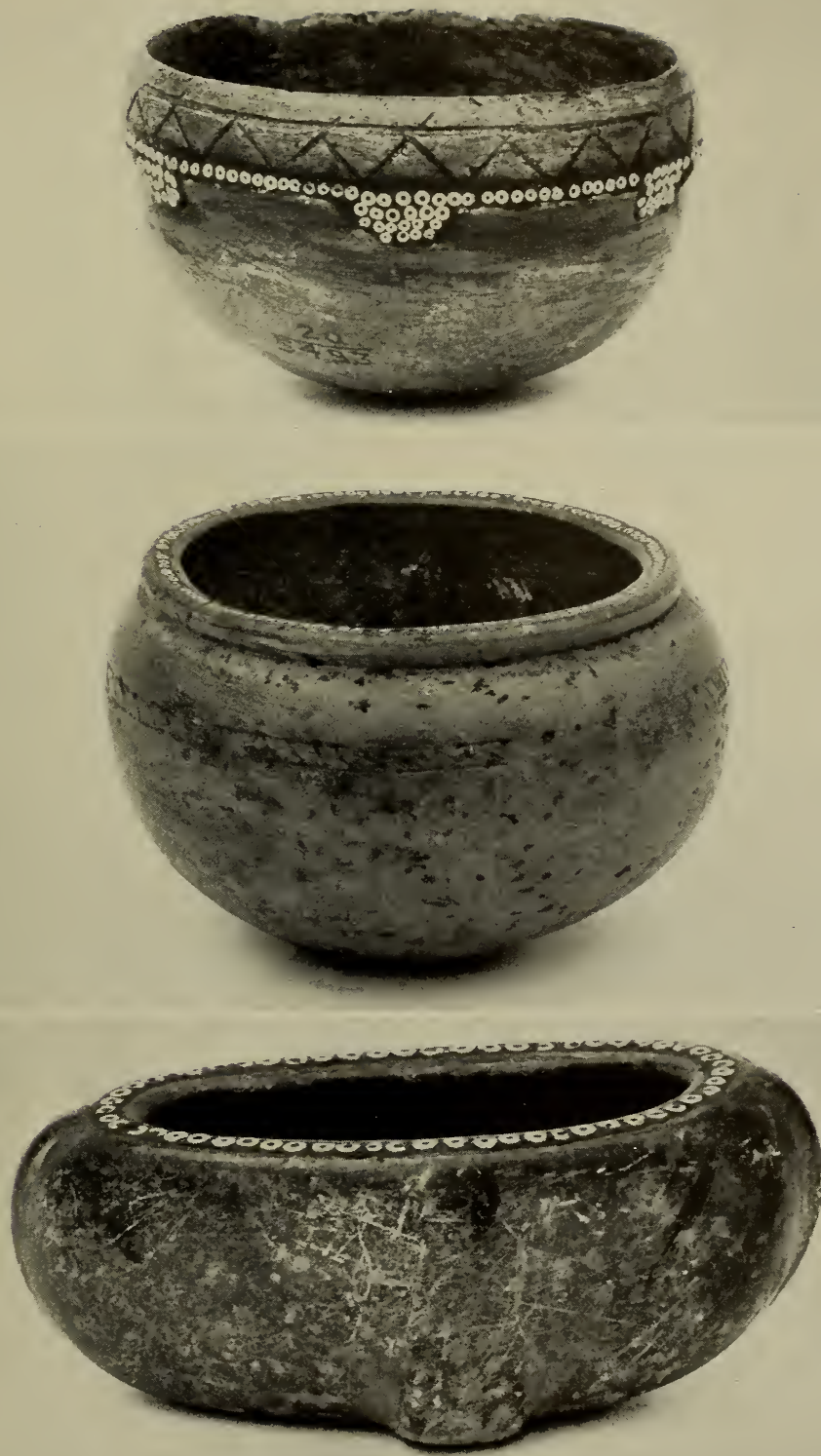

$20 / 5493$

$20 / 4652$

$20 / 3837$ 


\section{PLATE LXIV}

$20 / 37+2$

Sequit Canyon, Malibu Ranch, Los Angeles County; material, steatite; color, gray; rim diameter, 2 in.; height, $1 \frac{7}{8}$ in.; weight, $6 \frac{1}{2} \mathrm{oz}$.

$20 / 37+3$

Sequit Canyon, Malibu Ranch, Los Angeles County; material, steatite; color, bluish gray; height, $1 \frac{7}{5}$ in.; weight, $3 \frac{1}{\frac{1}{4}} \mathrm{oz}$.

$$
20 / 37+1
$$

Sequit Canyon, Malibu Ranch, Los Angeles County; material, steatite; color, brown; height, $2 \frac{1}{2}$ in.; greatest diameter, $6 \frac{1}{4}$ in.; weight, $1 \mathrm{lb}$. $12 \mathrm{oz}$.

\section{$20 / 1578$}

Vicinity of Point Dume, Malibu Ranch, Los Angeles County; material, steatite; color, light brown; height, $3 \frac{1}{8}$ in.; greatest diameter, $8 \frac{3}{5}$ in.: weight, 4 lb. $8 \mathrm{oz}$. 

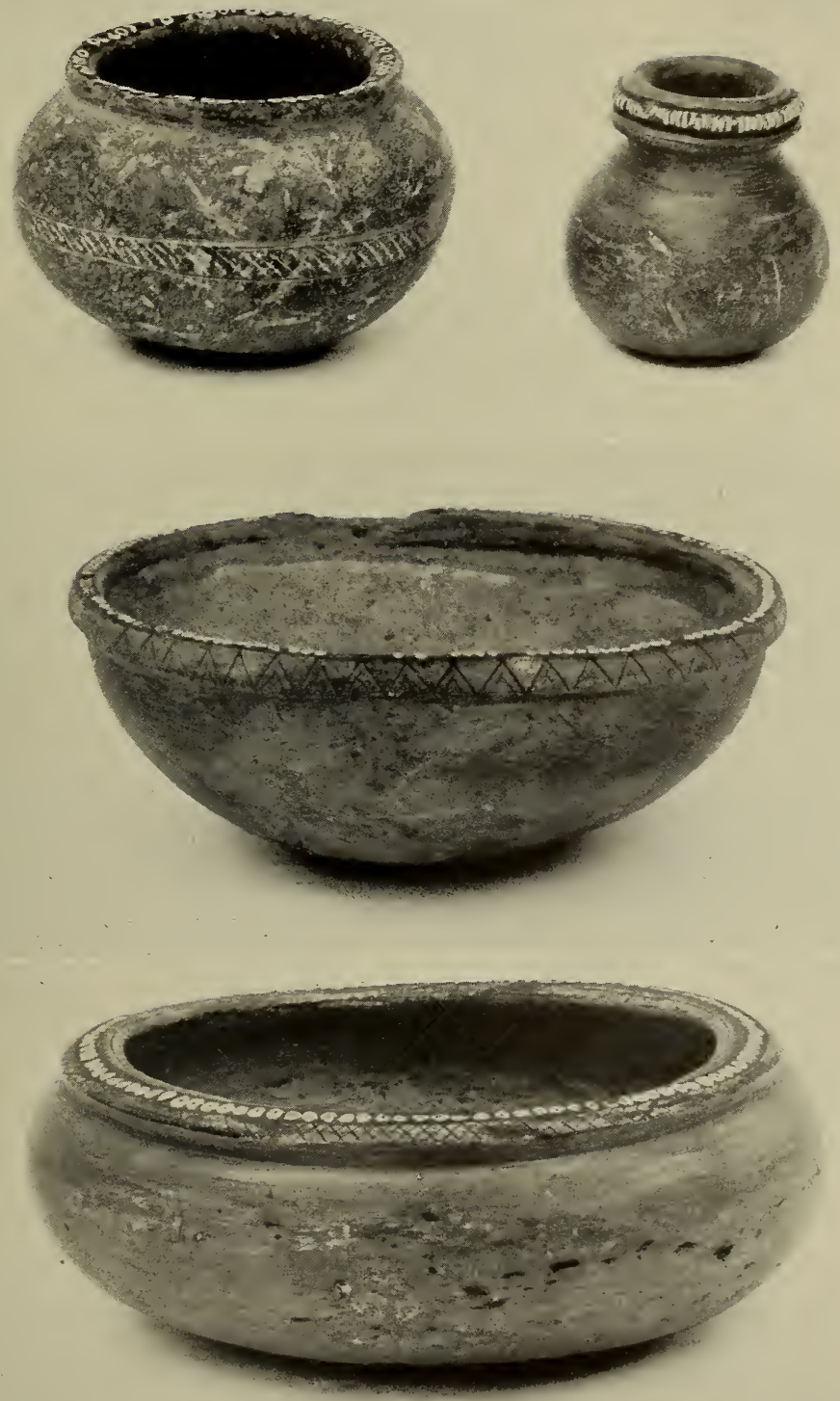

$20 / 3742$

$20 / 3741$

$20 / 3743$

$20 / 1578$ 


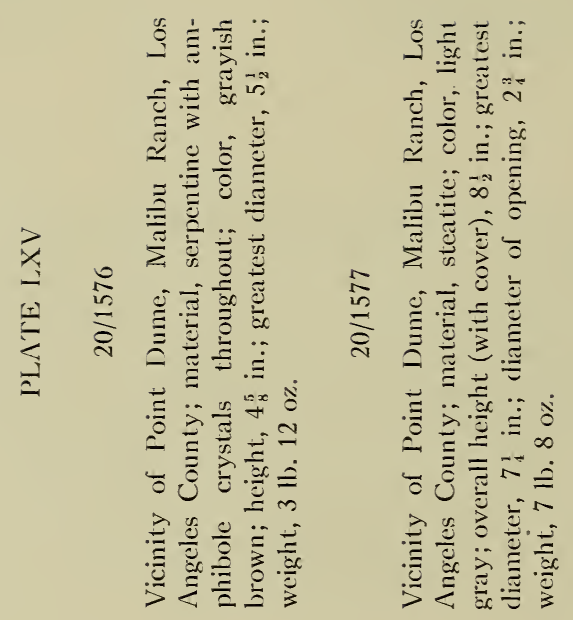


文

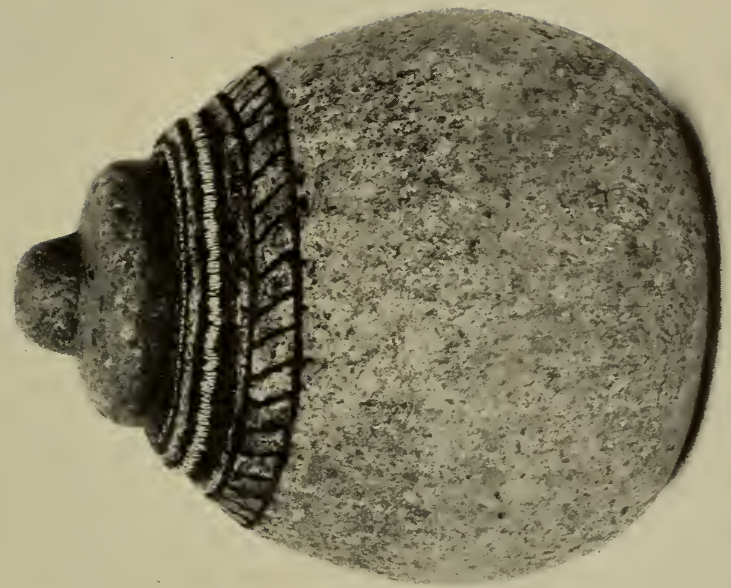

충

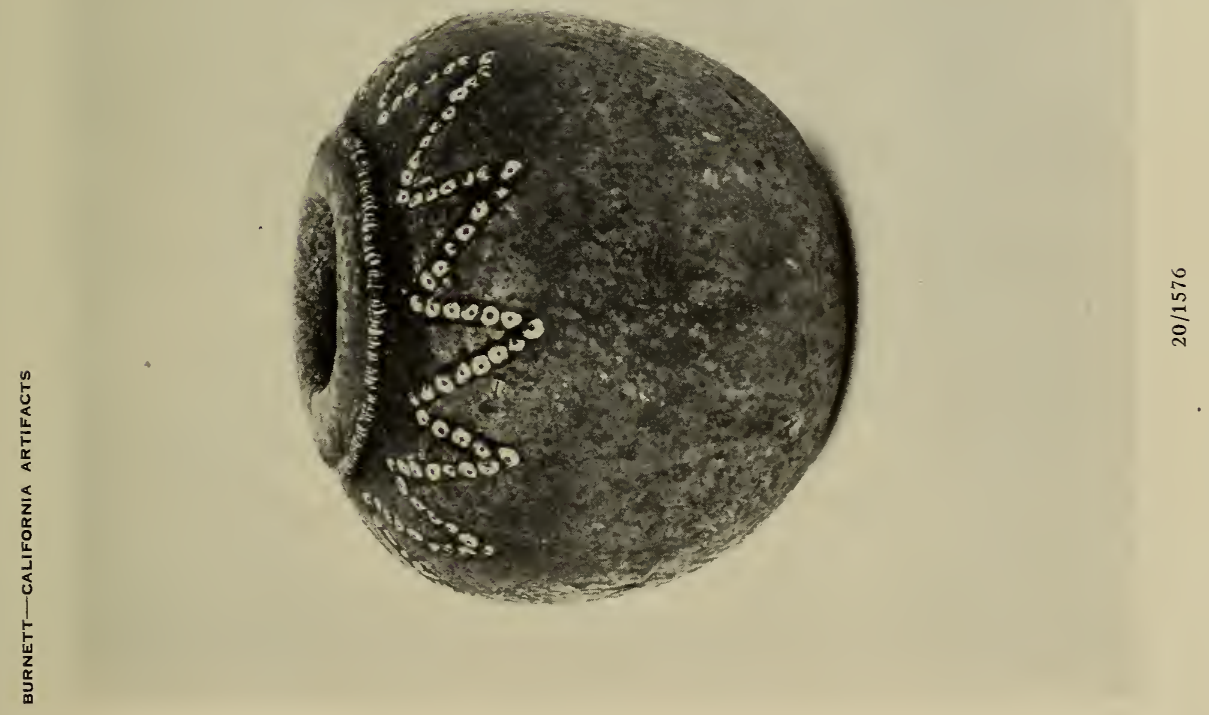




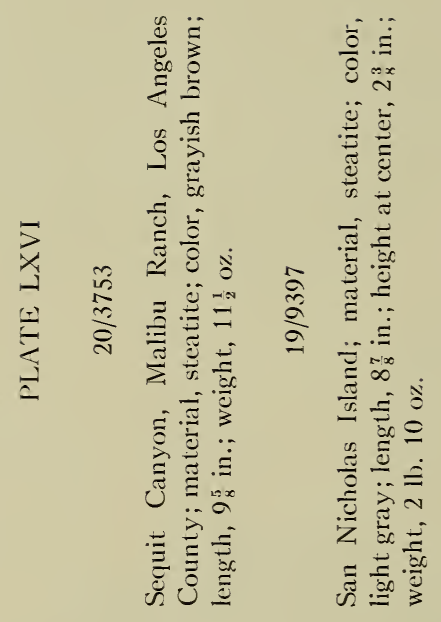


$\frac{5}{3}$
$\frac{w}{5}$
$\frac{1}{a}$

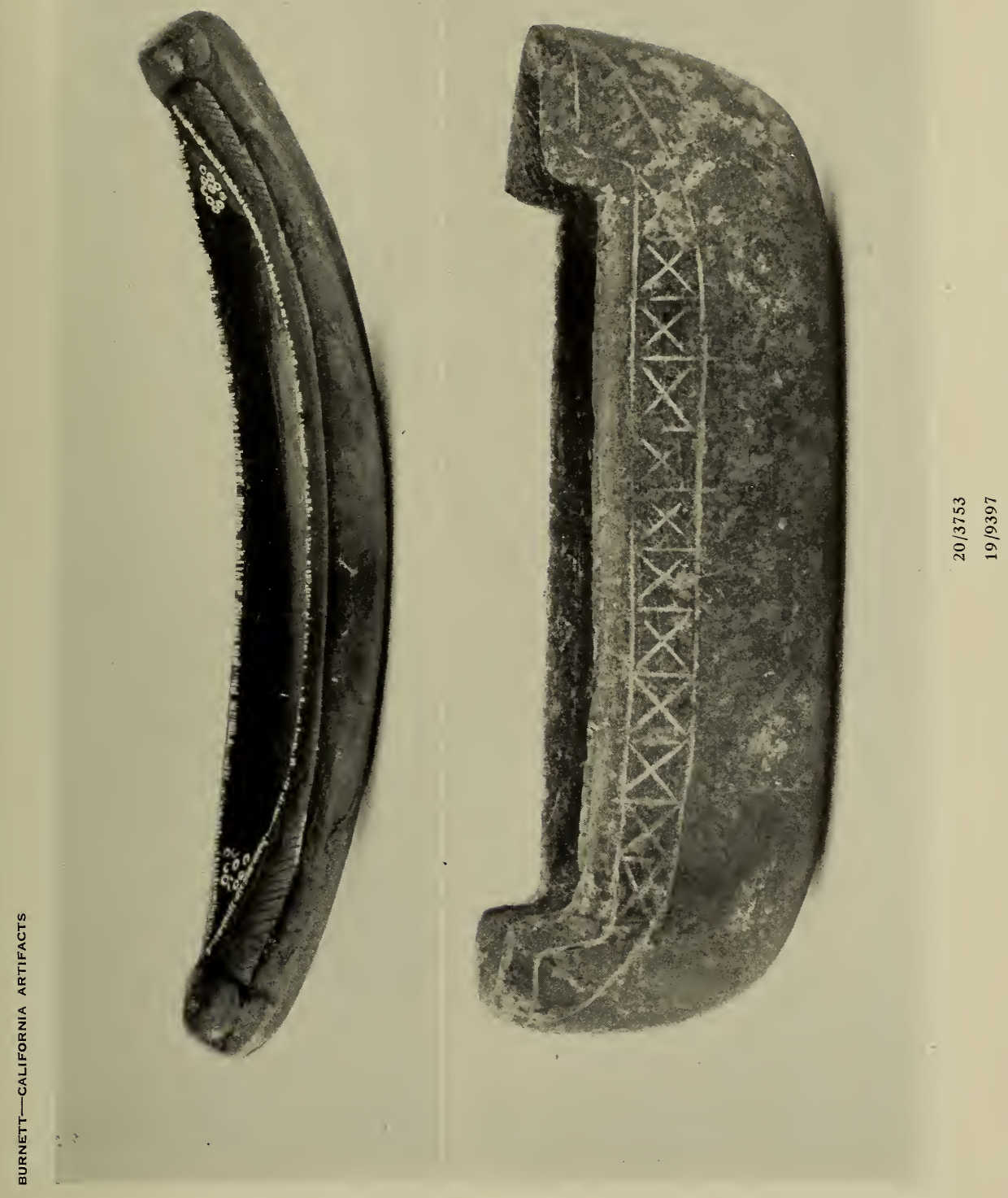




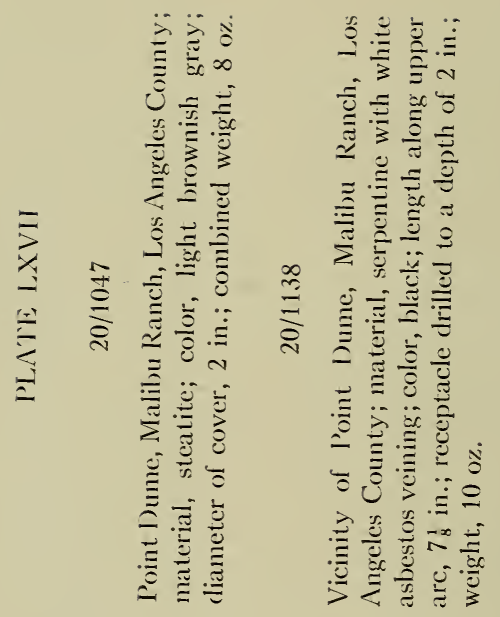




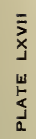
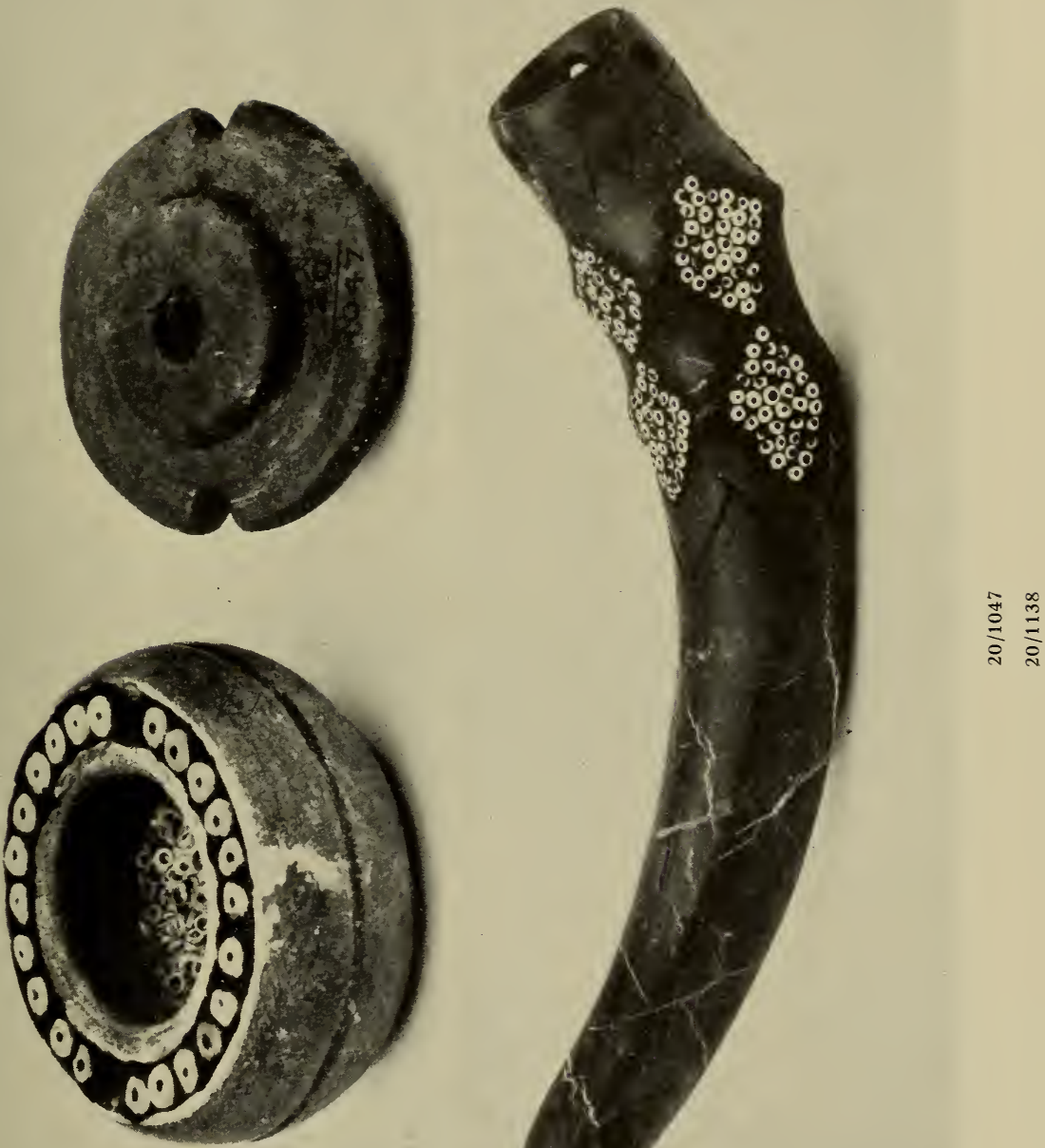

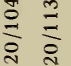




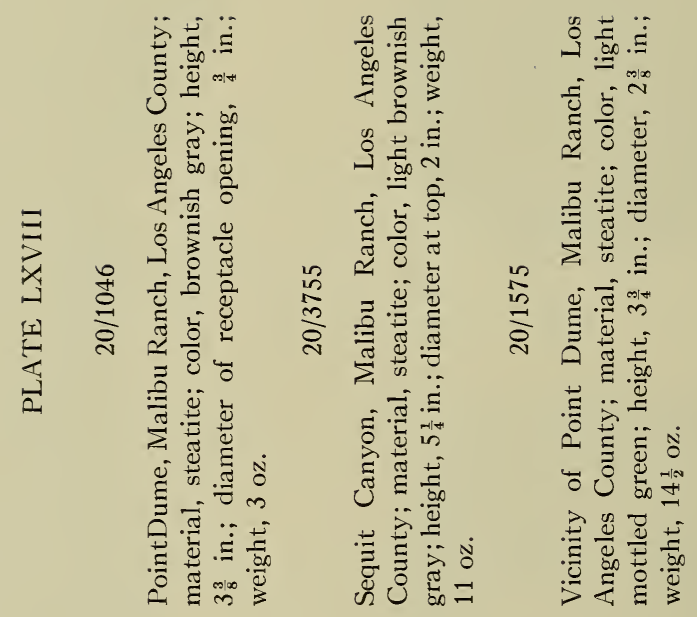




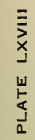

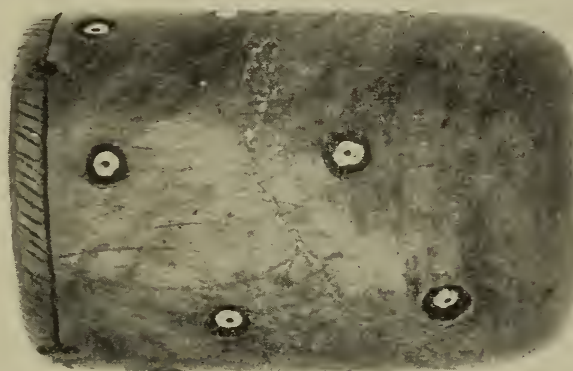

$\frac{\text { in }}{\frac{1}{2}}$

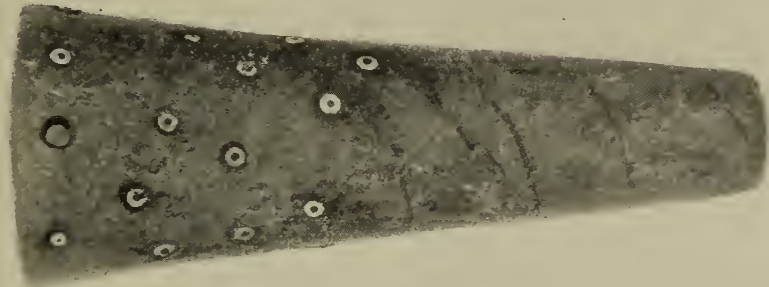

管

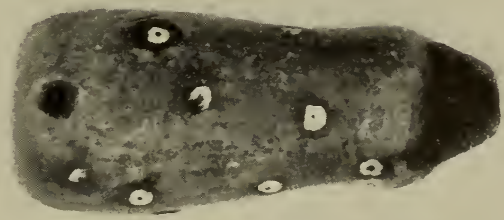

$\frac{\mathfrak{1}}{\stackrel{0}{0}}$ 


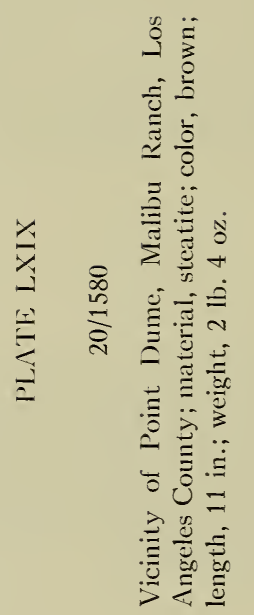




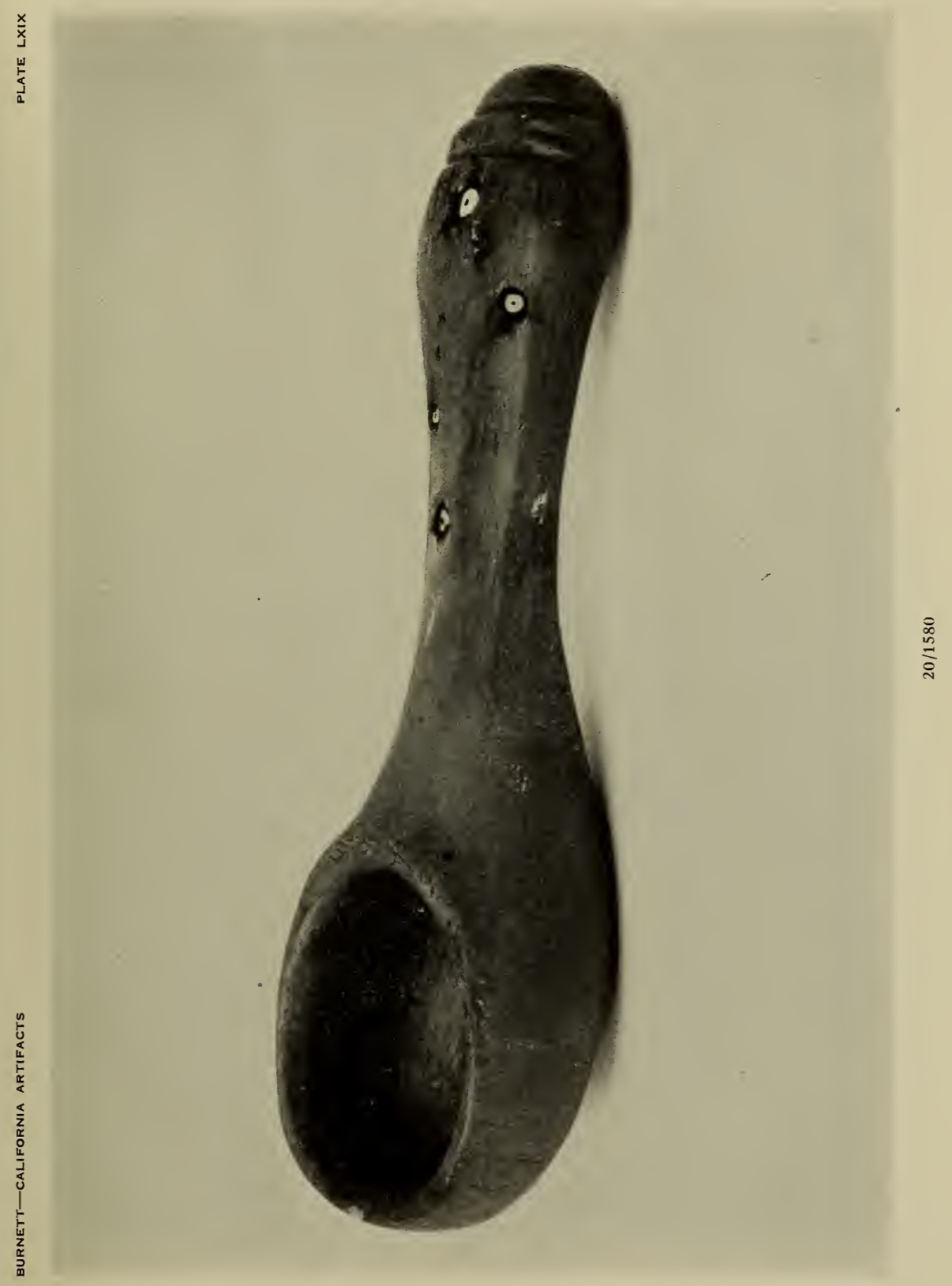




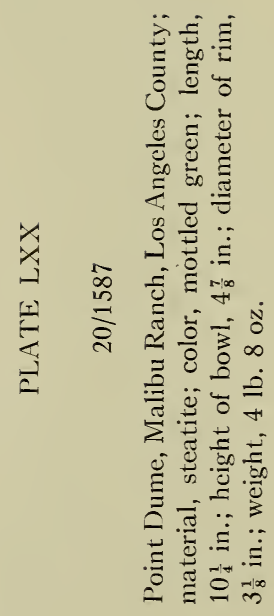


\begin{tabular}{l}
$x$ \\
\hdashline \\
$\underline{a}$ \\
$\frac{1}{a}$
\end{tabular}

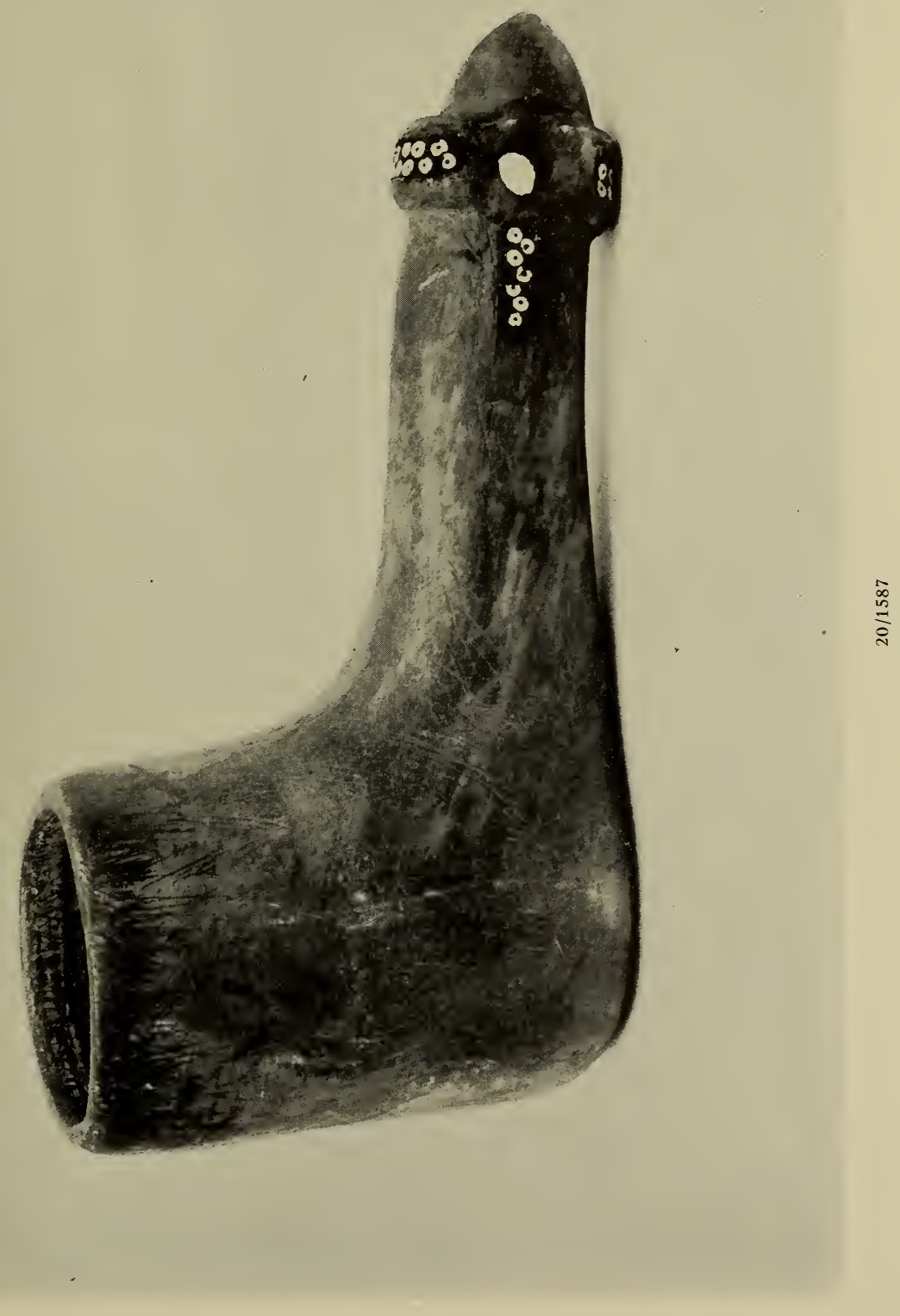




\section{PLATE LXXI}

\section{$20 / 4653$}

Sequit Canyon, Malibu Ranch, Los Angeles County; material, steatite; color, grayish brown; length, $1 \mathrm{ft} .3 \frac{1}{8}$ in.; diameter of opening, $2 \frac{1}{2}$ in.; depth of receptacle, $6 \frac{1}{4}$ in.; weight, $7 \mathrm{lb} .8 \mathrm{oz}$. 


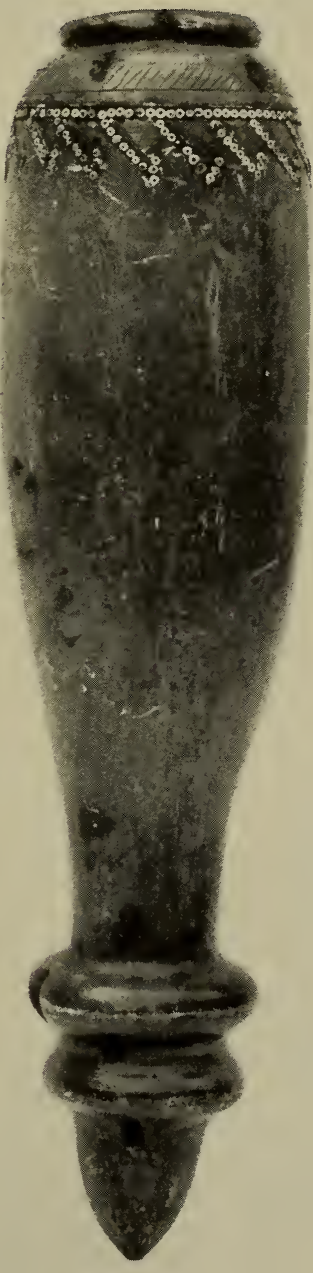

$20 / 4653$ 


• 
